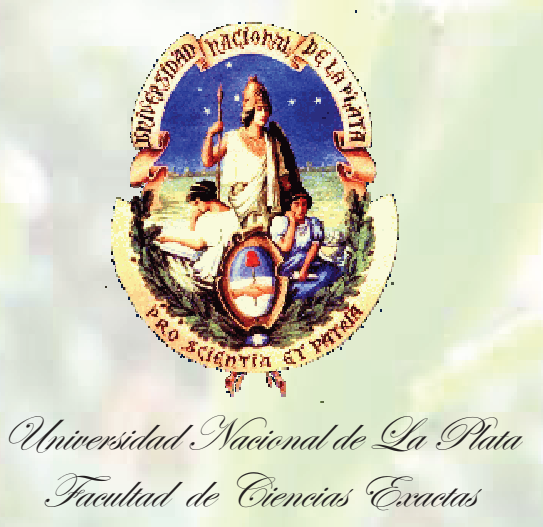

\title{
Viola arguta (Violaceae), una especie de la medicina tradicional ecuatoriana
}

\section{Elementos de diagnóstico, ensayos fitoquímicos y actividades biológicas}

\section{Tesis de Maestría para optar al grado de} Magíster en Plantas Medicinales, UNLP

\author{
Bioquímico \\ Juan Marcelo Carpio Arevalo
}

Directora de Tesis

Dra. María Adelaida Rosella

Lugar de trabajo:

Cátedras de Farmacobotánica y Farmacognosia,

Departamento de Ciencias Biológicas, Facultad de Ciencias Exactas, UNLP 

Muy especial:

A mis padres y hermanos por su inmenso apoyo, amor, por motivarme y hacerme creer que con esfuerzo puedo conseguir lo que me proponga.

Para mi tío Gastón, mi tía Suky y al Ady por su afecto y ayuda en cada uno de mis proyectos y por confiar siempre en mí.

A mi tía Zoily y a mi Abuelito por su increíble cariño y por estar siempre pendientes de todo lo que hago.

A toda mi familia que de una manera u otra me han hecho sentir su afecto a la distancia.

A mis amigos de la infancia en especial a Martin y Carlos.

Con aprecio y un gracias muy grande a mi amiga Paulina por su ayuda incondicional.

A la Universidad Nacional de La Plata y a la Facultad de Ciencias Exactas por permitirme realizar este trabajo.

Mi más profundo agradecimiento a la Dra María Rosella, por todos los conocimientos que recibí, su amabilidad, por su ayuda, por abrirme las puertas de su hogar y tener la suerte de conocer a su familia, mil gracias.

A la Dra. Raffaella Ansaloni y demás investigadores del Herbario de la Universidad del Azuay (Cuenca - Ecuador) por su gentil ayuda en la Determinación de la planta utilizada en este trabajo.

A la Dra. Alicia Consolini, Directora del Magister, por su amabilidad y constante apoyo.

Mi gratitud con la Dra. Etile Spegazzini por estar siempre pendiente de mi avance en la Maestría.

A la Magister Marta Colares por su colaboración con la parte de anatomía vegetal y por haber estado siempre dispuesta a brindarme su ayuda y conocimientos.

Al Lcdo. Guillermo Schinella por su colaboración y por facilitar su laboratorio para los ensayos in- vitro.

Mi gratitud a la Lcda. Silvia Aquila por su ayuda en los ensayos in-vitro y por transmitir siempre su alegría.

Muchas gracias a la Dra. Guillermina Volonté por su apertura y la ayuda en su laboratorio.

A la Lcda. Griselda Haag por su colaboración con los ensayos de actividad antioxidante. 
A la Magister Mariela del Valle por facilitarme gentilmente reactivos.

Al Lcdo. Carlos Valle por sus conocimientos y amabilidad.

A Agustín Asuaje por su ayuda con el procesamiento de los datos.

A todo el personal de las cátedras de Farmacognosia, Farmacobotánica y Fitopatología por su gran calidad humana.

A todas las persona que tuve la suerte de conocer en La Plata, gracias por hacer que este tiempo lejos de casa haya sido más llevadero y de manera especial muchas gracias Lucho y Catu. 
Indice

\section{Indice}


Pag.

1.- Introducción 4

Fundamentos de la elección del tema $\quad 7$

2.- Antecedentes 9

2.1.- Género Viola 10

2.1.1.- Antecedentes botánicos y distribución geográfica 10

2.1.2.- Antecedentes de uso en medicina tradicional 10

2.1.3.- Antecedentes Fitoquímicos 12

2.2.- Viola arguta 20

3.- Objetivos 22

4.- Materiales y Métodos 24

4.1.- Material vegetal 25

4.1.1.- Procedencia 25

4.1.2.- Recolección y acondicionamiento del material vegetal 26

4.1.3.- Determinación taxonómica 26

4.2.- Microscopia analítica 28

4.2.1.- Equipos utilizados 28

4.2.2.- Observación de epidermis foliar con microscopio óptico (MO) 30

4.2.3.- Observación de la epidermis foliar con microscopio electrónico de $\quad 30$ barrido (MEB)

4.3.- Ensayos fitoquímicos 31

4.3.1.- Preparación de los extractos 31

4.3.2.- Pruebas químicas orientativas 33

4.3.3.- Cromatografía en capa delgada (CCD) 36

4.3.4.- Caracterización de ciclótidos por CCD 38

4.3.5.- Detección de ácidos por CCD 39

4.4.- Actividades 39

4.4.1.- Actividad antioxidante por métodos espectrofotométricos 39

4.4.2.- Actividad antiinflamatoria $\quad 47$

5.- Resultados y Discusión 53

5.1.- Elementos de diagnostico y determinación de valores numéricos en
hojas de $V$. arguta

5.1.1.- Análisis micrográfico de las hojas de V. arguta 56

5.1.2.- Determinación de valores numéricos o magnitudes proporcionales $\quad 59$

5.1.3.- Observación de la epidermis foliar mediante MEB 60

5.2.- Ensayos fitoquímicos 61

5.2.1.- Rendimientos de los extractos de V. arguta 61

5.2.2.- Pruebas químicas orientativas efectuadas a los extractos acuoso,
diclorometánico y metanólico de $V$. arguta

5.2.3.- Análisis de las cromatografías en capa delgada (CCD) efectuadas a 
los extractos acuoso, diclorometánico y metanólicos de $V$. arguta

5.2.5.- Detección de ácidos por CCD 75

5.3.- Actividades 76

5.3.1.- Actividad antioxidante por métodos espectrofotométricos 76

5.3.2.- Actividad antiinflamatoria: Estudio de la inhibición de la producción de oxido nítrico in vitro 
1.- Introducción. 


\section{1. - Intraducción}

Desde tiempos remotos, las sociedades humanas han recurrido a la naturaleza, principalmente a las plantas, como fuente medicinal. En la actualidad, un gran porcentaje de la población mundial, en particular en los países en desarrollo, utiliza las plantas para hacer frente a necesidades primarias de asistencia médica. (Paladini, 1996).

Según la OMS el $80 \%$ de la población mundial hace uso de los remedios naturales y las medicinas tradicionales y el Ecuador no es una excepción.

Ecuador se reconoce desde la Constitución del año 1998 como un País pluricultural y multiétnico y que además está ubicado en uno de los sitios de mayor megabiodiversidad del Planeta, todos estas características confluyen en una pequeña extensión de territorio que tiene el potencial de ofrecer a la humanidad mucho de sus recursos naturales, sus secretos y los conocimientos ancestrales de sus pueblos.

Numerosas especies de la familia Violaceae han sido reconocidas desde la antigüedad como un grupo de plantas con importantes propiedades medicinales, algunos de los ejemplos más importantes incluye a Viola tricolor L. conocida popularmente como "pensamientos" entre cuyos usos en medicina tradicional se incluyen: tratamiento de las vías respiratorias superiores, diurético, antitumoral (Vukics et al, 2008), sudorífico, para el reumatismo (Al-Qura, 2008), y externamente en casos de impétigo, eczemas, acné, (Ewa Witkowska-Banaszczak et al., 2005) entre otras.

Una de las especies ampliamente distribuida en el mundo es Viola odorata Thunb., comúnmente llamada "violeta dulce". Las partes aéreas de esta planta han sido utilizadas por vía oral para tratamiento de bronquitis, tos, asma, desórdenes del sueño, agitación nerviosa. Externamente las decocciones de la planta son utilizadas para tratar infecciones de boca y garganta al igual que afecciones cutáneas. (Anastasia Karioti et al. 2010)

En el Ecuador los usos de esta planta incluyen el tratamiento de diversas afecciones tales como tos, resfrío, catarro, tisis, laringitis, viruela, sarampión, escarlatina de la piel, úlceras cancerosas, abscesos del estómago e intestino, empachos e intoxicaciones. (Rios Moserrat et al., 2007) 


\section{1. - Intraducción}

Una de las especies utilizadas en la medicina natural Oriental es Viola yedoensis Makino distribuida en Corea, Japón y China. (Chen Xie et al. 2003)

Otro ejemplo es Viola ibukiana Makino, especie que se encuentra en el sur de Corea y que en medicina tradicional ha sido utilizada como expectorante, diurético, para tratamientos de bronquitis, reumatismo, eczemas y erupciones de la piel.

Se ha reportado que uno de los componentes de naturaleza flavonoide $\left(2^{\prime}, 44^{\prime}, 5,7\right.$-tetrahydroxyisoflavona) encontrado en esta planta tiene la capacidad de inhibir la expresión de la metaloproteinasa I de la matriz extracelular en cultivos de fibroblastos de piel humana sometidos a irradiación con luz UV, lo cual demuestra que este compuesto puede ser útil en el tratamiento y prevención de la expresión de esta endoproteasa dependiente de Zinc, cuyo aumento en condiciones fisiológicas permite la normal remodelación del tejido dañado, pero que está vinculada también con el proceso de envejecimiento foto-inducido. (Hyung-In Moon et al., 2005)

Viola websteri Hemsley, es una especie que contiene entre sus principios activos al ácido 6-(8'Z-pentadecenil)-salicílico que, según se ha demostrado en ensayos in vivo, posee actividad esquizonticida sobre Plasmodium berghei en los primeros estadíos de infección inducida en ratón. ( III-Min Chung. et al. 2009)

El potencial antioxidante de algunos miembros de la familia Violaceae también ha sido evaluado, por ejemplo el extracto metanólico de hojas de $V$. odorata ha mostrado una IC50 ( $\mu \mathrm{g} / \mathrm{ml})$ de alrededor de 245 en el ensayo con DPPH (Ebrahimzadeh Mohammad, et al., 2010)

Sin embargo, uno de los principios activos ampliamente distribuido en la familia Violaceae y que más ha llamado la atención en las dos últimas décadas es el de un grupo de péptidos cíclicos, formados por 28 a 37 aminoácidos, ricos en cisteína, que recibieron el nombre de ciclótidos, de su acrónimo en inglés: péptidos cíclicos (yclic peptides).

Los ciclótidos exhiben diversas actividades biológicas, tales como: 


\section{1. - Intraducción}

- Actividad inhibitoria sobre el Virus causante del SIDA (VIH)

- Actividad antimicrobiana

- Actividad citotóxica

- Actividad antagonista de neurotensina

- Actividad hemolítica. (Norelle L. Daly et al., 2009)

En ensayos realizados sobre parásitos de animales, se ha comprobado un importante efecto de algunos de los ciclótidos de Oldenlandia affinis (R\&S) DC (Rubiaceae) sobre Hemonchus contortus y Trichostrongylus colubriformis, resultando ser potentes inhibidores del desarrollo de larvas de nematodos y letales para parásitos adultos, aunque presentan una baja actividad ovicida. (Colgrave et al. 2008)

Todos estos ciclótidos fueron originalmente encontrados en programas de screening para actividades biológicas o en el caso de la actividad uterotónica, a partir de su uso en medicina tradicional. (Bin Chen et al. 2005)

Hasta la fecha, los ciclótidos han sido hallados en todas las especies de Violaceae estudiadas.

Son mucho menos frecuentes en las Rubiaceae $(5 \%-10 \%$ de las aproximadamente 200 especies examinadas).

En las Cucurbitaceae se ha estudiado una sola especie, encontrándose solo dos ciclótidos en ella y recientemente se ha reportado su presencia en la familia Apocynaceae. (Norelle L. Daly, et al. 2009)

\section{Fundamentos de la elección del tema}

Viola arguta Willd. ex Roem. \& Schult. (Nombre vulgar en el Ecuador: Violeta del campo o Violeta Roja) es una especie de la Familia Violaceae que puede ser encontrada en la zona sur-andina del Ecuador en las Provincias de Zamora-Chinchipe y Loja a altitudes entre 1500 y 3500 msm, (Izco Jesús et al., 2007). 


\section{1. - Intraducción}

Tiene algunos usos en medicina tradicional: los habitantes de las provincias antes mencionadas preparan una infusión con las partes aéreas frescas de esta planta y se menciona que es utilizada para tratar influenza y fiebre. (Tene Vicente et al., 2006; Minga O. et al., 2009).

También se registra su uso medicinal en la provincia del Cañar, ubicada en el Centro- Sur del Ecuador, donde es utilizada por las personas de esta zona para "el dolor de huesos." (Minga O. et al., 2009)

El interés por el estudio de Viola arguta se fundamenta en que hasta el momento no existen datos botánicos que permitan su reconocimiento.

Tampoco existe información sobre su composición química y actividades biológicas comprobadas que justifiquen su empleo en terapéutica.

Además resulta interesante su estudio fitoquímico para confirmarla como una nueva especie de la familia Violaceae poseedora de ciclótidos, que van erigiéndose como principios activos con potenciales aplicaciones farmacológicas y dentro de esta familia de plantas en particular, como marcadores quimiotaxonómicos. 
2. - Antecedentes

2.- Antecedentes 


\section{1.- Genero Viola}

\subsection{1.- Antecedentes Botánicos y distribución geográfica:}

Harvey E. Ballard, Jr. (1994), describe el género Viola L., como “... plantas herbáceas perennes, rara vez anuales o subarbustivas; hojas alternas sobre tallos erectos o ascendentes, o bien, dispuestas en rosetas basales, estípulas típicamente conspicuas, membranáceas o foliáceas, láminas linear-lanceoladas a reniformes, estrechándose en forma gradual a profundamente cordadas en la base, enteras a manifiestamente divididas; flores casi siempre axilares y solitarias, pedúnculos bibracteolados, desprovistos de articulaciones; cáliz (en las especies americanas) con aurículas bien desarrolladas a modo de prolongaciones que se dirigen hacia atrás de las bases de los sépalos, éstos (a veces considerablemente) más cortos que los pétalos; corola fuertemente zigomorfa, el pétalo inferior prolongado hacia atrás en mayor o menor grado para formar un espolón manifiesto, su limbo por lo general glabro, conspicuamente más corto que los pétalos laterales, los que a menudo llevan interiormente un mechón de pelos; filamentos libres en la base, las dos anteras inferiores provistas de nectarios bien desarrollados; estilo sencillo y uniformemente cilíndrico, o con más frecuencia variadamente modificado; fruto en forma de cápsula trivalvada, sobre un pedúnculo postrado o erecto, con pocas o numerosas semillas..."

El género Viola es el más grande de la familia Violaceae con ca. 650 familias.

Se las encuentra en las regiones templadas del hemisferio norte y en zonas tropicales del hemisferio sur, especialmente en la zona cordillerana, donde son endémicas.

Suelen ser plantas ornamentales, aunque muchas de ellas también tienen importancia como plantas medicinales y en la alimentación (Ballard, 1994)

\subsection{2.- Antecedentes de uso en medicina tradicional.}

Numerosas especies de esta familia Violaceae han sido reconocidas desde la antigüedad como un grupo de plantas con importantes propiedades medicinales, 
algunos de los ejemplos más importantes incluye a Viola tricolor conocida popularmente como "pensamientos" y algunos de sus usos en medicina tradicional incluyen: tratamiento de las vías respiratorias superiores, diurético (Viktoria Vukics et al, 2008; Rimkiene et al., 2003), sudorífico, para el reumatismo (S. Al-Qura.n, 2008), y externamente en casos de impétigo, eczemas, acné, (Witkowska-Banaszczak et al. , 2005) entre otras.

Una de las especies ampliamente distribuida en el mundo es Viola odorata, comúnmente llamada violeta dulce, las partes aéreas de esta planta han sido utilizadas por vía oral para tratamiento de bronquitis, tos, asma, desórdenes del sueño, agitación nerviosa; externamente las decocciones de la planta son utilizadas para tratar infecciones de boca y garganta al igual que afecciones cutáneas. (Anastasia Karioti et al. 2010)

En el Ecuador los usos tradicionales de esta planta incluyen: tratamiento de la tos, resfrío, catarro, tisis, laringitis, viruela, sarampión, escarlatina de la piel, úlceras cancerosas, abscesos del estómago e intestino, empachos e intoxicaciones. (Rios Moserrat et al., 2007)

Una de las especies con usos en la medicina natural Oriental es Viola yedoensis distribuida en Corea, Japón y China, con muchos usos en estas medicinas tradicionales. (Chen Xie et al. 2003)

Otro ejemplo es Viola ibukiana, especie que se encuentra en el sur de Corea y que en medicina tradicional ha sido utilizada como expectorante, diurético, para tratamientos de bronquitis, reumatismo, eczemas y erupciones de la piel. (Hyung-In Moon et al. 2005)

Otra especie del sur de Corea es Viola hondoensis, cuyos usos en medicina tradicional son similares a los indicados para V. ibukiana.

Resultados interesantes se han obtenido para una especie que no cuenta con referencias de uso en medicina tradicional, $V$. declinata. Siguiendo el enfoque quimiotaxonómico de búsqueda de principios activos se ha demostrado que tiene una composición fitoquímica muy similar a los de $V$. tricolor, por lo que se estima que compartirían algunas actividades biológicas. (Anca Toiu et al. 2009) 


\subsection{3.- Antecedentes Fitoquímicos}

Dentro del género Viola se han caracterizado a numerosos principios activos: en el caso de Viola tricolor se ha reportado que contiene un 0,3\% de ácido salicílico y derivados como su metil ester y violutósido que es el glucósido-arabinosido del metil ester del ácido salicílico. Adicionalmente contiene ácidos fenilcarboxílicos como el trans-cafeico, un $10 \%$ de mucílago compuestos principalmente de glucosa, galactosa, arabinosa y ramnosa, taninos, flavonoides, carotenoides, cumarinas como umbeliferona, pequeñas cantidades de saponinas, ácido ascórbico y tocoferol. (Rimkienë, et al., 2003)

Las propiedades antiinflamatorias, expectorantes y diuréticas se atribuyen a la presencia de saponinas, flavonoides, mucílagos, carotenoides y derivados del ácido salicílico, siendo responsables de la acción antiinflamatoria estos últimos compuestos junto con la rutina, ejerciendo las saponinas un efecto sinérgico. (Anca Toiu et al., 2009)

Para el caso de Viola odorata se ha podido determinar la presencia de taninos, flavonoides, esteroles/triterpenos, (Khatibi et al., 1989; Samra et al., 2006), compuestos fenólicos, glucósidos y alcaloides. (Vishal Antil, et al., 2011)

Se ha reportado que uno de los componentes de naturaleza flavonoide $\left(2^{\prime}, 44^{\prime}, 5,7\right.$-tetrahydroxyisoflavona) encontrado en Viola ibukiana tiene la capacidad de inhibir la expresión de la Metaloproteinasa I de la Matriz extracelular en cultivos de fibroblastos de piel humana sometidos a irradiación con luz UV, por lo que este compuesto podría ser útil en el tratamiento y prevención de la expresión de esta endoproteasa dependiente de Zinc, cuyo aumento en condiciones fisiológicas permite la normal remodelación del tejido dañado, pero que está vinculada también con el proceso de envejecimiento foto-inducido. (Hyung-In Moon et al. 2005)

Viola websteri, es una especie que contiene entre sus principios activos compuestos conocidos colectivamente como ácidos anacárdicos. 
De V. websteri fueron aislados el ácido 6-(8'Z-pentadecenil)-salicílico (Figura 2.1) y el acido 6-(8'Z, 11'Z, 14'Z-heptadecatrienil)- salicílico (Figura 2.1), que poseen actividad in vitro contra Plasmodium falciparum (Sung Jae Lee et al. 2009)

En experimentos in vivo para evaluar la actividad y empleando como modelo de estudio ratón infectado con Plasmodium berghei, el ácido 6-(8'Z-pentadecenil)salicílico mostró actividad esquizonticida en los primeros estadíos de infección. (III-Min Chung et al. 2009)

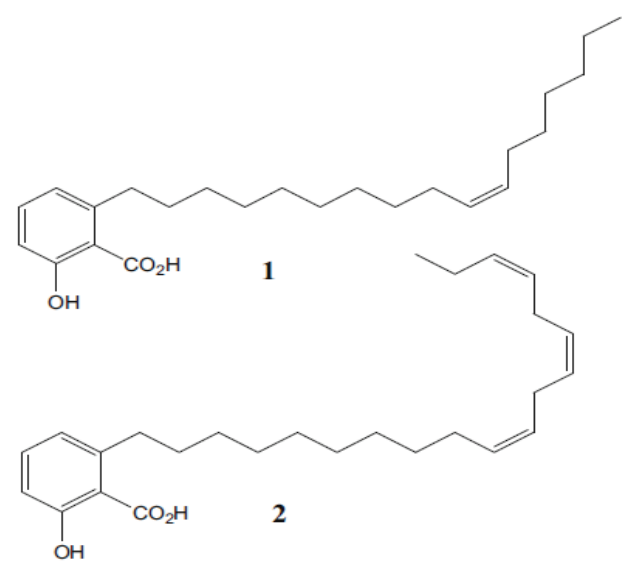

Fig. 2.1. Ácidos anacárdicos de Viola websteri

Los ácidos anacardicos han mostrado otras actividades y dentro de las que se destaca su actividad antioxidante derivada de su capacidad para quelar metales como $\mathrm{Cu}^{++}$y $\mathrm{Fe}^{+++}$, que participan como co-factores enzimáticos en la generación de radicales libres de oxígeno por reacciones tipo Fenthon. Además pueden inhibir directamente a enzimas como la Xantina Oxidasa (Isao Kubo et al., 2005) que produce estas especies reactivas como subproductos de su catálisis.

También han mostrado capacidad de ser activos contra varias líneas celulares cancerosas, sensibilizan células tumorales a la radioterapia, y a nivel molecular se ha comprobado que produce una inhibición potente sobre la activación del Factor Nuclear Kappa B (NF-kB) lo que posiblemente justifica su acción anti-angiogénica, antiproliferativa y anti-metástica (Gomes de Melo et al., 2011)

Son también inhibidores de Transacetilasas de Histonas (TAHs), enzimas que tienen como función modificar el grado de condensación de la cromatina y a través de 
este mecanismo regulan varios procesos celulares y dentro de las vías involucradas están las de señalización para inflamación y cáncer (Massimo Ghizzoni, et al., 2010)

En otra especie con antecedentes de uso tradicional, Viola canescens, utilizada en la región de Garhwal (India) para el tratamiento de infecciones por protozoarios y fiebre, se ha aislado a partir del extracto éter de petróleo un metabolito identificado como acido epi-Oleanólico, el cual presenta una interesante actividad anti-plasmodial (Hyung-In Moon et al.,2006)

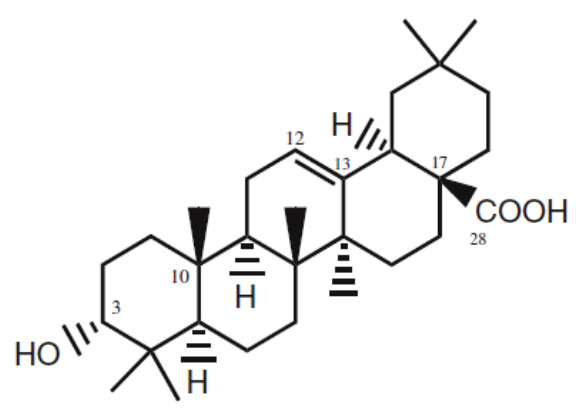

Ácido epi-Oleanólico

Sin embargo, uno de los principios activos ampliamente distribuido en la familia Violaceae y que más ha llamado la atención en las dos últimas décadas es el de un tipo de Ciclopéptidos Ilamados Ciclótidos por acrónimo en inglés ( $\underline{\text { Cyclic peptides }}=$ péptidos cíclicos). (Lars Bohlin, et al 2010)

Los ciclótidos constituyen uno de los ocho tipos en los que se han agrupado los ciclopéptidos.

Se definen como ciclopéptidos a compuestos cíclicos formados por 2 a 37 aminoácidos de tipos proteínicos así como no proteínicos pero en los que predominan los isómeros $L$.

Si el ciclo está constituido enteramente por enlaces peptídicos se los designa como homociclopéptidos de lo contrario se denominan heterociclopéptidos. (Ning-H Tan y Jun Zhou, 2006) 




Fue a finales de la década del cincuenta del siglo XX que algunos grupos de investigación reportaron la presencia de varios ciclopéptidos de importancia. (NingHua Tan y Jun Zhou, 2006)

Algunos de los ciclopéptidos poseen potentes efectos biológicos de tipos: citotóxica, inmunosupresora, antiplasmodial, vasorelajante, inhibidora de ciclooxigenasa, inhibidora de la ECA y Tripsina, entre otras. (Afef Dellai et al, 2010)

Uno de los sistemas que se han utilizado para clasificarlos los dividen en 8 Tipos, éstos son:

Tipo I: Alcaloides Ciclopéptidos

Tipo II: Depsiciclopéptidos

Tipo III: Ciclopéptidos tipo Solanaceae

Tipo IV: Ciclopéptidos tipo Urticaceae

Tipo V: Ciclopéptidos tipo Compositae

Tipo VI: Ciclopéptidos tipo Caryophillaceae

Tipo VII: Ciclopéptidos tipo Rubiaceae.

Tipo VIII: Ciclótidos.

(XU WenYan, et al. 2008).

Algunos ejemplos de cada uno de los ocho tipos se incluyen en la siguiente tabla (tabla 1.1.): 
Tabla 1.1. Clasificación y ejemplos de ciclopéptidos

\begin{tabular}{|c|c|c|c|c|}
\hline Tipo & Ciclopéptido & Planta & $\begin{array}{l}\text { Actividad del } \\
\text { ciclopéptido }\end{array}$ & Referencia \\
\hline \multirow{2}{*}{$\begin{array}{l}\text { I. Alcaloides } \\
\text { Ciclopéptidos }\end{array}$} & sanjoinia $\mathrm{A}$ & $\begin{array}{c}\text { Zizyphus sp } \\
\text { (Rhamnaceae) }\end{array}$ & Sedante & $\begin{array}{l}\text { XU WenYan, } \\
\text { et al. } 2008\end{array}$ \\
\hline & zizifinas & $\begin{array}{l}\text { Zizyphus oenoplia } \\
\text { var. brunoniana }\end{array}$ & antiplasmodial & $\begin{array}{c}\text { Sunit } \\
\text { Suksamrarn } \\
\text { et al. } 2005\end{array}$ \\
\hline $\begin{array}{c}\text { II. } \\
\text { Depsiciclopéptidos }\end{array}$ & FR 900359 & $\begin{array}{c}\text { Ardisia crenata } \\
\text { (Myrsinaceae) }\end{array}$ & $\begin{array}{c}\text { Hipotensora (en } \\
\text { ratas } \\
\text { anestesiadas) }\end{array}$ & $\begin{array}{l}\text { Hua Tan y } \\
\text { Jun Zhou, } \\
2006\end{array}$ \\
\hline $\begin{array}{l}\text { III. Ciclopéptidos } \\
\text { tipo Solanaceae }\end{array}$ & luciuminas & $\begin{array}{l}\text { Lycium chinense } \\
\text { (Solanaceae) }\end{array}$ & $\begin{array}{l}\text { Inhibidora de la } \\
\text { Enzima } \\
\text { Conversora de } \\
\text { Angiotensina } \\
\text { (ECA) }\end{array}$ & $\begin{array}{l}\text { Hua Tan y } \\
\text { Jun Zhou, } \\
2006\end{array}$ \\
\hline \multirow[t]{2}{*}{$\begin{array}{l}\text { IV. Ciclopéptidos } \\
\text { tipo Urticaceae }\end{array}$} & moroidina & $\begin{array}{c}\text { Laportea } \\
\text { moroides } \\
\text { (Urticaceae) }\end{array}$ & \multirow{2}{*}{$\begin{array}{l}\text { Inhibidora de la } \\
\text { polimerización } \\
\text { de tubulina con } \\
\text { mayor potencia } \\
\text { que la Colchicina }\end{array}$} & \multirow[t]{2}{*}{$\begin{array}{l}\text { Hua Tan y } \\
\text { Jun Zhou, } \\
2006\end{array}$} \\
\hline & moroidina & $\begin{array}{l}\text { Celosia argéntea } \\
\text { (Amarantaceae) }\end{array}$ & & \\
\hline $\begin{array}{l}\text { V. Ciclopéptidos } \\
\text { tipo Compositae }\end{array}$ & astinas & $\begin{array}{l}\text { Aster tataricus } \\
\text { (Compositae) }\end{array}$ & Antitumoral & $\begin{array}{c}\text { Rosanna } \\
\text { Cozzolino, et } \\
\text { al } 2005\end{array}$ \\
\hline $\begin{array}{l}\text { VI. Ciclopéptido tipo } \\
\text { Cariophilaceae }\end{array}$ & ciclolinopéptido A & $\begin{array}{c}\text { Linum } \\
\text { usitatissimum } \\
\text { (Lináceae) }\end{array}$ & Inmunosupresora & $\begin{array}{l}\text { Stefanowitz } \\
\text { Piotr, } 2004\end{array}$ \\
\hline \multirow[t]{2}{*}{$\begin{array}{l}\text { VII. Ciclopéptidos } \\
\text { Tipo Rubiaceae }\end{array}$} & $\begin{array}{c}\text { bouvardina, } \\
\text { deoxibouvardina }\end{array}$ & $\begin{array}{c}\text { Bouvardia } \\
\text { ternifolia } \\
\text { (Rubiaceae) }\end{array}$ & \multirow[t]{2}{*}{$\begin{array}{l}\text { Antitumoral } \\
\text { in vivo e in vitro }\end{array}$} & \multirow{2}{*}{$\begin{array}{l}\text { Peter Seydel } \\
\text { y Heike } \\
\text { Dörnenburg, } \\
2006\end{array}$} \\
\hline & RA-VII & $\begin{array}{l}\text { Rubia cordifolia } \\
\text { (Rubiaceae) }\end{array}$ & & \\
\hline VIII. Ciclótidos & Circulina A & $\begin{array}{l}\text { Chassalia } \\
\text { parviflora } \\
\text { (Rubiaceae) }\end{array}$ & $\begin{array}{c}\text { Antibacterial } \\
\text { Anti HIV } \\
\text { Citotóxica }\end{array}$ & $\begin{array}{l}\text { Hua Tan y } \\
\text { Jun Zhou, } \\
2006\end{array}$ \\
\hline
\end{tabular}

Uno de los Tipos de ciclopéptidos que ha tenido más atención en las últimas dos décadas es el Tipo VIII, también conocido como Ciclótidos. (Hua Tan y Jun Zhou, 2006)

La historia de su descubrimiento se remonta al año 1970: 
Lorenz Gran, médico Noruego de la Cruz Roja en Congo, se percató del uso que los nativos del lugar hacían de una planta: Oldelandia affinis (Rubiaceaea), con ésta preparaban una decocción y se la administraban a las embarazadas previo al parto, de esta manera se facilitaba la labor ( Burman, 2011) pero al mismo tiempo se dio cuenta de las fuertes contracciones que se producían y de la inusual frecuencia de complicaciones en el parto que obligaban a practicar un alto número de cesáreas. (Trabi y Craik, 2004)

Gran, llevó muestras de esta planta a Noruega y realizó estudios en búsqueda del principio activo responsable de la actividad uterotónica, logrando identificar a la sustancia como un polipéptido.

Para el año 1973 logró secuenciar el péptido casi completamente y lo llamó Kalata B1 por el nombre nativo de la planta: Kalata-Kalata pero pasaron varios años y recién en 1995 se logró determinar por R.M.N. su estructura. (Burman R, 2011)

Los Ciclótidos contienen de 28 a 37 aminoácidos y poseen una extraordinaria estructura: son macrociclos cabeza-cola con tres enlaces disulfuro organizados en el motivo denominado Nudo Cíclico de Cistinas (Cyclic Cystine Knot o CCK) el cual está conservado dentro de la familia de ciclótidos y los hacen extremadamente estables ya que resisten degradaciones térmica, química y enzimáticas.

Adicionalmente, estas interconexiones en el ciclo obligan a sus regiones hidrofóbicas a exponerse en la superficie de la molécula. (Anders Herrmann, et al, 2007)

Otra característica definida por estos enlaces disulfuro es la presencia de lazos (Loops), que en número de 6 son los segmentos del péptido comprendidos entre cisteínas consecutivas involucradas en la formación del puente disulfuro. Uno de los aminoácidos que es fundamental en la estructura de los ciclótidos es Cis-prolina en el lazo 5, ya que define dos subfamilias de ciclótidos: Möbius y brazalete (fig. 2.4.). Este aminoácido está presente en la primera subfamilia y ausente en la otra. (Jun Tang et al., 2010) 


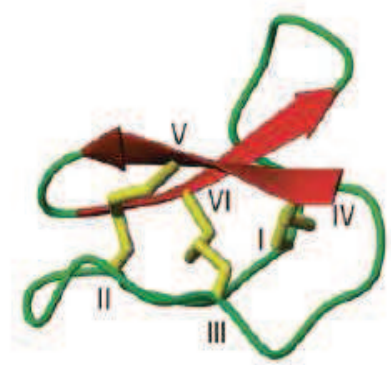

Möbius



Bracelet

Fig. 2.4. Estructura esquemática de las dos subfamilias de ciclótidos: Moebius y brazalete. (Burman R, 2011)

Las plantas individualmente expresan grupos de muchos diferentes ciclótidos, su rol natural en éstas parece ser el de agentes de defensa principalmente contra insectos (David J. Craik, et al. 2010).

Este grupo de péptidos son genéticamente codificados a diferencia de la mayoría de péptidos cíclicos que se habían identificado con tamaños menores a 12 aminoácidos y que son sintetizados por las enzimas Sintetasas de Péptidos No Ribosomales o NRPS (Non-Ribosomal-Peptido-Synthetase ).

Los genes de los ciclótidos codifican para proteínas precursoras de 11 a 14 KDa, las cuales pueden contener hasta tres dominios de Ciclótidos maduros junto con la secuencia señal para el Retículo Endoplasmático (RE) (David J. Craik. et al., 2010), un Pro-dominio y los dominios ciclótidos precedidos por una pequeña región repetida Ilamada Repetición N- Terminal o NTR (N-Terminal Repeat) (Norelle L Daly. et al., 2009)

Si bien el procesamiento del precursor no se conoce totalmente se piensa que la escisión proteolítica y la ciclación estarían generadas por una asparaginil endopeptidasa (Janette Contreras, et al 2011; Saska et al., 2007)

$\mathrm{OaK} 4$

\begin{tabular}{|l|l|l|l|l|l|l|l|l|} 
RE & PRO & NTR & B2 & NTR & B2 & NTR & B2 & \\
\hline
\end{tabular}

OaK2

\begin{tabular}{|c|c|c|c|c|c|c|}
\hline $\mathrm{RE}$ & PRO & NTR & B6 & NTR & B3 & \\
\hline
\end{tabular}


Muchos ciclótidos fueron originalmente encontrados en programas de screening para actividades biológicas o en el caso de la actividad uterotónica, de su uso en medicina tradicional.( Bin Chen et al., 2005)

Los estudios dirigidos a la búsqueda de ciclótidos, los han encontrado en todas y cada una de las especies de Violaceas estudiadas, por otro lado son menos frecuentes en las Rubiaceae (5\%-10\% de las aproximadamente 200 especies examinadas), en las Cucurbitáceas se ha estudiado una sola especie y se han encontrado 2 ciclótidos, además se ha reportado su presencia en la familia Apocynaceae. (Norelle L. Daly, et al. 2009) y en la familia Fabaceae (Julio A. Camarero. 2011)

Los ensayos in vitro realizados sobre parásitos de animales, permitieron comprobar un importante efecto de algunos de los ciclótidos de Oldenlandia affinis sobre Hemonchus contortus y Trichostrongylus colubriformis, demostrándose que constituyen potentes inhibidores del desarrollo de larvas de nematodos y letales para parásitos adultos aunque presentan una baja actividad ovicida. (Colgrave et al., 2008)

También se han estudiado posibles usos en el control de plagas de cultivos, los ciclótidos han mostrado actividad molusquicida ensayada contra Pomacea canaliculata; los ciclotidos kalata B1 y kalata B2 de O. affinis y cicloviolacina $\mathrm{O} 1$ de $V$. Odorata exhiben una actividad superior a la del propio metaldehido, que es tradicionalmente empleado en el control de gasterópodos. (Manuel Rey R Plan, et al. 2008; Pranting, 2002). Estas actividades se resumen en la tabla 2.2.

Los diferentes campos de aplicación que tienen los ciclótidos han despertado mucho interés y han llevado a investigar la posibilidad de emplear el cultivo in vitro como herramienta para conseguir su producción. El cultivo por ésta técnica de $O$. affinis abre las puertas a la posibilidad de que en un futuro se pueda obtener rendimientos convenientes por medios biotecnológicos. (Peter Seydel y Heike Dörnenburg, 2006) Además se ha empezado la investigación de su expresión heteróloga en bacterias. (Julio A. Camarero, et al. 2007) 
El interés en los ciclótidos va mas allá de las actividades que ya han demostrado En efecto, debido a las características de estabilidad que presentan se podrían lograr modificaciones en esta estructura mediante la incorporación de secuencias de aminoácidos con el fin de conseguir nuevas estructuras con potenciales aplicaciones farmacéuticas y agroquímicas adicionales a las que ya se han mencionado. (Craik et al., 1999)

Tabla 2.2. Ejemplos de ciclotidos, sus fuentes de obtención y actividades

\begin{tabular}{|c|c|c|}
\hline Ciclótido & Planta & Actividad \\
\hline \multirow[t]{2}{*}{ Kalata B1 } & $\begin{array}{l}\text { Oldelandia affinis } \\
\text { Viola odorata } \\
\text { Viola baoshanensis } \\
\text { Viola yedoensis }\end{array}$ & $\begin{array}{c}\text { Nematocida } \\
\text { Molusquicida } \\
\text { Insecticida } \\
\text { Anti-HIV } \\
\text { Antibacterial } \\
\text { Inhibición de proteasas }\end{array}$ \\
\hline & Viola odorata & $\begin{array}{l}\text { Nematocida } \\
\text { Molusquicida }\end{array}$ \\
\hline Kalata B2 & Oldelandia affinis & $\begin{array}{l}\text { Nematocida } \\
\text { Moluscida } \\
\text { Insecticida }\end{array}$ \\
\hline \multirow[t]{2}{*}{ Palicourein } & Palicourea condensata & Anti- HIV \\
\hline & $\begin{array}{l}\text { Viola odorata } \\
\text { Viola biflora } \\
\end{array}$ & $\begin{array}{c}\text { Nematocida } \\
\text { Toxicidad para células cancerosas }\end{array}$ \\
\hline Ciclopsicotrida A & Psychotria longipes & Inhibidor de Neurotensina \\
\hline
\end{tabular}

Tomado de Cybase (2011)

\section{2.- Viola arguta Willd. ex Roem. \& Schult}

Nombre común en el Ecuador: Violeta del campo o Violeta Roja

Es una especie de la Familia Violaceae que puede ser encontrada en la zona surandina del Ecuador en las Provincias de Zamora-Chinchipe y Loja a altitudes entre 1500 y 3500 msm, (Izco et al., 2007).

Jesus Izco no hace referencia a su presencia en otras provincias de este país, debido a que en su estudio se ha limitado a las provincias antes mencionadas. Sin embargo, en el Catalogo de plantas vasculares de Ecuador (2011) se cita su existencia 
en las provincias de Azuay, Bolívar, Cañar, Carchi, Chimborazo, Cotopaxi, Imbabura, Loja, Morona-Santiago, Pichincha, Zamora-Chinchipe (Ver fig 2.5.)

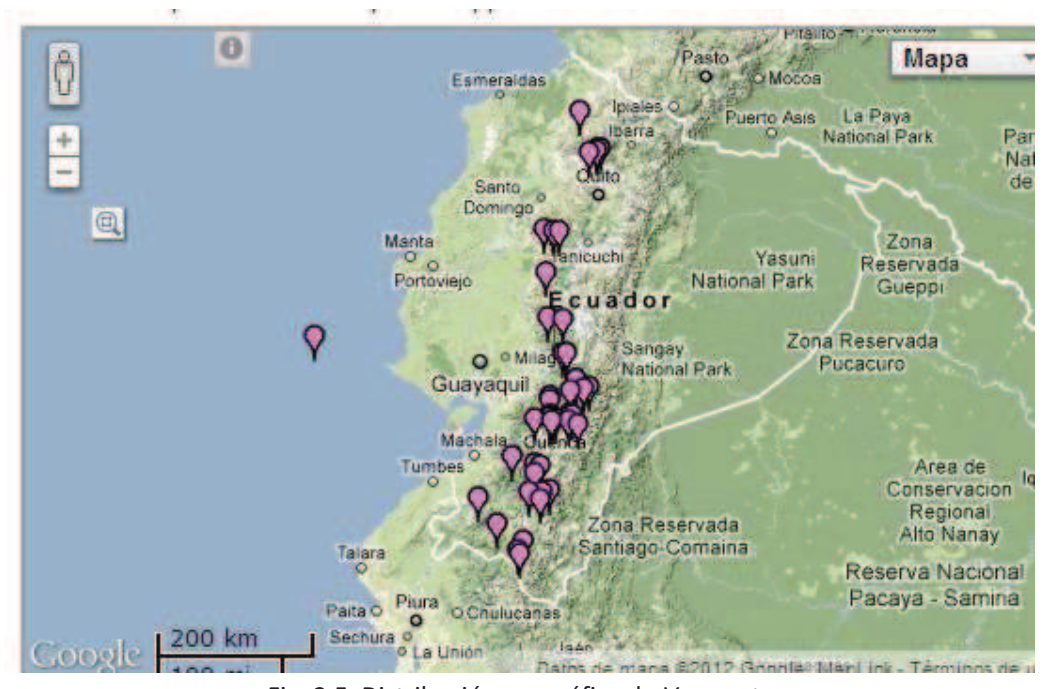

Fig. 2.5. Distribución geográfica de $V$. arguta http://www.tropicos.org/NamePage.aspx?nameid=50073572\&projectid=2

Su tamaño supera los $0,5 \mathrm{~m}$ de longitud, el tallo es leñoso. Sus pétalos son de color rojo, anteras amarillas y estilo rojo.

Tiene algunos usos en medicina tradicional: los habitantes de las provincias antes mencionadas preparan una infusión con partes aéreas de esta planta y se menciona que es utilizada para tratar influenza y fiebre. (Tene Vicente et al., 2006).

También se registra su uso medicinal en la provincia del Cañar, ubicada en el Centro- Sur del Ecuador, donde es utilizada por las personas de esta zona para "el dolor de huesos" según su propia expresión.

También existen referencias del uso de esta planta en medicina tradicional en Colombia. Específicamente María Cristina Arango Mejía en su libro: "Plantas medicinales: botánica de interés medico" (2006) menciona a Viola arguta como una planta utilizada con fines terapéuticos en el Departamento del Putumayo, que está ubicado en la frontera con Ecuador, aunque no especifica cuáles son estos usos medicinales . 
3. - Objetivas

\section{3.- Objetivos}




\section{1.- Objetivo general}

El presente trabajo de investigación se encuentra dirigido a la micrográfica, ensayos fitoquímico y de bioactividades de Viola arguta (Violaceae), ya que no existen datos analíticos que permitan su correcta identificación, o estudios fitoquímicos o farmacológicos que posibiliten la justificación de su uso tradicional o ausencia de toxicidad.

Por tratarse de una especie de uso medicinal es necesario definir características botánicas macro y microscópicas para su correcta identificación e investigar los grupos fitoquímicos presentes, estableciendo perfiles cromatográficos para su reconocimiento.

El objetivo general es contribuir a la revalorización de la flora autóctona latinoamericana, para su mejor aprovechamiento medicinal.

\section{2.- Objetivos específicos}

> Efectuar ensayos químicos preliminares y determinación de perfiles cromatográficos (Cromatografía en capa delgada) de los extractos de V. arguta.

$>$ Determinar la actividad antiinflamatoria y antioxidante in vitro.

D Establecer los elementos de diagnostico micrográficos y valores numéricos de las hojas de Viola arguta.

$>$ Establecer la presencia de metabolitos secundarios característicos del género Viola 
4.- Materiales y métodos. 


\section{4. - Materiales y métadas}

\section{1.- Material vegetal}

\subsection{1.- Procedencia}

Las plantas de Viola arguta Willd. ex Roem. \& Schult. fueron recolectadas el 21 de marzo de 2011 en la Parroquia Baños del Cantón Cuenca, en la Provincia del Azuay, República del Ecuador.

El sitio de recolección corresponde a una colina que se encuentra en la carretera Baños - Insayana a una altura de $2.800 \mathrm{msnm}$, siendo sus coordenadas: S: $2^{0}$ $55^{\prime} 13^{\prime \prime}$ W: $79^{0} 04^{\prime} 47^{\prime \prime}$ ("Catalogue of the Vascular Plants of Ecuador").
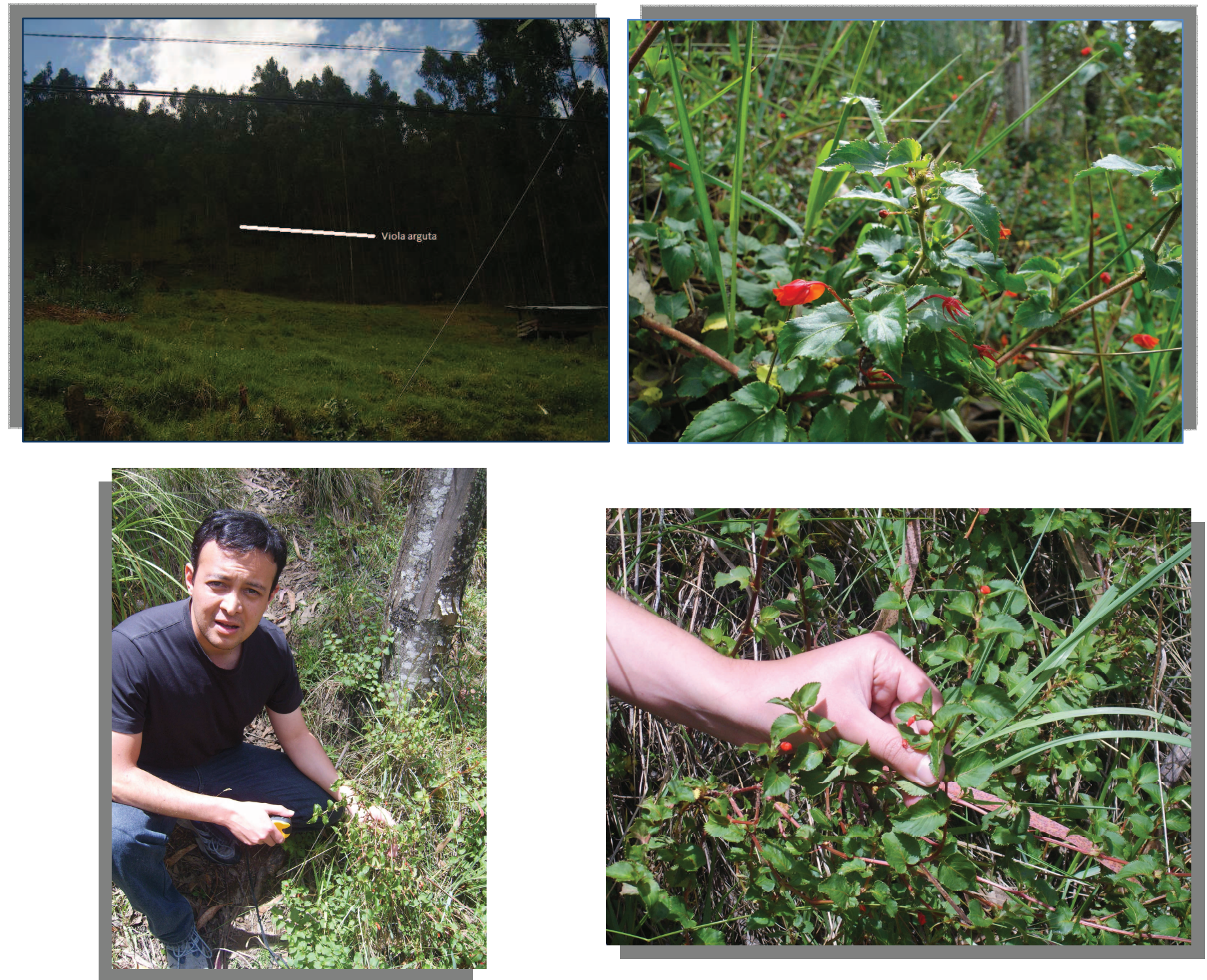

Fig.4.1. Etapas de la recolección del material vegetal 


\section{4. - Materiales y métados}

\subsection{2.- Recolección y acondicionamiento del material vegetal}

Para el desarrollo del trabajo se utilizó material fresco correspondiente a la parte aérea vegetativa de la planta. La recolección se realizó en forma manual con el empleo de tijera de jardinería.

Para la realización de los estudios botánicos, varios ejemplares de la planta fueron acondicionados para su herborización, mientras que otra parte del material vegetal se fijó en líquido conservador: FAA (Formol- alcohol etílico 96 - ácido acético glacial- agua destilada 50:25:250:175)

El resto del material vegetal obtenido fue acondicionado y secado en estufa con convección forzada de aire a $37^{\circ} \mathrm{C}$ por 5 días en el laboratorio del Proyecto de Plantas Medicinales de la Universidad de Cuenca, por gentileza de la Dra. Rafaella Ansaloni y posteriormente acondicionado en bolsas de papel tipo empaque.

En esas condiciones, el material fue transportado hacia Argentina a la Cátedra de Farmacobotánica de la Facultad de Ciencias Exactas de la Universidad Nacional de la Plata. Allí, a los efectos de la realización de los estudios fitoquímicos, fue molido y conservado en recipientes de cierre perfecto y al abrigo de la luz.

Un ejemplar del material herborizado (fig. 4.2.) fue depositado en el Museo "Carlos Spegazzini", de la Facultad de Ciencias Exactas de la UNLP, bajo el registro (LPE1161).

\subsection{3.- Determinación taxonómica}

La determinación de la especie fue realizada por la Profesora Dra. Rafaella Ansaloni, Directora del Herbario de la Universidad del Azuay (HA-7827) y confirmada por la Dra. Etile D. Spegazzini de la Facultad de Ciencias Exactas de la UNLP, Argentina. 


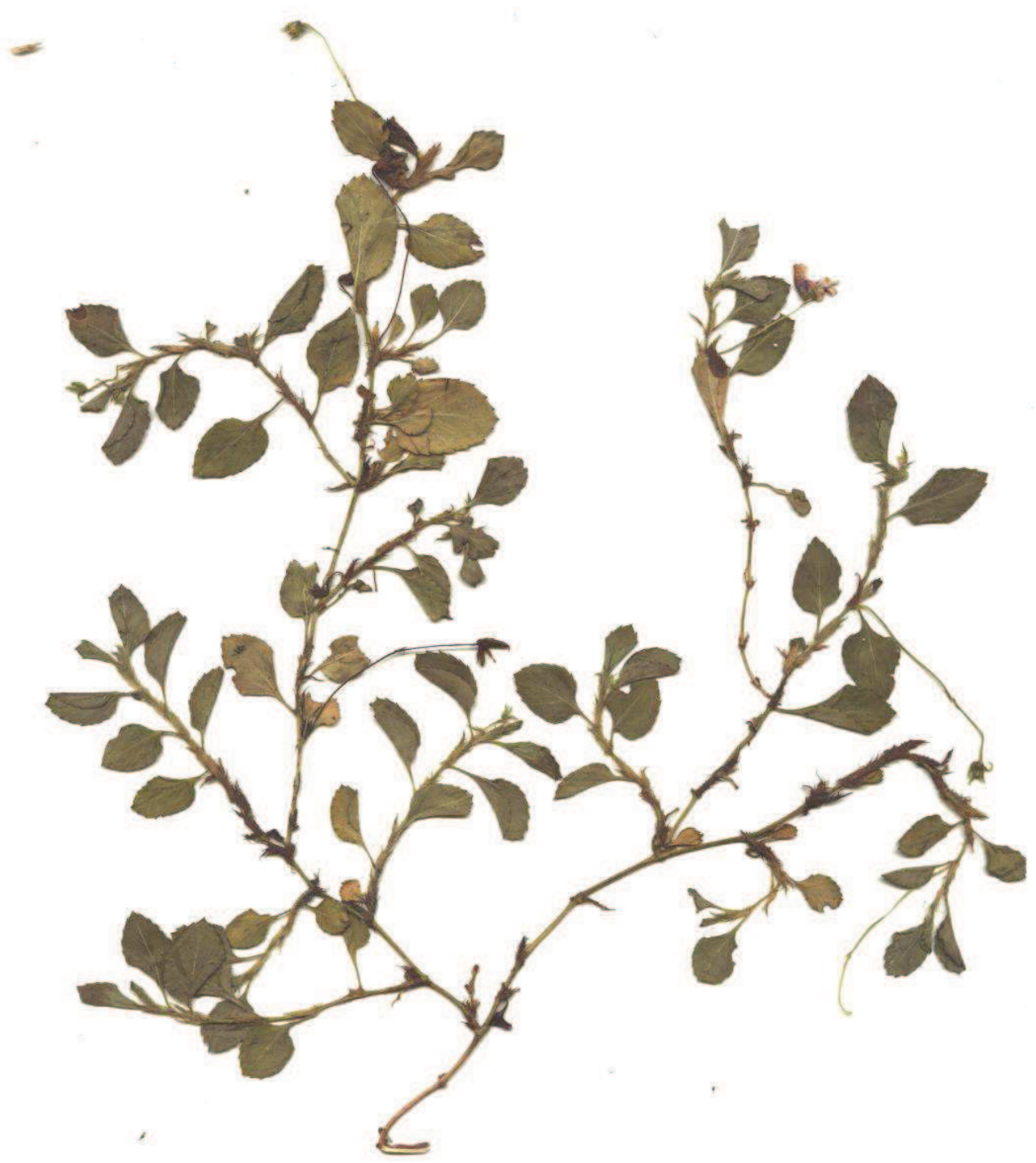

FLORA DEL ECUAI

Fig. 4.2. Ejemplar de V. arguta HA-7827

Recolector: J.M. Carpio Arevalo

Foto: HA 


\section{2.- Microscopía analítica}

\subsection{1.- Equipos utilizados}

Las observaciones se efectuaron con microscopio estereoscópico Iroscope YZ-6 y microscopio óptico (MO) Olympus CX31 equipado con tubo de dibujo Iroscope. Las microfotografías fueron tomadas Cámara Fotográfica Olympus Camedia y software y con una cámara digital Samsung.

Las observaciones y microfotografías con microscopio electrónico de barrido (MEB) fueron realizadas con un equipo Philips 505 perteneciente al Servicio de Microscopía Electrónica de Barrido del Centro de Investigación y Desarrollo en Ciencias Aplicadas “Dr. Jorge J. Ronco" (CINDECA), CONICET, UNLP.

\subsection{2.- Observación de epidermis foliar con microscopio óptico (MO)}

\section{Diafanización de las hojas}

El procedimiento de diafanización según técnica de Dizzeo de Stritmatter (1973) se llevó a cabo aplicando el siguiente protocolo:

- Se colocaron hojas de Viola arguta en un vaso precipitado con un volumen suficiente de etanol de 96 y se llevó a ebullición durante 5 minutos.

- Se agregó igual volumen de hidróxido de sodio al 5\% y se mantuvo en ebullición por 1 minuto.

- Las hojas se lavaron con agua destilada varias veces hasta eliminar el álcali.

- Se colocaron en hipoclorito de sodio comercial diluido al 50\% hasta decoloración total.

- Se lavaron con agua destilada varias veces hasta eliminar el decolorante.

- Se colocaron en una solución de Hidrato de Cloral (5 gr. en 100 ml) por 24 horas. 


\section{4. - Materiales y métados}

-El material transparente de hoja fue lavado y montado en gelatina glicerina.

Estos preparados permitieron analizar la distribución de estomas y tricomas en la parte media y sobre ambas caras de la lámina. Los recuentos de células epidérmicas, estomas y células en empalizada permitieron establecer los valores numéricos proporcionales correspondientes a los índices de estomas (Salisbury, 1927) y empalizada (Zornig y Weiss, 1925).

\section{Determinación de valores numéricos o magnitudes proporcionales}

\section{- Determinación del índice de estomas}

Esta determinación se realizó en base al valor numérico definido por Salisbury (1927), quien define al índice de estomas como la relación existente entre el número de estomas y el número total de células por unidad de superficie.

$$
\mathrm{IS}=\frac{\mathrm{S}}{\mathrm{S}+\mathrm{E}} \times 100
$$

IS: Indice de estomas

S: número de estomas

E: número de células epidérmicas

Se trabajó con 25 muestras de hojas diafanizadas de $V$. arguta, para cada una de las cuales se repitió el conteo de estomas y células epidérmicas en diez campos distintos y seleccionados. Los campos observados fueron dibujados mediante el tubo de dibujo en unidades de superficie representadas por cuadrados de $10 \mathrm{~cm}$ de lado.

\section{- Determinación del índice de empalizada}

Esta magnitud representa el promedio de células en empalizada que aparecen por debajo de cada célula epidérmica.

Se obtiene contando el número de células en empalizada que se encuentran debajo de cuatro células epidérmicas y dividiendo por cuatro

$$
\mathrm{IE}=\frac{\mathrm{E}}{4 \mathrm{Ep}} \times 100
$$


IE: índice de empalizada

E: número de células en empalizada

Ep: Célula epidérmica

Veinticinco muestras correspondientes a fragmentos de $5 \mathrm{~mm}$ de lado, de las hojas diafanizadas de $V$. arguta fueron examinados en visión frontal o adaxial. De esta manera, las células en empalizada aparecen como pequeños círculos por debajo de las células epidérmicas. Se efectuaron observaciones microscópicas de 5 campos para cada muestra, realizándose los diseños correspondientes con el tubo de dibujo, obteniéndose los valores promedio.

Todos los valores obtenidos de cada parámetro se expresaron en rangos, promedio y moda (Mo).

\subsection{3.- Observación de la epidermis foliar con microscopio electrónico de barrido} (MEB)

Porciones de $1 \mathrm{~mm}$ de pecíolo y lámina foliar fueron fijadas en FAA, deshidratadas hasta alcohol etílico absoluto y secadas al aire. Las muestras montadas sobre un soporte metálico fueron cubiertas con una fina capa conductora de oropaladio. Se registraron imágenes digitalizadas de las estructuras del pecíolo, lámina y cristales con el uso de un microscopio electrónico de barrido Philips. 


\section{3.- Ensayos fitoquímicos}

\subsection{1.- Preparación de los extractos}

\section{* Extracción con solventes de polaridad creciente}

a) Extracción para los ensayos fitoquímicos preliminares y actividades biológicas in vitro

El material seco y molido (10 g) fue extraído a temperatura ambiente con hexano $(\mathrm{Hx})$, durante 24 horas con agitación frecuente. Luego de este tiempo se repitió el procedimiento. Los extractos se filtraron por papel y se reunieron.

El marco de la extracción anterior se dejo secar a temperatura ambiente y se volvió a extraer con diclorometano (DCM) como segundo solvente de extracción, procediendo de igual manera que con el solvente anterior. El procedimiento se repitió, utilizando metanol $(\mathrm{MeOH})$.

Los solventes utilizados fueron solventes Merck grado analítico.

Los solventes fueron evaporados a presión reducida en un evaporador rotatorio Heidolph y el rendimiento fue calculado en gramos de extracto/100 gramos de planta seca.

Con los extractos así obtenidos se efectuaron los ensayos químicos y cromatográficos preliminares.

b) Extracción de ciclótidos a partir de un extracto en $\mathrm{MeOH} 60 \%$ (Método de Claeson y Burman modificados)

Los ciclótidos presentes en $V$. arguta fueron extraídos y semipurificados mediante un procedimiento basado en los trabajos de Claeson et al (1998) y Burman et al. (2010), que hemos modificado según el siguiente protocolo:

El material seco y molido (10 g) fue extraído a temperatura ambiente con hexano $(\mathrm{Hx})$, durante 24 horas con agitación frecuente. Luego de este tiempo se repitió el procedimiento. Los extractos se filtraron por papel y se reunieron.

El marco de la extracción anterior se dejo secar a temperatura ambiente y se volvió a extraer con diclorometano (DCM) como segundo solvente de extracción, procediendo 


\section{4. - Materiales y métados}

de igual manera que con el solvente anterior. El procedimiento se repitió, utilizando una solución de Metanol al 60\% (Burman et al., 2010)

Evaporar a sequedad el extracto $\mathrm{MeOH} 60 \%$.

Retomar el extracto seco con $\mathrm{MeOH}$ 99,9\% (10 ml), transferir a un tubo de centrifuga y añadir $1 \mathrm{ml}$ de diclorometano. Centrifugar durante $10 \mathrm{~min}$.

Desechar el sobrenadante y lavar 3 veces con MeOH/DCM 10:1.

Redisolver el precipitado con $\mathrm{MeOH} 60 \%$

c) Extracción de ácidos orgánicos a partir del extracto hexánico (Soares Costa Oliveira et al., 2011)

Macerar $10 \mathrm{~g}$ de material vegetal con $40 \mathrm{ml}$ de hexano

Filtrar

Diluir el filtrado con $30 \mathrm{ml}$ de $\mathrm{MeOH} 5 \%$

Añadir 2,5g de $\mathrm{Ca}(\mathrm{OH}) 2$, poco a poco y con agitación constante

Elevar la temperatura a 50 C con agitación constante por 3 hs

Filtrar y lavar el precipitado con $\mathrm{MeOH}$ en embudo Buchner

Secar el precipitado en estufa a 45-50ㅇ C durante 2 hs

Resuspender en 40 mlde agua destilada, conteniendo 5,45 ml de $\mathrm{HCl} 11 \mathrm{M}$.

Agitar durante 1 hs

Extraer la soluciòn resultante con Acetato de etilo (14 ml x 2)

Lavar la capa organica con agua desionizada y secar sobre SO4Na2 anhidro.

Evaporar el acetato de etilo hasta pequeño volumen.

\section{* Extracción acuosa}

Las partes aéreas de Viola arguta (hojas, tallos y flores) fueron extraídas con agua, mediante una infusión realizada con $10 \mathrm{~g}$ de planta pulverizada en $100 \mathrm{ml}$ de agua destilada durante 15 minutos. El extracto acuoso así obtenido se liofilizó en un equipo liofilizador L-T4 Rificor y se calculó su rendimiento en g de liofilizado/100 g de planta. 
Sobre este liofilizado se efectuaron ensayos químicos preliminares, y los ensayos de actividad in vitro.

\subsection{2.- Pruebas químicas orientativas}

\section{1) Detección de Alcaloides:}

Para la extracción de los alcaloides que podrían estar presentes en el material vegetal se procedió a utilizar el método de extracción en medio ácido, proceso que permite que estos metabolitos formen sales solubles en agua.

Para esto se pesaron $10 \mathrm{~g}$ de Viola arguta seca y pulverizada, se maceraron por 24 horas con $40 \mathrm{ml}$ de ácido clorhídrico al 2\%, transcurrido este tiempo se filtró y se distribuyeron $20 \mathrm{ml}$ del filtrado en 4 tubos de ensayo $(5 \mathrm{ml} \mathrm{c} / \mathrm{u})$ sobre los que se adicionaron 2 o 3 gotas de cada uno de los reactivos para precipitación de alcaloides: Dragendorff, Mayer, Acido Tánico y Bouchardat. (Domínguez, 1973)

\section{Caracterización de alcaloides}

$\begin{array}{lll}\text { ○ Dragendorff : } & \text { Reacción de precipitación } \\ \text { ○ Mayer: } & \text { Reacción de precipitación } \\ \text { ○ Acido Tánico: } & \text { Reacción de precipitación } \\ \circ \text { Bouchardat: } & \text { Reacción de precipitación }\end{array}$

\section{2) Detección de Antraquinonas (Aglicones y Heterósidos)}

Para la extracción de los aglicones y heterósidos de antraquinonas que podrían estar presentes en la plantas se procedió a una extracción con acido sulfúrico $1 \mathrm{M}$ y la detección de antraquinonas se realizó usado la reacción de Borntrager.

Se pesó $1 \mathrm{~g}$ de Viola arguta seca y pulverizada, se añadieron $10 \mathrm{ml}$ de $\mathrm{H}_{2} \mathrm{SO}_{4} 1 \mathrm{M}$ y se calentó a ebullición en Baño de María por 10 minutos, transcurrido este tiempo se filtró en caliente, una vez frío tomamos $5 \mathrm{ml}$ de filtrado para realizar una extracción 


\section{4. - Materiales y métados}

Líquido-Liquido utilizando $3 \mathrm{ml}$ de Cloroformo, se separó la fase orgánica y se añadieron sobre ésta $3 \mathrm{ml}$ de Amoniaco concentrado (Reacción de Borntrager), de estar presentes aglicones libres en la planta o aglicones que se liberan de sus azúcares (heterósidos) en la hidrólisis del proceso anterior, debía producirse un color rojo-rosa intenso en la capa amoniacal (Domínguez, 1973).

\section{Caracterización de Antraquinonas}

○ Reacción de Borntrager

\section{3) Detección de Saponinas.}

Para la detección de saponinas se procedió a investigar su presencia los extractos Metanólico y Acuoso poniendo en evidencia su capacidad afrógena.

Para esto se colocaron $4 \mathrm{ml}$ de cada uno de los extractos en tubos de ensayo junto con $4 \mathrm{ml}$ de agua destilada, se agitaron vigorosamente por 30 segundos y se observó si se generó la formación de espuma estable (Domínguez, 1973)

\section{Caracterización de Saponinas}

- Capacidad afrógena

\section{4) Detección de taninos}

La investigación de la presencia de Taninos se efectuó en los extractos metanólico y acuoso.

La reacción para identificarlos se realizó añadiendo a $5 \mathrm{ml}$ de los extractos señalados 3 gotas de $\mathrm{Cl}_{3} \mathrm{Fe}$ al $10 \%$ y observando el cambio de coloración producido. (Domínguez, 1973)

\section{Caracterización de Taninos}

$$
\circ \mathrm{Cl}_{3} \mathrm{Fe}
$$




\section{4. - Materiales y métadas}

\section{5) Detección de Mucílagos y gomas}

Los mucílagos se investigaron únicamente en el extracto acuoso por ser insolubles en el resto de solventes utilizados.

Su caracterización se basa justamente en la insolubilidad de estas sustancias en alcohol y que se verifica por la precipitación que se da al añadir etanol al extracto acuso que los contenga.

Se toman $10 \mathrm{ml}$ de extracto acuoso y se añade poco a poco etanol absoluto, la formación de un precipitado es presuntiva de la presencia de gomas o mucílagos. (Korwar et. Al, 2010; FA VI ed, 1978)

Además de este ensayo, se realizó una reacción histoquímica consistente en tratar el preparado de hoja en vista superficial con una solución diluida de azul de metileno, con el cual, algunos mucílagos adquieren una coloración azul (Trease y Evans, 2008)

\section{Caracterización de Mucílagos y gomas}

○ Precipitación con etanol absoluto

- Reacción histoquímica con azul de metileno

\section{6) Detección de flavonoides}

La identificación de flavonoides se realizó en todos los extractos y se empleó para tal propósito la reacción de Shinoda.

A $3 \mathrm{ml}$ de cada uno de los extractos se les agregó unos pocos fragmentos de Magnesio metálico seguido de unas 5 gotas de $\mathrm{HCl}$ concentrado, la presencia de un color magenta indica la presencia de flavonoides.

Alícuotas de los extractos Hexánico, DCM, MeOH y acuoso obtenidos fueron retomados con sus correspondientes solventes y sometidos a una serie de ensayos químicos destinados a poner de manifiesto la presencia de los diferentes grupos fitoquímicos. (Domínguez, 1973) 
Caracterización de flavonoides:

- Reacción de Shinoda

○ Reacción con $\mathrm{Cl}_{3} \mathrm{Fe}$ al $2 \%$ en $\mathrm{EtOH}$ y observación visible

- Reacción con $\mathrm{Cl}_{3} \mathrm{Al}$ al $2 \%$ en EtOH y observación visible y UV366

- Reacción con $\mathrm{H}_{3} \mathrm{BO}_{3}$ al $2 \%$ en EtOH y observación visible y UV366

- Reacción con $\mathrm{KOH}$ al 1\% en EtOH y observación visible y UV366

\subsection{3.- Cromatografía en capa delgada (CCD):}

Las cromatografías se efectuaron sobre cromatofolios de silicagel 60 GF254 Merck 0,25 mm (origen Alemania)

\subsubsection{2.- Fases móviles utilizadas}

\begin{tabular}{|c|l|c|}
\hline Fase & Solventes & Proporción \\
\hline I & Acetato de etilo/Metanol/Agua & $100: 13,5: 10$ \\
\hline II & Hexano/Acetato de Etilo & $7: 3$ \\
\hline III & Tolueno/Acetato de etilo & $7: 3$ \\
\hline IV & Butanol/ Acido Acético/ Agua & $3: 1: 1$ \\
\hline V & Toleno/acetato de etilo & $8: 2$ \\
\hline VI & Eter etílico/éter de petróleo/ acido formico & $70: 30: 1$ \\
\hline VII & $\begin{array}{l}\text { Acetato de etilo/ acido acetico/ acido formico/ } \\
\text { agua }\end{array}$ & \\
\hline
\end{tabular}

\subsubsection{3.- Detección}

Los reveladores utilizados en las CCD fueron:

i. Observación a la luz ultravioleta de $254 \mathrm{~nm}$ y $366 \mathrm{~nm}+$ vapores de $\mathrm{NH}_{3}$

ii. Pulverización con reactivo de productos naturales (éster del acido 2-amino etil difenil borico al $1 \%$ en metanol) + calor y posterior observación al visible $y$ al $U V_{366}$

iii. Pulverización con Anisaldehido sulfúrico y calentamiento en estufa a $120^{\circ} \mathrm{C}$ durante 5 minutos. Observación al visible 


\section{4. - Materiales y métados}

iv. Pulverización con solución diclorometánica al $1 \%$ de $\beta$-caroteno.y observación al visible a tiempo 0, 30 y 60 minutos.

v. Pulverización con Ninhidrina al $0,2 \%$ en Etanol Absoluto

vi. Pulverización con Azul Brillante de Coomassie G-250

vii. Pulverización con Azul de bromofenol al 0,1\% en etanol

viii. Pulverización con $\mathrm{Cl}_{3} \mathrm{Fe}$ al $10 \%$

\subsubsection{4- Testigos utilizados}

Para el análisis por cromatografía en capa delgada (CCD) se utilizaron con fines comparativos los compuestos: (aclarar en cada uno marca y/u origen)

○ Rutina (Rt) (provisto por la Cátedra de Farmacognosia, Fac. de Cs. Exactas, UNLP)

○ Quercetina (Q) (provisto por la Cátedra de Farmacognosia, Fac. de Cs. Exactas, UNLP)

- Acido Salicílico (AS) (gentilmente provisto por la Mg. Maria E. Del Valle (Cátedra de Farmacognosia, Fac. de Cs. Exactas, UNLP)

O Salicilato de metilo (SM) (gentilmente provisto por la Mg. Maria E. Del Valle (Cátedra de Farmacognosia, Fac. de Cs. Exactas, UNLP)

○ Vitexina (Cátedra de Farmacognosia, Fac. de Cs. Exactas, UNLP)

○ Isovitexina (Cátedra de Farmacognosia, Fac. de Cs. Exactas, UNLP)

\subsubsection{5.- Sistemas cromatográficos utilizados para los distintos extractos}

Los sistemas cromatográficos utilizados para examinar los extractos obtenidos, surgen de la combinación de fase estacionaria, fases móviles y sistemas de detección descriptos en los ítems anteriores.

Se detallan en las siguientes tablas: 
Tabla Sistemas cromatográficos utilizados para CCD de los extractos Hexánico y DCM

\begin{tabular}{|c|c|c|}
\hline $\begin{array}{c}\text { Sistemas } \\
\text { cromatográficos }\end{array}$ & Fase móvil & Revelador \\
\hline 1 & II & i, ii, iii, iv \\
\hline 2 & III & i, ii, iii, iv \\
\hline 2 b & VI & lii, vii \\
\hline
\end{tabular}

Tabla Sistemas cromatográficos utilizados para la CCD del extracto Metanólico

\begin{tabular}{|c|c|c|}
\hline $\begin{array}{l}\text { Sistemas } \\
\text { cromatográficos }\end{array}$ & Fase & Revelador \\
\hline 3 & I & i, ii, iii, iv \\
\hline 4 & II & i, ii, iii, iv \\
\hline 5 & III & i, ii, iii, iv \\
\hline 6 & V & vi \\
\hline
\end{tabular}

Tabla Sistemas cromatográficos utilizados para la CCD del extracto Metanólico al 60\%

\begin{tabular}{|c|c|c|}
\hline $\begin{array}{l}\text { Sistemas } \\
\text { cromatográficos }\end{array}$ & $\begin{array}{l}\text { Fase } \\
\text { Móvil }\end{array}$ & Revelador \\
\hline 4 & IV & $i, i i, v, v i$ \\
\hline
\end{tabular}

\subsection{4.- Caracterización de ciclótidos por CCD}

El extracto Metanólico al 60\% obtenido por el método de Claeson y Burman modificado, se sembró en tres placas de sílica gel (Placas A, B y C) que se desarrollaron simultáneamente en las condiciones del sistema cromatográfico antes indicado (Sistema IV). 


\section{4. - Materiales y métadas}

Concluido el desarrollo se evaporó la fase móvil y se colocó una de las placas (A) suspendida en un tubo de vidrio tapado junto a $1 \mathrm{ml}$ de $\mathrm{HCl}(37 \%)$ y se lo sometió a calentamiento en una estufa a $110^{\circ} \mathrm{C}$ por 2 horas para generar la hidrólisis de los péptidos presentes.

Pasadas las dos horas se sacó la placa del tubo, se eliminó totalmente el $\mathrm{HCl}$ en corriente de aire caliente y se reveló

La placa C (no hidrolizada) se reveló con el Azul Brillante de Coomassie mientras que la placa A (hidrolizada) y la placa B (no hidrolizada) se revelaron con ninhidrina al $0,2 \%$ y calentando con corriente de aire caliente durante varios minutos.

\subsection{5.- Detección de ácidos por CCD}

La solución obtenida en 4.3.1. c (ver materiales y métodos) fue cromatografiada utilizando el sistema $2 \mathrm{~b}$ (Eter etílico/éter de petróleo/ acido formico) y revelada alternativamente con anisaldehido sulfurico y azul de bromofenol.

\section{4.- Actividades}

\subsection{1.- Actividad antioxidante por métodos espectrofotométricos}

La ingesta de productos naturales con capacidad antioxidante suele ser relacionada con el efecto beneficioso de éstos en la prevención y/o tratamiento de diversas enfermedades tales como cáncer, enfermedades coronarias, degeneración macular relacionada con la edad, enfermedades respiratorias, fibrosis quística, enfermedades del sistema inmune, Alzheimer, etc. (Ing-Chien Chen, et al.,2004; PhamHuy e al., 2008; Pourahmad, 2002)

Entre los metabolitos secundarios con capacidad antioxidante que pueden estar presentes en estos productos podemos citar ácidos fenólicos, flavonoides, quinonas, cumarinas, lignanos, estilbenos, taninos, alcaloides, aminas, betalainas, vitaminas, terpenoides, etc. (Yizhong Cai, et al., 2003) 


\section{4. - Materiales y métados}

En general, las determinaciones de la capacidad antioxidante de un extracto constan de una serie de etapas comunes a todas ellas, que pueden resumirse:

- Preparación del extracto.

- Preparación de solución madre de extracto:

$\checkmark$ disolución de $10 \mathrm{mg}$ de extracto seco en $1 \mathrm{ml}$ dimetilsulfoxido (DMS).

$\checkmark$ Preparación de diluciones en DMS

- Preparación del Standard (St):

$\checkmark$ disolución de $10 \mathrm{mg}$ de standard en $1 \mathrm{ml}$ DMS.

$\checkmark$ Preparación de diluciones en DMS

$\checkmark$ Construcción de curva patrón.

- Realización de las reacciones según cada ensayo, buscando que cada dilución de extracto quede en el rango de absorción de la curva de calibración.

- Cálculo como equivalentes de St /mg de extracto seco.

La actividad antioxidante de los extractos de $V$. arguta, fue ensayada mediante distintos métodos in vitro, en comparación con patrones conocidos tales como ácido ascórbico, Trolox, acido tánico, rutina, etc. (Cavin et al. 1998; Kuskoski et al., 2005; Muñoz Jáuregui et al., 2007; Aubad López et al., 2007; Neira González , 2009). También fue determinada la concentración de flavonoides y fenoles totales.

\subsubsection{1.- Actividad frente al radical 2,2-difenil-1-picrilhidrazilo (DPPH)}

Esta determinación se realizó mediante el método de Brand Williams et al. (1995), modificado.

Esta técnica se basa en la reducción que sufre el radical estable 2,2-difenil-1picrilhidrazilo (DPPH) en presencia de un antioxidante, pasando del color violeta intenso que exhibe la forma oxidada al incoloro de la forma reducida.

La decoloración producida se traduce en una disminución de la absorbancia a $517 \mathrm{~nm}\left(\mathrm{~A}_{517}\right)$, proporcional a la concentración del DPPH reducido, y permite 
cuantificar la capacidad captadora de radicales libres que poseen determinados compuestos.

La capacidad antioxidante de los compuestos presentes en un extracto, puede ser expresada como actividad antioxidante equivalente, (TEAC en $\mu \mathrm{g}$ compuesto referencia/mg muestra), a un antioxidante de referencia: el 6-hidroxi-2,5,7,8tetrametilcroman-2-ácido carboxílico (Trolox) (PM 250,3) (Aubad López et al., 2007).<smiles>Cc1c(C)c2c(c(C)c1O)CCC(C)(C(=O)O)O2</smiles>

Según el protocolo de Cavin et al. (1998) se introduce en un tubo de reacción 7,5 $\mu \mathrm{L}$ de la muestra a ensayar, vehículo o compuestos de referencia (2,6-di(ter-butil)-4metilfenol o BHT, quercetina, trolox) a las concentraciones estudiadas, $250 \mu \mathrm{L}$ de agua destilada y $500 \mu \mathrm{L}$ de la disolución de DPPH $(20 \mathrm{mg} / \mathrm{mL})$. Tras incubación a temperatura ambiente y en oscuridad durante $30 \mathrm{~min}$, se lee la absorbancia a 517 $\mathrm{nm}$.

Curva de calibración: se realiza aplicando el protocolo descripto precedentemente y determinando la $A_{517}$ para soluciones de trolox a distintas concentraciones. La actividad de los antioxidantes de la muestra, expresados como $\mu \mathrm{g}$ trolox/mg extracto seco, puede ser calculada a partir del gráfico $A_{517}$ vs. [ $\mu$ g trolox]

Preparación de la muestra a ensayar: $10 \mathrm{mg}$ de los extractos a ensayar se disolvieron a un volumen final de $1 \mathrm{ml}$ con DMSO. De esta solución madre se tomaron 7,5 $\mu \mathrm{l}$ y se llevaron a $100 \mu \mathrm{l}$ con DMSO. Para la mezcla de reacción se tomaron $10 \mu \mathrm{l}$ de esta dilución y se llevaron a un volumen final de $1 \mathrm{ml}$.

Preparación de la solución de DPPH (20 mg/L): $10 \mathrm{mg}$ DPPH se disuelven con cantidad suficiente de $\mathrm{MeOH}$ hasta $50 \mathrm{ml}$. Esta solución madre se conserva a $4^{\circ} \mathrm{C}$ en envase de vidrio color caramelo y envuelto en papel de aluminio. 


\section{4. - Materiales y métadas}

El ensayo se realiza con una dilución 1/10 de la solución madre, en $\mathrm{MeOH}$.

El ensayo con DPPH se realiza según el siguiente protocolo:

\begin{tabular}{|l|c|c|c|c|}
\hline \multicolumn{5}{|c|}{ Ensayo con DPPH } \\
\hline & $\begin{array}{c}\text { Blanco Control } \\
(-)\end{array}$ & Control (-) & $\begin{array}{c}\text { Blanco } \\
\text { Muestra }\end{array}$ & Muestra \\
\hline Muestra & - & - & $7.5 \mu \mathrm{L}$ & $7.5 \mu \mathrm{L}$ \\
\hline Vehículo & $7.5 \mu \mathrm{L}$ & $7.5 \mu \mathrm{L}$ & - & - \\
\hline AD & $250 \mu \mathrm{L}$ & $250 \mu \mathrm{L}$ & $250 \mu \mathrm{L}$ & $250 \mu \mathrm{L}$ \\
\hline $\begin{array}{l}\text { DPPH } \\
\text { (20mg/L) }\end{array}$ & - & $500 \mu \mathrm{L}$ & - & $500 \mu \mathrm{L}$ \\
\hline MetOH & $500 \mu \mathrm{L}$ & - & $500 \mu \mathrm{L}$ & - \\
\hline $\begin{array}{l}\text { Incubar a temperatura ambiente y en oscuridad durante } 30 \mathrm{~min} \\
\text { Leer la absorbancia a } 517 \mathrm{~nm} .\end{array}$
\end{tabular}

\subsubsection{2.- Actividad frente al radical 2,2'-azino-bis(3-etilbenztiazolin-6-sulfonato de amonio) (ABTS)}

El ensayo se efectuó según la metodología desarrollada por Re et al., (1999). Esta técnica se basa en la reducción que sufre el radical catiónico 2,2'-azino-bis(3etilbenztiazolin-6-sulfonato de amonio) $\left(\mathrm{ABTS}^{\bullet+}\right)$ en presencia de un antioxidante, pasando del color verde que exhibe la forma oxidada $\left(\mathrm{ABTS}^{\bullet+}\right)$ al incoloro de la forma reducida (ABTS).

El radical $\mathrm{ABTS}^{\bullet+}$ presenta cuatro máximos de absorción a 414, 645, 732 y 815 $\mathrm{nm}$ lo cual permite seleccionar la longitud de onda adecuada para evitar interferencias con los compuestos presentes en la muestra a estudiar. En el caso de los extractos de $V$. arguta, la decoloración producida se traduce en una disminución de la absorbancia a $732 \mathrm{~nm}\left(\mathrm{~A}_{732}\right)$, proporcional a la concentración del ABTS reducido, y permite cuantificar la capacidad captadora de radicales libres que poseen determinados compuestos (Kuskoski et al., 2004). 


\section{4. - Materiales y métadas}

El radical $\mathrm{ABTS}^{\bullet+}$ se formó tras la reacción de $\mathrm{ABTS}(3,5 \mathrm{mM})$ con persulfato potásico (1,25 mM, concentración final) incubados a temperatura ambiente y en oscuridad durante $16 \mathrm{~h}$. Una vez formado el radical $\mathrm{ABTS}^{\bullet+}$ se diluyó con etanol hasta obtener un valor de absorbancia de 0,700 $\pm 0,100$ a $732 \mathrm{~nm}$ (longitud de máxima absorción).

Las muestras filtradas se diluyeron con etanol hasta que se obtuvo un $20-80 \%$ de inhibición comparadas con la absorbancia del blanco tras añadir $20 \mu \mathrm{l}$ de la muestra. A $980 \mu \mathrm{l}$ de dilución del radical $\mathrm{ABTS}^{\bullet+}$ así generado se le determina la $\mathrm{A}_{732}$ a 30 으, se añade $10 \mu \mathrm{l}$ de la muestra y se mide de nuevo a $A_{732}$ pasado 1 minuto. La absorbancia fue continuadamente medida después de 4 minutos. Se ensayaron extractos en un rango de concentración final entre 1 y $200 \mu \mathrm{g} / \mathrm{ml}$.

La actividad antioxidante se evalúa midiendo el cambio de $A_{732}$ de la solución de $\mathrm{ABTS}^{\bullet+}$ cuando se alcanza el estado estacionario (Aubad López et al., 2007)

Curva de calibración: se realiza aplicando el protocolo descripto precedentemente y determinando la $A_{517}$ para soluciones de trolox a concentración de $0-15 \mu \mathrm{M}$ (concentración final) en etanol. La actividad de los antioxidantes de la muestra, expresados como $\mu \mathrm{g}$ trolox/mg extracto seco (TEAC), puede ser calculada a partir del gráfico $A_{732}$ vs [ $\mu$ g trolox]

Preparación de la muestra a ensayar: $10 \mathrm{mg}$ de los extractos a ensayar se disolvieron a un volumen final de $1 \mathrm{ml}$. De esta solución madre se tomaron $10 \mu \mathrm{l}$ que se diluyeron a $40 \mu \mathrm{l}$ finales (dilución 1:4). Para la mezcla de reacción se tomaron $10 \mu \mathrm{l}$ de esta dilución y se llevaron a un volumen final de $1 \mathrm{ml}$.

\subsubsection{Evaluación de la capacidad reductora por el método FRAP}

Este método evalúa la capacidad antioxidante de una muestra biológica de acuerdo a su capacidad para reducir un determinado compuesto. Originariamente este método se lo denominó "Ferric reducing ability of plasma" (FRAP) porque fue utilizado 


\section{4. - Materiales y métadas}

para medir la actividad antioxidante del plasma humano. Actualmente se lo denomina "Ferric reducing/antioxidant power" y su utilización se ha extendido al estudio de diferentes compuestos, mezclas o extractos biológicos.

El fundamento del método consiste en la reducción de un compuesto o mezcla de compuestos $(\mathbf{X})$ sobre el $\mathrm{Fe}^{+3}$ presente en un complejo con un compuesto orgánico: Tripyridyltriazina (TPTZ). Cuando el hierro del complejo es reducido a la forma ferrosa toma un color azul que presenta un máximo de absorción a $593 \mathrm{~nm}$ y cuya intensidad de color es proporcional a la capacidad reductora del compuesto o compuestos ensayados (Benzie et al., 1996).

$\begin{array}{ccc}\text { TPTZ-Fe }^{+3} \text { ) } & {[\mathrm{X}]} & \text { TPTZ-Fe }^{+2} \\ { } } & \stackrel{+1 \mathrm{e}^{-}}{ } & \text {(color azul intenso) }\end{array}$

La determinación de la capacidad reductora se lleva a cabo en tampón acético acetato de sodio $0,3 \mathrm{M}$ a pH 3,6 conteniendo TPTZ (1 mM) y $\mathrm{FeCl}_{3}(2 \mathrm{mM})$. Las soluciones deben ser preparadas el mismo día del ensayo.

Para la medida de la capacidad antioxidante se mezcla un volumen de la muestra con 10-100 volúmenes del reactivo recientemente preparado. Se determina la absorbancia a $593 \mathrm{~nm}$ se compara con la obtenida en una determinación paralela utilizando una sal de $\mathrm{Fe}^{+2}\left(\mathrm{FeSO}_{4}, 100\right.$ - $\left.1000 \mu \mathrm{M}\right)$ o Acido Ascórbico (5 a 25) como compuesto de referencia.

Las actividades de las muestras en estudio se expresan como equivalentes de $\mathrm{Fe}^{+2}$ o de acido ascórbico. También se puede utilizar ácido ascórbico como compuesto de referencia. Los volúmenes a utilizar dependerán de los instrumentos disponibles ya que la determinación se puede realizar en forma automatizada o manual.

El tiempo que se requiere para completar la reacción puede ser muy variable en función de los compuestos o mezclas de ellos a estudiar, variando desde segundos hasta minutos, aunque se considera que tras 8 minutos la reacción se completa, al menos con la mayoría de compuestos ensayados. 


\section{4. - Materiales y métados}

La relación dosis-respuesta es linear hasta un $\Delta A$ bs de 2,0 para concentraciones de compuestos de $1 \mathrm{mM}$ o superiores. Se puede realizar también un monitoreo cinético determinando las pendientes de crecimiento de la absorbancia a tiempos variables, si el objetivo del trabajo lo requiere.

Las soluciones de los reactivos utilizados y el método aplicado se resumen en los siguientes protocolos:

\begin{tabular}{|l|c|}
\hline Ensayo & $\begin{array}{c}900 \mu \mathrm{L} \text { Rvo FRAP } \\
\mathrm{X} \mu \mathrm{L} \text { muestra o soluciones de calibración } \\
(100-\mathrm{X}) \mu \mathrm{L} \mathrm{AD}\end{array}$ \\
\hline Mezclar y leer inmediatamente a $593 \mathrm{~nm}\left(\mathrm{~A}_{0}\right)$. \\
Esperar 8 min (o lo que corresponda) y leer $\mathrm{A}_{8}$
\end{tabular}

\section{Soluciones}

a) Buffer Acetato de sodio - Acido acético $300 \mathrm{mM} \mathrm{pH3,6}$

Acetato de sodio. 3 H2O.......... 3,1 g

Ácido Acético........................ $16 \mathrm{~mL}$

AD csp ................................ $1 \mathrm{~L}$

Ajustar a $\mathrm{pH}=3,6$

b) TPTZ - $10 \mathrm{mM}$ en $\mathrm{HCl} 40 \mathrm{mM}$

b.1) $\mathrm{HCl} 40 \mathrm{mM}$

$\mathrm{HCl} \mathrm{cc...........} 170 \mu \mathrm{L}$

$A D \operatorname{csp}$.......... $50 \mathrm{~mL}$

b.2) TPTZ - $10 \mathrm{mM}$

TPTZ …............ 15,6 mg

$\mathrm{HCl} 40 \mathrm{mM}$ csp...... $5 \mathrm{~mL}$

c) $\mathrm{FeCl}_{3} .6 \mathrm{H}_{2} \mathrm{O}-20 \mathrm{mM}$

$\mathrm{FeCl}_{3} .6 \mathrm{H}_{2} \mathrm{O}$....... $54 \mathrm{mg}$

$A D \operatorname{csp} \ldots \ldots \ldots \ldots \ldots . . . .5 \mathrm{~mL}$

\section{Reactivo de Trabajo "Reactivo FRAP" \\ Buffer AcONa - AcOH 300 mM pH 3,6 ........ $25 \mathrm{~mL}$ \\ TPTZ - 10 mM ................. 2,5 mL}

$\mathrm{FeCl}_{3} .6 \mathrm{H}_{2} \mathrm{O}-20 \mathrm{mM} \ldots \ldots \ldots .2,5 \mathrm{~mL}$ 


\section{Soluciones para calibrar}
a) Solución de $\mathrm{FeSO}_{4} \cdot 7 \mathrm{H}_{2} \mathrm{O}(100-1000 \mu \mathrm{M})$
$27,8 \mathrm{mg} / 10 \mathrm{~mL} \rightarrow$ Dil. $1 / 10(1 \mathrm{mM})$
b) Solucion de ácido ascórbico $(100-1000 \mu \mathrm{M})$
$17,6 \mathrm{mg} / 10 \mathrm{~mL} \rightarrow$ Dil. $1 / 10(1 \mathrm{mM})$

\subsubsection{4.- Determinación del contenido de fenoles totales}

La cuantificación de fenoles totales se efectuó espectrofotométricamente utilizando el reactivo de Folin-Ciocalteau que por reducción produce un pigmento azul en solución alcalina.

La curva de calibración $\left(A_{760}\right.$ vs $[\mu g$ ácido tánico/ml]) se realiza midiendo la absorbancia a $760 \mathrm{~nm}$ de las diluciones obtenidas a partir de una solución de ácido tánico de concentración conocida. A partir de esa curva puede ser calculada la concentración de polifenoles en la muestra. (Georgé et al., 2005; Rodrigo-García et al., 2006).

Los resultados se expresaron como $\mu \mathrm{g}$ ácido tánico/mg extracto seco

\subsubsection{5.- Determinación del contenido de flavonoides totales}

Los flavonoides se cuantificaron con el método colorimétrico de cloruro de aluminio, modificado (Chang et al., 2002; Meneses Reyes et al, 2008).

El método se basa en la formación de un complejo entre el flavonoides y el $\mathrm{Cl}_{3} \mathrm{Al}$, cuya coloración es proporcional a la concentración

La curva de calibración ( $A_{510}$ vs $[\mu g$ rutina/mg extracto seco]) se realiza midiendo la absorbancia a $510 \mathrm{~nm}$ de las diluciones obtenidas a partir de una solución de rutina de concentración conocida. A partir de esa curva puede ser calculada la concentración de flavonoides en la muestra.

Los resultados se expresaron como $\mu \mathrm{g}$ rutina/mg extracto seco 


\section{Preparación del extracto a ensayar}

En cada tubo de reacción se colocan $400 \mu$ l de agua y se agrega el extracto (10 a 100 $\mu l)$ disuelto en dimetisulfoxido (DMSO) o agua.

Se completa el volumen a $500 \mu \mathrm{l}$ totales con DMSO o agua según en que esté el extracto disuelto. Se agrega en cada tubo $30 \mu \mathrm{l}$ de (NO2Na al 5\%).

Se deja reposar 5 min y se agregan $30 \mu \mathrm{l}$ de $\mathrm{Cl}_{3} \mathrm{Al}$ al $10 \%$ en metanol, se deja reposar 5 min y luego se agregan $200 \mu \mathrm{l}$ de $\mathrm{NaOH} 1 \mathrm{M}$.

Completar a $1000 \mu \mathrm{l}$ con $240 \mu \mathrm{l}$ de agua destilada. Dejar en la oscuridad durante 15 $\min$.

Leer la absorbancia a 510nm

Hacer cada ensayo por duplicado

\section{Curva de calibración con Rutina}

Se preparan 5 diluciones, por duplicado, con una concentración de rutina entre $15-250 \mu \mathrm{g} / \mathrm{ml}$, las cuales son tratadas según un protocolo similar al descripto anteriormente.

Resultados

A partir de la curva de calibración puede calcularse la concentración de flavonoides totales expresado como rutina, en $\mu \mathrm{g}$ equivalente Rutina /mg de muestra

\subsection{2.- Actividad antiinflamatoria}

La inflamación es una reacción localizada de tipo protectora que surge en respuesta a irritación alérgica o química, heridas o infecciones; se caracteriza por dolor, calor, rubor, hinchazón que resultan de la vasodilatación que produce incremento del aporte de sangre y aumento de los espacios intercelulares que permite el movimiento de leucocitos, proteínas y fluidos a las zonas inflamadas. (E. O. Iwalewa, et al., 2007) 


\section{4. - Materiales y métadas}

Este mecanismo que se pone en marcha bajo las condiciones antes indicadas es la característica de varias enfermedades como aterosclerosis, artritis reumatoide, esclerosis múltiple, psoriasis, enfermedad de Crhon, asma, (Olga Barreiro, et al., 2010), artritis gotosa (N. Dalbeth y D. O. Haskard, 2005), etc.

En el proceso inflamatorio se produce la acumulación de varios factores solubles que intervienen en el reclutamiento de leucocitos, activación de células residentes (fibroblastos, células endoteliales, macrófagos tisulares y mastocitos) así como de células reclutadas (monocitos, linfocitos, neutrófilos y eosinófilos), también estos factores son responsables de efectos sistémicos tales como fiebre, caquexia, hipotensión, síntesis de proteínas de la fase aguda de la inflamación, leucocitosis, etc. (Carol A. Feghali y Timothy M. Wright, 1997).

El óxido nítrico constituye uno de los mediadores proinflamatorios (B Fermor, et al., 2007) que está vinculado a una gran variedad de efectos biológicos como la homeostasis vascular, neurotransmisión defensa contra agentes infecciosos (Gaby Walker, et al.,1997) y es reconocida su participación en procesos como la vasodilatación que se genera en shock séptico e inflamación. (Eun-Jin YANG, et al., 2009).

El descubrimiento de la participación del Oxido Nítrico en las respuestas defensivas e inmunes se remonta a los trabajos de Stuehr and Marletta con macrófagos murinos, quienes constataron la producción de nitritos y nitratos en respuesta a la presencia de Lipolisacáridos bacterianos y probaron que un compuesto con la reactividad del Oxido Nítrico era el intermediario en el proceso; luego Hibbs y col. demostraron que este gas era la molécula efectora de la citotoxicidad mediada por macrófagos. (Riku Korhonen, et al., 2005).

El Óxido Nítrico es sintetizado por enzimas denominadas Oxido Nítrico Sintetasas (ONS) a través de una reacción oxidación que involucra a 5 electrones y que produce como intermediario a $N_{\mathrm{G}}$-hidroxi-L-arginina; los sustratos para esta reacción son el aminoácido Arginina, Oxígeno molecular, Nicotinamida y Adenina Dinucleótido Fosfato en su forma reducida (NADPH) y los cofactores que se requieren son 


\section{4. - Materiales y métados}

Tetrahidrobiopteridina, (BH4) Dinucleótido de Adenina y Flavina (FAD) y el Mononucleótido de Flavina (FMN) (Roland Govers y Ton J. Rabelink, 2001).

Existen tres isoformas diferentes de Oxido Nítrico Sintetasas:

- La Oxido Nítrico Sintetasa Neuronal o Tipo I (Neuronal Oxide Nitric Synthase o nNOS): se expresa de forma constitutiva y predominantemente en el Sistema Nervioso Central y Sistema Nervioso Periférico, su activación es dependiente del aumento de los niveles de Calcio citosólico.

- Oxido Nítrico Sintetasa Inducible o Tipo II (Inducible Oxide Nitric Synthase o iNOS): No se detecta su expresión en la mayoría de células y solo se sintetiza tras estímulos por productos microbianos como Lipopolisacáridos, RNA de doble cadena (dsRNA) o por citocinas proinflamatorias como Interleucina-1(IL1), Factor de Necrosis Tumoral- $\alpha$ (TNF- $\alpha$ ) e Interferón - $\gamma$

- Oxido Nítrico Sintetasa Endotelial o Tipo III (Endothelial Oxide Nitric Synthase o eNOS): se expresa de forma constitutiva y principalmente por las células endoteliales su activación también es dependiente del aumento de los niveles de Calcio citosólico. (P. L. Beck. et al., 2004)

A nivel molecular las acciones del ON pueden dividirse en tres categorías:

1. Regulación de la actividad de enzimas que tiene como grupos prostéticos a metales de transición como $\mathrm{Fe}, \mathrm{Cu}$ y $\mathrm{Zn}$ y que pueden reaccionar directamente con el ON

2. El ON puede reaccionar con grupos Tiol de las Cisteinas de proteinas en una reacción conocida como $\mathrm{N}$ - Nitrosilación y por la cual puede modificar sus actividades. 


\section{4. - Materiales y métadas}

3. El anión Superoxido puede reaccionar muy rápidamente con el ON y de esta manera generar el radical peroxinitrito (ONOO') que es un agente nitrante y poderoso oxidante que puede reaccionar con múltiples blancos celulares como lípidos, proteínas y ácidos nucleicos.

Dado el papel relevante que desempeña el oxido nítrico en enfermedades con alta prevalencia como Osteoartritis y artritis reumatoide ha existido considerable interés en desarrollar inhibidores de la producción de oxido nítrico, además es conocida la interacción de otros medidores de la inflamación como prostaglandinas y leucotrienos con el oxido nítrico por lo que la posibilidad de encontrar inhibidores duales de la cascada de la inflamación es una idea atractiva reciente. (B Fermor, et al.,2007)

En la medicina tradicional existen plantas que han sido muy utilizadas para combatir la inflamación, un sitial preponderante tiene el Sauce (Salix sp.), desde los registros que se tienen de Celsus en el año $30 \mathrm{AC}$ sobre el uso de esta planta para tratar los síntomas de la inflamación que el describió como rubor, calor, dolor y tumor, ya mencionó el uso de extractos de las hojas de esta planta para aliviarlos.

Otra planta con varios siglos de uso como antiinflamatorio es el álamo que comparte con el sauce uno de los metabolitos a los que se le atribuyó el efecto terapéutico: el ácido Salicílico (John Vane y Regina Botting, 1987).

Mucha investigación se ha realizado sobre plantas con actividad antiinflamatoria y de los principios activos responsables de esta acción, dentro de los que destacan la Curcumina (Curcuma longa), Partenólido (Tanacetum parthenium), 1,8-Cineole (Eucaliptus sp.), Pseudopterosins de (Pseudopterogorgia elisabethae), (Gaofeng Yuan, et al., 2006), flavonoides (Lien Ai Pham-Huy, et al., 2008), etc.

\section{Estudio de la inhibición de la producción de oxido nitrico in vitro}

Extractos utilizados 


\section{4. - Materiales y métadas}

Para la determinación de la actividad inhibidora de la producción de óxido nítrico, se emplearon los extractos Hexánico, Diclorometánico, Metanólico evaporados y la decocción liofilizada, obtenidas de las partes aéreas de Viola arguta.

Con el fin de establecer el nivel de acción y cuantificar los efectos farmacológicos se han seleccionado conocidas técnicas in Vitro

\section{- Ensayo de viabilidad celular.}

Este ensayo se realiza con la Linea RAW 264,7 con la finalidad de conocer el efecto de las diferentes concentraciones de los extractos sobre la viabilidad de estas células y así determinar el rango de concentraciones para el ensayo, considerándose adecuada una viabilidad celular del 95-98\%.

El efecto citotóxico de los productos sobre los distintos tipos celulares se mide usando el ensayo del 3-(4,5dimetiltiazol-2-il)-2,5-difenilbromuro de tetrazolio (MTT) (Mossman, 1983), que se basa en la conversión del MTT de color amarillo a formazán de color azul oscuro. Esta reacción está catalizada por succinildeshidrogenasas mitocondriales. Las células $\left(1 \times 10^{6} / 195 \mu\right.$ PBS) se tratan con $5 \mu$ de la muestra durante 30 min. en estufa a $37 \stackrel{\circ}{\circ}$, en una placa de 96 pocillos. Una vez eliminado el xenobiótico se añade a cada pocillo $100 \mu \mathrm{l}$ de MTT de una solución de $0.45 \mathrm{mg} / \mathrm{ml}$. Se incuba la placa a 37 ํ C hasta la aparición de color azul, al menos en los controles. El medio se elimina y se añaden $100 \mu \mathrm{l}$ de DMSO (dimetilsulfóxido) a cada pocillo que disuelve los cristales de formazán. Se mide la absorbancia en un lector de placas a 492 $\mathrm{nm}$.

\section{- Inhibición de la producción de NO (óxido nítrico) en macrófagos RAW 264.7.}

Basado en el método descrito por De León et al. (2003). Se prepara una curva patrón de nitritos para poder extrapolar las absorbancias que se obtengan con los productos y conocer su concentración. Se preparan concentraciones decrecientes desde $80 \mathrm{mM}$ hasta 2,5 mM. Se añaden $100 \mathrm{ml}$ de cada disolución al pocillo 


\section{4. - Materiales y métados}

correspondiente y $100 \mathrm{ml}$ del reactivo de Griess (Naftilendiamina al 0,1\% en H2O y sulfanilamida al $1 \%$ en H3PO4). Se siembran $2 \times 10^{6}$ células $/ \mathrm{ml}$ en una placa de 96 pocillos y se dejan incubar $24 \mathrm{~h}$ para que la población se doble. Se elimina el medio y se añaden $200 \mathrm{ml}$ medio fresco sin suero fetal bovino. Se añaden los productos a las concentraciones finales de: control y blanco (DMSO al 0,5\%), productos objeto de estudio $(0,1-50 \mu \mathrm{M})$ y se deja incubar a 37 ㅇ C en una atmósfera del $5 \%$ en $\mathrm{CO}_{2}$ durante 3 h. La liberación de NO se estimula mediante la adición de $20 \mathrm{ml}$ de lipopolisacárido (LPS) $(1 \mathrm{mg} / \mathrm{ml})$. Se toman alícuotas de $100 \mathrm{ml}$ del sobrenadante a las $24 \mathrm{~h}$ y se disponen en otra placa de 96 pocillos, añadiendo $100 \mathrm{ml}$ del reactivo de Griess. Se mide la absorbancia a $570 \mathrm{~nm}$. 
5. - Resultados y Discusión

\section{5.- Resultados y discusión}




\section{1.- Elementos de diagnostico y determinación de valores numéricos en hojas de $V$. arguta}

Las hojas de $V$. arguta se presentan como hojas simples, pecioladas, ovallanceoladas, de ápice agudo,

El borde presenta dientes glandulares que se ven oscuros bajo el microscopio estereoscópico.

Presenta estipulas persistentes y laciniadas (ver fig. )
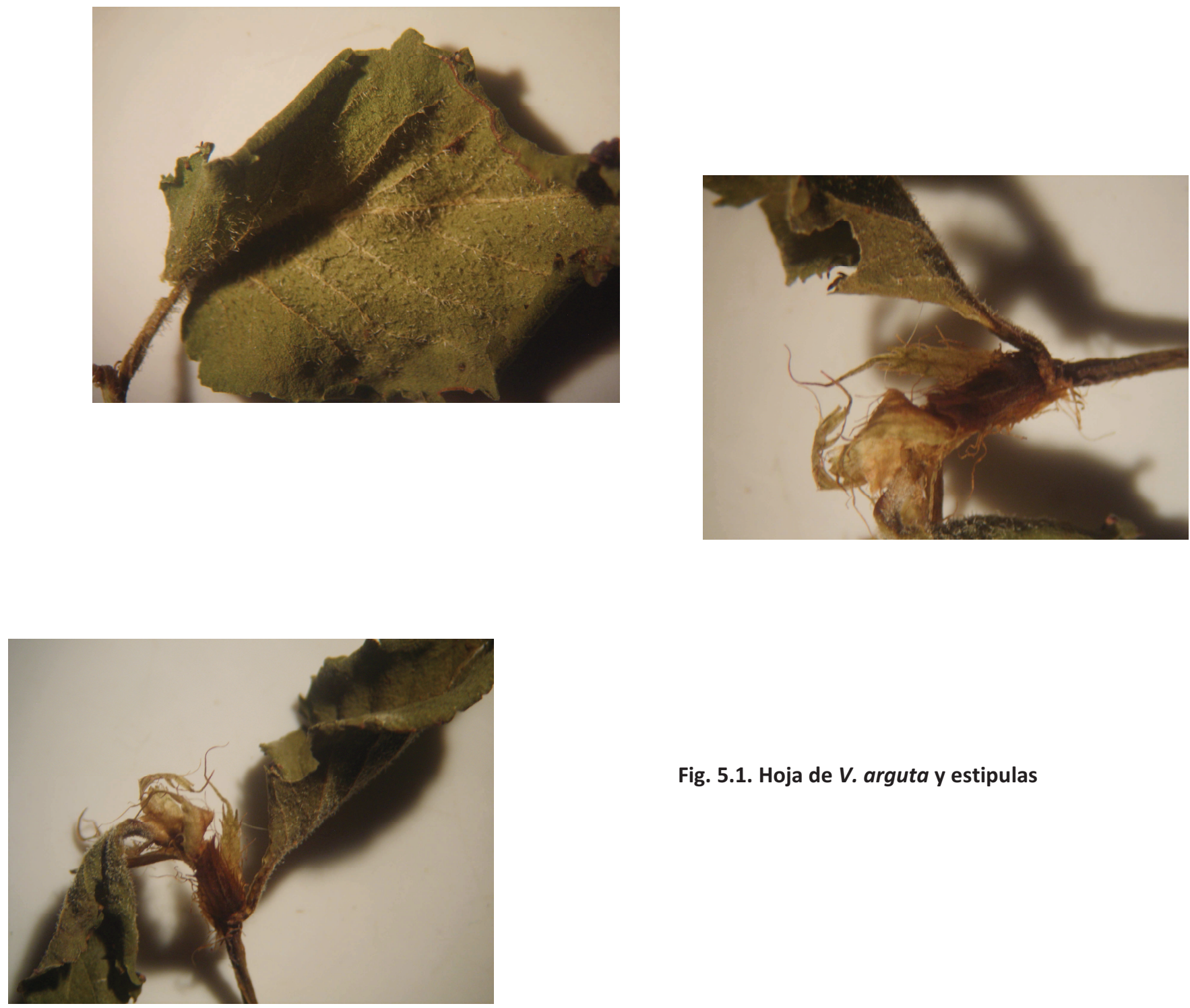

Fig. 5.1. Hoja de V. arguta y estipulas 


\section{5. - Resultados y Discusión}

Bajo el microscopio estereoscópico la superficie del envés presenta un aspecto rugoso con puntos brillantes y abundante pubescencia en toda la superficie, especialmente sobre las nervaduras. Los pelos tienen aspecto de cintas, aplanados (ver fig.5.2.)
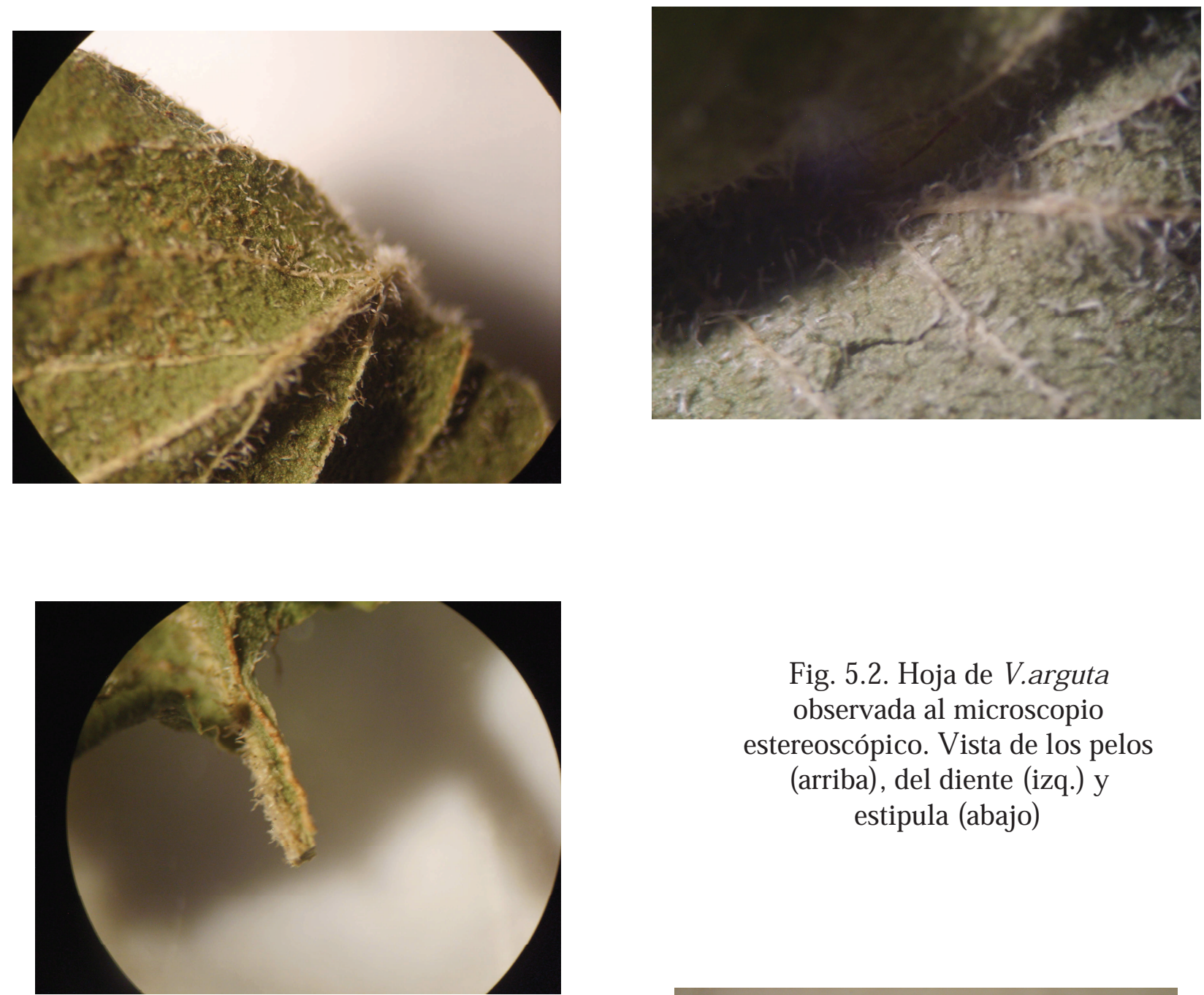

Fig. 5.2. Hoja de V.arguta observada al microscopio estereoscópico. Vista de los pelos (arriba), del diente (izq.) y estipula (abajo)

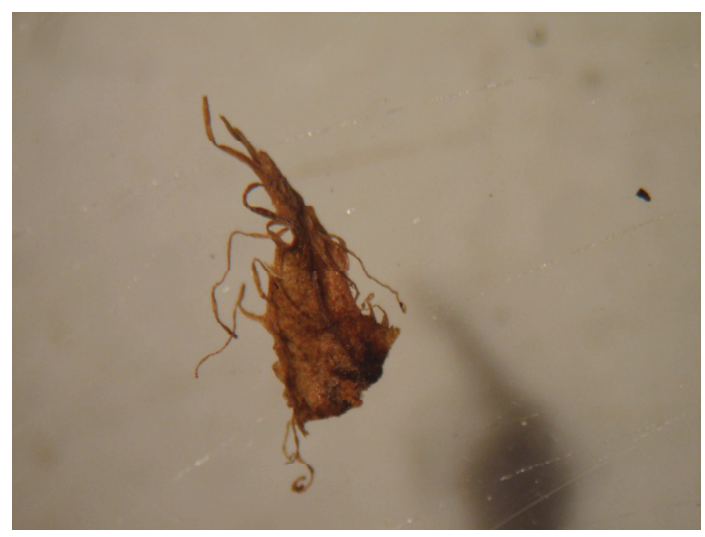




\subsection{1.- Análisis micrográfico de las hojas de Viola arguta}

\section{Epidermis vista en superficie (VS)}

Las hojas están cubiertas en ambas caras por una capa de cutícula estriada con abundantes ceras epicuticulares. Tanto la epidermis adaxial como la abaxial presentan células de paredes anticlinales rectas (penta o hexagonales) y células mucilaginíferas de forma aovada,(fig. 5.3) las cuales son más grandes que las restantes células epidérmicas y que en algunos casos presentan un contenido de color anaranjado. Estas se encontraron en mayor cantidad en los dientes (fig. 5.4).

Los estomas son una transición entre rubiáceos y crucíferos y se hallan distribuidos en toda la superficie de la cara abaxial, caracterizando a la hoja como hipostomática (fig. 5.5.).

En el envés de la hoja especialmente a nivel de las nervaduras, se observan tricomas tectores o eglandulares, unicelulares o uniseriados con cutícula estriada y arrugada y ceras epicuticulares (fig. 5.6.).

Por transparencia se observa en el mesófilo una capa de cristales en forma de drusas. El borde de la hoja presenta papilas (fig. 5.8, que toman una coloración azul en presencia de azul de metileno, lo cual también sugiere la presencia de mucílagos.
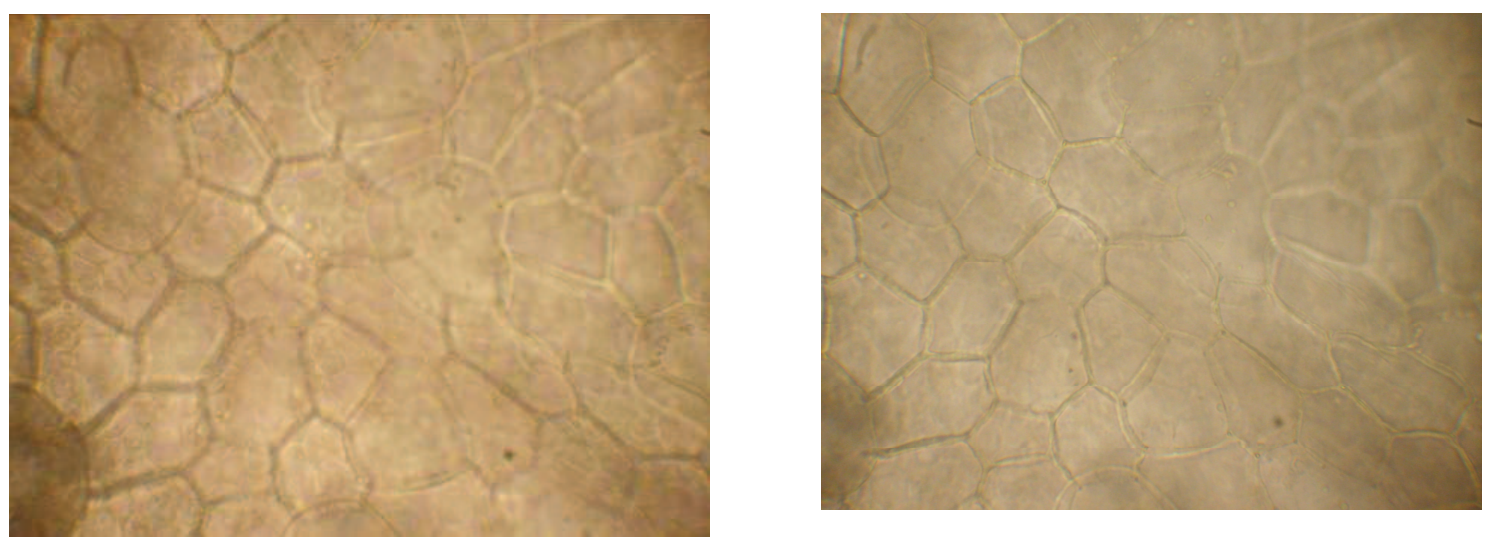

Fig. 5.3. Epidermis adaxial 
5. - Resultados y Discusión



Fig. 5.4. Hoja diafanizada a nivel del diente

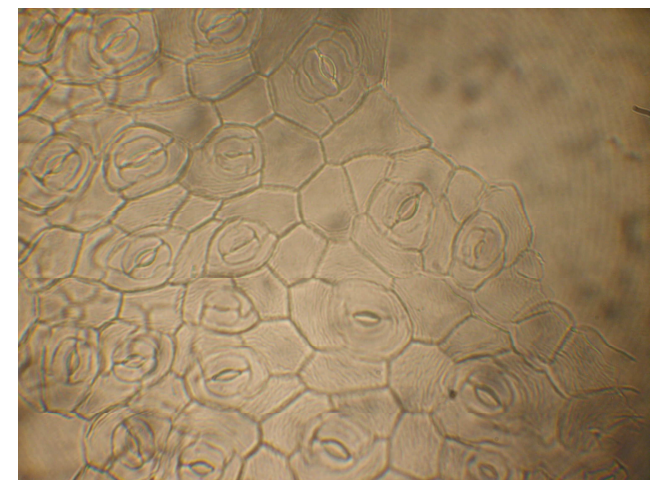

Fig. 5.5. Epidermis abaxial y estomas
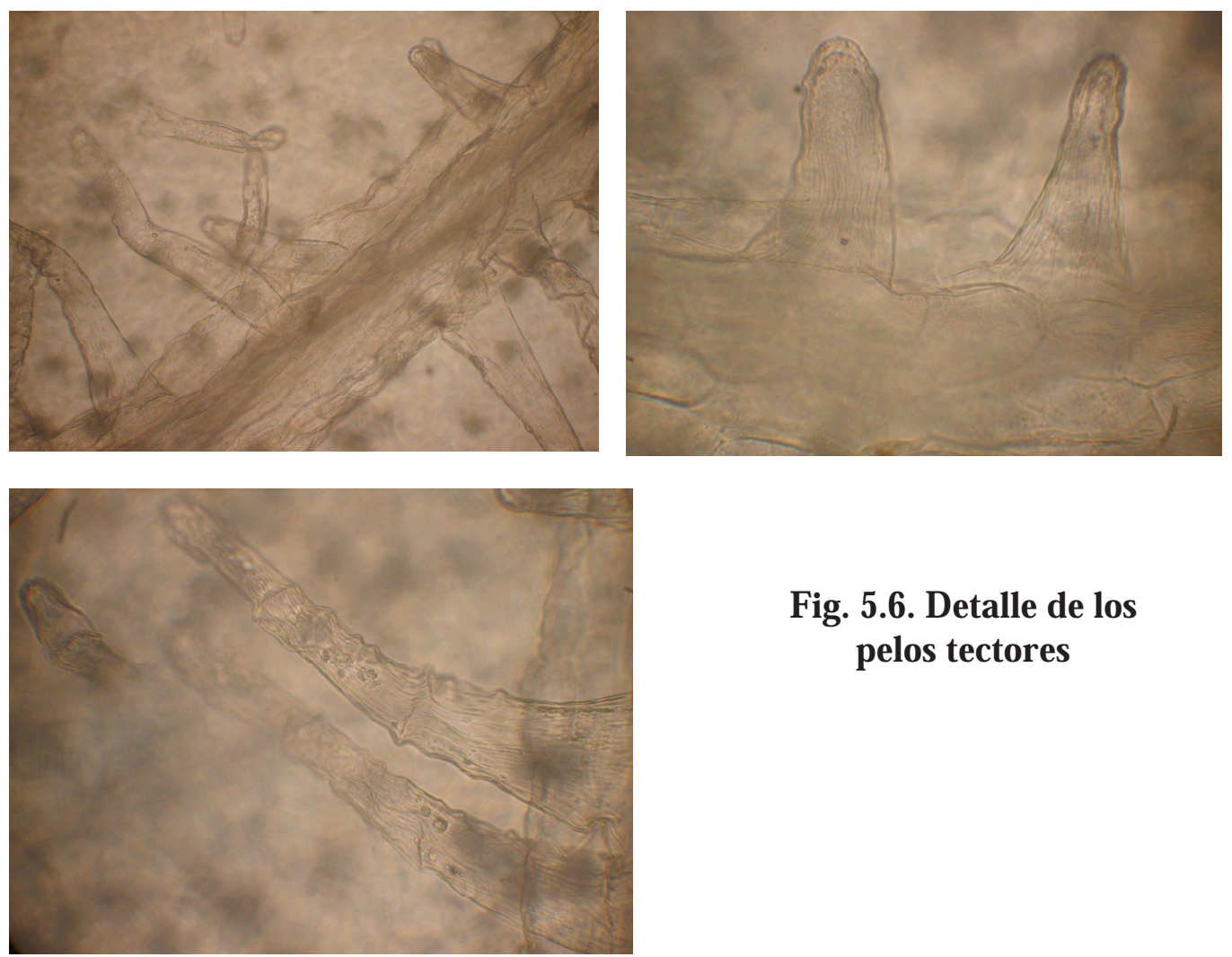

Fig. 5.6. Detalle de los pelos tectores 

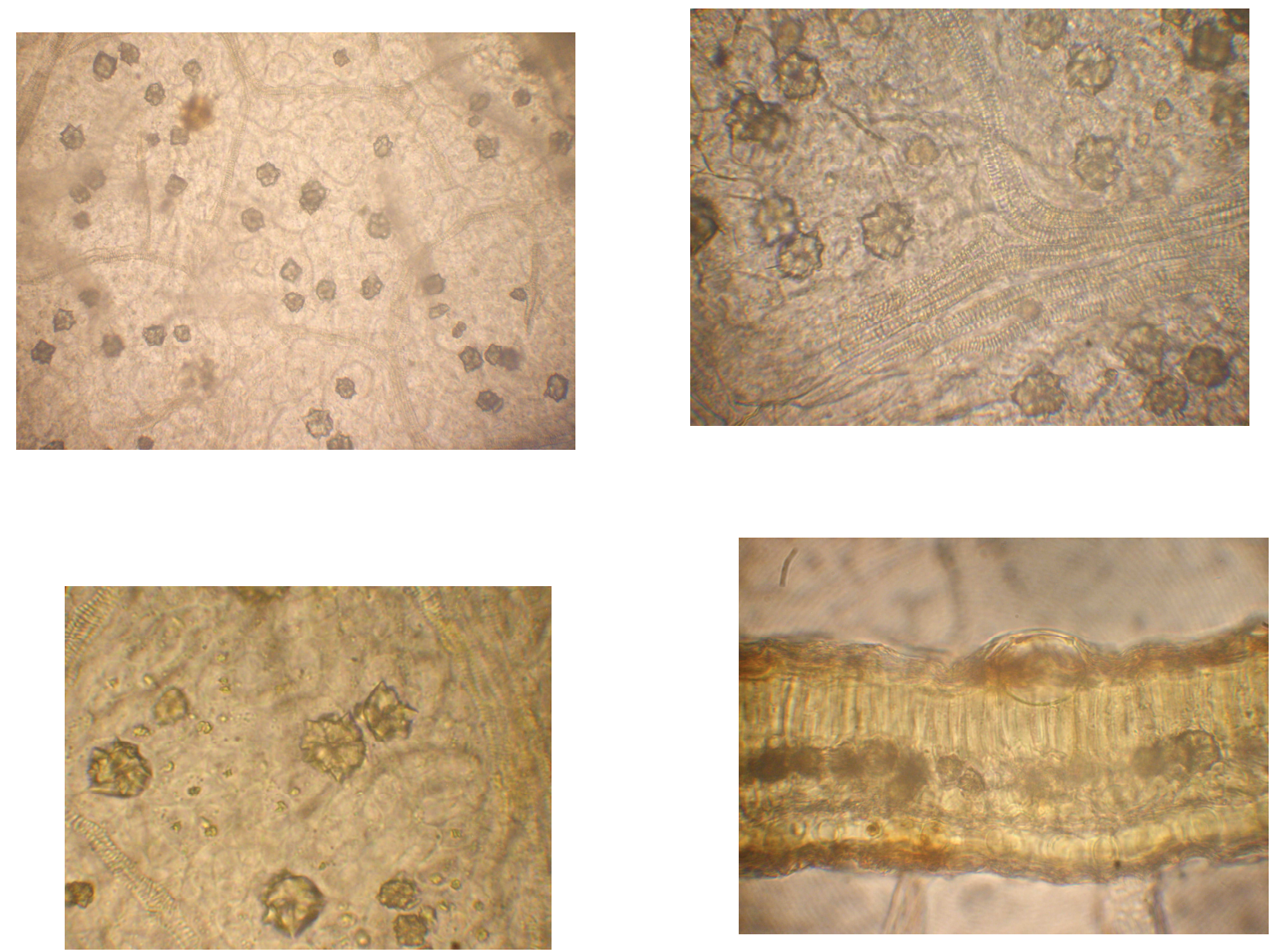

Fig. 5.7. Drusas observadas en vista superficial (arriba e izq.) y en corte transverso (abajo der.)

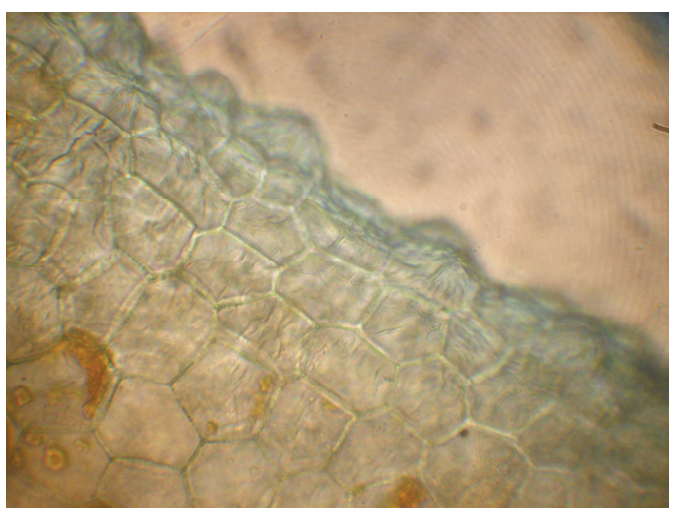

Fig. 5.8. Papilas 
En el corte transversal, se observa la nervadura central biconvexa y entre 5 y 7 capas colénquima (fig. 5.9.).

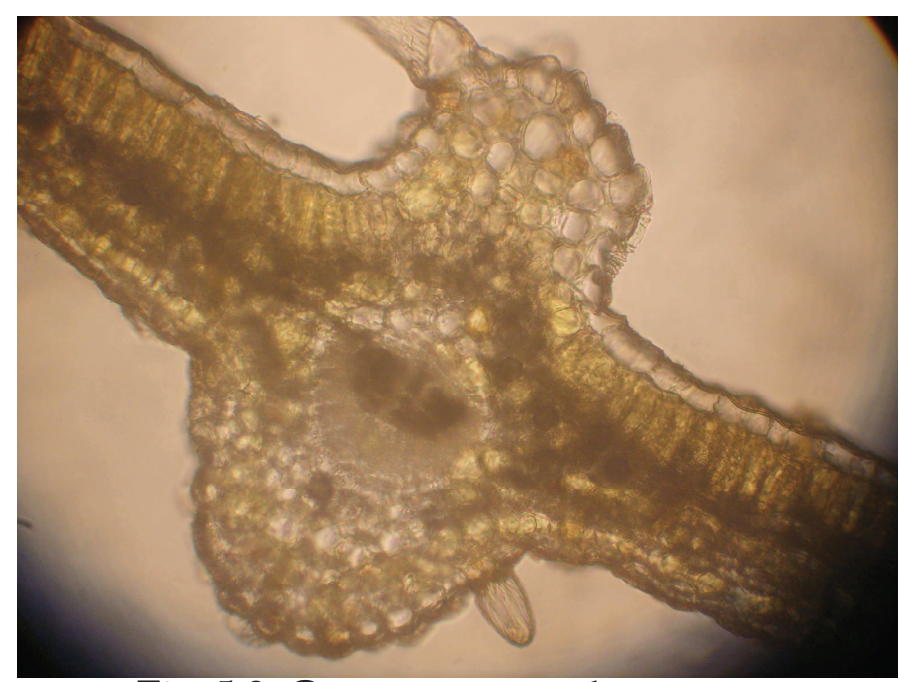

Fig. 5.9. Corte transversal a nivel de la nervadura central

\subsubsection{Determinación de valores numéricos o magnitudes proporcionales}

\section{Determinación de los índices de estomas y de empalizada}

Para cada una de las 25 muestras seleccionadas de hojas diafanizadas de $V$. arguta se efectuó, con auxilio del MO, la determinación de los índices de estoma y empalizada, según se describió en el capítulo de "Materiales y métodos".

Con los valores obtenidos para cada una de estas magnitudes proporcionales, fue establecido un rango y calculado el valor promedio y la moda (Mo), obteniéndose los siguientes resultados.

Tabla 5.1. Magnitudes cuantitativas

\begin{tabular}{|l|c|c|c|}
\hline & Rango & Promedio & Moda \\
\hline Índice estomático & $15,15-21,42$ & 17,31 & 15,30 \\
\hline Índice empalizada & $5,00-14,50$ & 9,65 & 9,00 \\
\hline
\end{tabular}




\section{5. - Resultados y Discusión}

\subsubsection{Observación de la epidermis foliar mediante MEB}

Observada al microscopio electrónico de barrido (MEB), la superficie foliar presenta una cutícula estriada. El MEB también permite apreciar en la cara abaxial la presencia de estomas, así como tricomas eglandulares, acintados, con cutícula estriada y ceras epicuticulares.
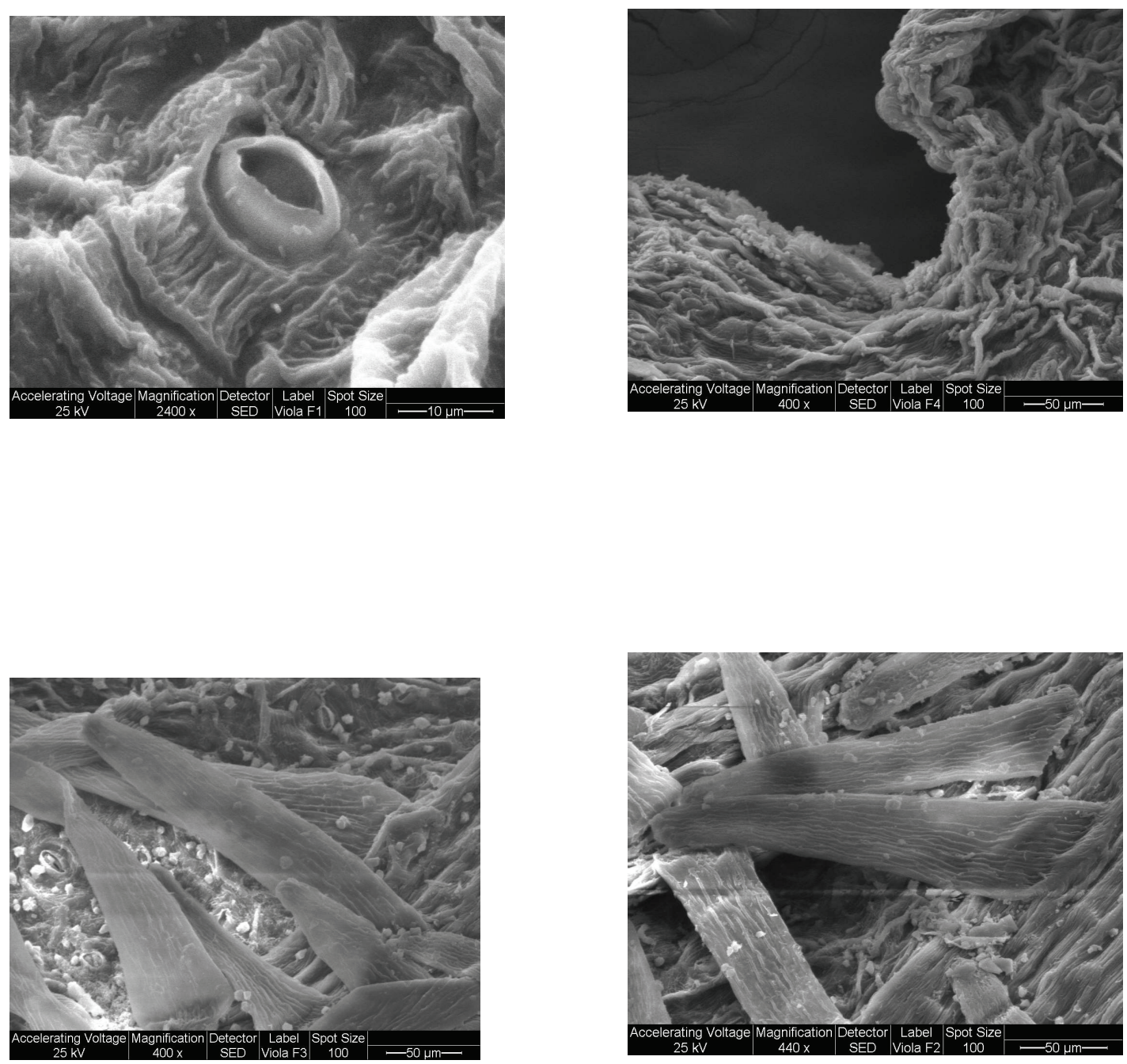

Fig. $\mathbf{5 . 1 0}$ 


\section{2.- Ensayos fitoquímicos}

5.2.1.- Rendimientos de los extractos de Viola arguta calculado en \% (g extracto/100 g material vegetal seco)

\begin{tabular}{|c|c|}
\hline Extracto & $\begin{array}{c}\text { \% } \\
\text { (g extracto seco /100 g material vegetal seco) }\end{array}$ \\
\hline Extracto hexánico: & 1,30 \\
\hline Extracto diclorometanico & 1,29 \\
\hline Extracto Metanólico & 14,77 \\
\hline Extracto Metanólico 60\% & 18,85 \\
\hline Extracto acuoso & 5,58 \\
\hline
\end{tabular}

5.2.2.- Pruebas químicas orientativas efectuadas a los extractos acuoso, diclorometánico y metanólico de Viola arguta

1) Detección de Alcaloides:

\begin{tabular}{|c|c|c|}
\hline Reactivo & Tipo de precipitado con alcaloides & Resultado en Viola arguta \\
\hline Dragendorff & Rojo & Negativo \\
\hline Mayer & Crema & Negativo \\
\hline Acido Tánico & Beige & Negativo \\
\hline Bouchardat & Rojo - pardo & Negativo \\
\hline
\end{tabular}

2) Detección de Antraquinonas (Aglicones y Heterósidos)

\begin{tabular}{|c|c|c|}
\hline Reacción & $\begin{array}{c}\text { Color en presencia de } \\
\text { antraquinonas: }\end{array}$ & Resultado en Viola arguta \\
\hline Borntrager & Rojo-rosa & Negativo \\
\hline
\end{tabular}

3) Detección de Saponinas.

\begin{tabular}{|c|c|c|c|c|}
\hline Reacción positiva & Hexánico & Diclorometánico & Metanólico & Acuoso \\
\hline Formación de espuma & NR & NR & Positivo & Positivo \\
\hline & & & & \\
\hline
\end{tabular}

4) Detección de taninos

\begin{tabular}{|c|c|c|c|c|}
\hline Reacción positiva & Extr. Hexánico & $\begin{array}{c}\text { Extr. } \\
\text { Diclorometánico }\end{array}$ & Extr. Metanólico & Extr. Acuoso \\
\hline $\begin{array}{c}\text { Coloración Azul } \\
\text { obscura o Verde } \\
\text { Obscura }\end{array}$ & $\mathrm{N} / \mathrm{R}$ & $\mathrm{N} / \mathrm{R}$ & $\begin{array}{c}\text { Positivo } \\
\text { (Azul oscuro) }\end{array}$ & $\begin{array}{c}\text { Positivo } \\
\text { (Azul oscuro) }\end{array}$ \\
\hline
\end{tabular}


5) Detección de Mucílagos y gomas

\begin{tabular}{|c|c|c|c|c|c|}
\hline Reacción & $\begin{array}{c}\text { Reacción } \\
\text { positiva }\end{array}$ & Hexánico & Diclorometánico & Metanólico & Acuoso \\
\hline Etanol absoluto & Precipitado & N/R & N/R & N/R & Positivo \\
\hline Azul de metileno & $\begin{array}{c}\text { Coloración } \\
\text { azul }\end{array}$ & Positivo (observación microscópica de la coloración en vista \\
superficial de hoja)
\end{tabular}

6) Detección de flavonoides

\begin{tabular}{|c|c|c|c|c|c|}
\hline Reacción & $\begin{array}{l}\text { Reacción } \\
\text { positiva }\end{array}$ & Hexánico & Diclorometánico & Metanólico & Acuoso \\
\hline Shinoda & $\begin{array}{c}\text { Color } \\
\text { magenta }\end{array}$ & Positivo & Positivo & Positivo & Positivo \\
\hline $\mathrm{Cl}_{3} \mathrm{Fe}$ al $2 \%$ & $\begin{array}{c}\text { Color verde o } \\
\text { azul }\end{array}$ & Positivo & Positivo & Positivo & Positivo \\
\hline $\mathrm{Cl}_{3} \mathrm{Al}$ al $2 \%$ & $\begin{array}{c}\text { Fluorescencia } \\
\text { amarilla } \\
\left(\mathrm{UV}_{366}\right)\end{array}$ & Positivo & Positivo & Positivo & Positivo \\
\hline $\mathrm{H}_{3} \mathrm{BO}_{3}$ al $2 \%$ & $\begin{array}{c}\text { Fluorescencia } \\
\text { amarillo- } \\
\text { verdosa } \\
\left(\mathrm{UV}_{366}\right)\end{array}$ & Positivo & Positivo & Positivo & Positivo \\
\hline KOHal 1\% & $\begin{array}{c}\text { Amarillo (vis) } \\
\text { fluorescente } \\
\left(\mathrm{UV}_{366}\right)\end{array}$ & Positivo & Positivo & Positivo & Positivo \\
\hline
\end{tabular}

Tabla Resumen.

\begin{tabular}{|c|c|c|c|c|c|c|}
\hline \multirow[b]{2}{*}{ Principio activo } & \multicolumn{4}{|c|}{ Extracto } & \multirow{2}{*}{$\begin{array}{c}\text { Extracto } \\
\text { especifico } \\
\text { MeOH 60\% }\end{array}$} & \multirow{2}{*}{$\begin{array}{c}\text { Reacción } \\
\text { histoquímica } \\
\text { en hoja }\end{array}$} \\
\hline & Hexánico & DCM & Metanólico & Acuoso & & \\
\hline Alcaloides & N/R & N/R & N/R & N/R & Negativo & N/R \\
\hline Antraquinonas & N/R & N/R & N/R & N/R & Negativo & N/R \\
\hline Saponinas & N/R & N/R & Positivo & Positivo & $\mathrm{N} / \mathrm{R}$ & N/R \\
\hline Taninos & $\mathrm{N} / \mathrm{R}$ & N/R & Positivo & Positivo & N/R & N/R \\
\hline Mucílagos /gomas & $\mathrm{N} / \mathrm{R}$ & N/R & N/R & Positivo & N/R & Positiva \\
\hline Flavonoides & Positivo & Positivo & Positivo & Positivo & $\mathrm{N} / \mathrm{R}$ & N/R \\
\hline
\end{tabular}




\subsection{3.- Análisis de las cromatografías en capa delgada (CCD) efectuadas a los extractos hexánico, diclorometánico y metanólico de $V$. arguta}

\section{Extracto Hexánico}

De todos los sistemas cromatográficos ensayados, el que tuvo mejor resolución fue el sistema cromatográfico II (Tolueno/Acetato de etilo 7:3) (Fig.5.11 y tabla 5.2)

Tabla 5.2. Perfil cromatográfico del extracto hexánico

\begin{tabular}{|c|c|c|c|c|}
\hline \multicolumn{5}{|c|}{$R f$} \\
\hline Vis & $U_{254}$ & $U V_{366}$ & RPN + UV 366 & AS \\
\hline \multicolumn{5}{|l|}{$\begin{array}{c}0 \\
\text { (amarillo claro) } \\
\end{array}$} \\
\hline \multicolumn{5}{|l|}{$\begin{array}{c}0,1 \\
\text { (amarillo) }\end{array}$} \\
\hline \multicolumn{5}{|l|}{$\begin{array}{c}0,13 \\
\text { (amarillo) } \\
\end{array}$} \\
\hline & & $\begin{array}{c}0,17 \\
\text { (café) }\end{array}$ & & \\
\hline \multicolumn{5}{|l|}{$\begin{array}{c}0,38 \\
\text { (verde amarillenta) }\end{array}$} \\
\hline \multicolumn{5}{|l|}{$\begin{array}{c}0,5 \\
\text { (verdosa) }\end{array}$} \\
\hline \multicolumn{5}{|l|}{$\begin{array}{c}0,52 \\
\text { (grisácea) }\end{array}$} \\
\hline \multicolumn{5}{|l|}{$\begin{array}{c}0,66 \\
\text { (grisácea) }\end{array}$} \\
\hline & 0,69 & & & \\
\hline & 0,75 & & & $\begin{array}{c}0,75 \\
\text { (violácea) }\end{array}$ \\
\hline & 0,82 & $\begin{array}{c}0,82 \\
\text { (azulado) }\end{array}$ & & \\
\hline & & & & $\begin{array}{c}0,88 \\
\text { (violácea) }\end{array}$ \\
\hline & 0,94 & $\begin{array}{c}0,94 \\
\text { (azul) }\end{array}$ & $\begin{array}{c}0,94 \\
\text { (crema-azulado) }\end{array}$ & $\begin{array}{c}0,94 \\
\text { (café) }\end{array}$ \\
\hline 0,98 (naranja) & & & & \\
\hline
\end{tabular}

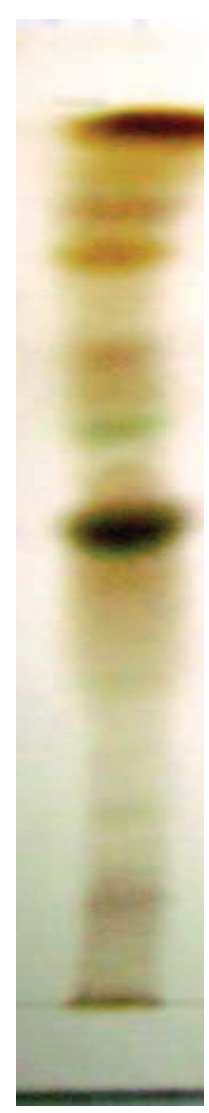

Fig. 5.11. Ext Hexanico + AS

El perfil cromatográfico de este extracto muestra al visible la presencia de 8 bandas, una de ellas de color amarillo pálido en el origen y otra amarilla-naranja intenso en $\mathrm{Rf}=0,98$. 


\section{5. - Resultados y Discusión}

Próximas al punto de siembra aparecen dos bandas amarillas (Rf 0,1 y 0,13 ) y otra de color verde amarillenta a $\mathrm{Rf} 0,38$

Hacia la mitad de la placa ( $\mathrm{Rf} 0,5)$ se observa una banda verdosa poco intensa y justo sobre ésta otra grisácea ( $\operatorname{Rf} 0.52$ ); a $\operatorname{Rf} 0,66$ también aparece una de color grisáceo.

La observación al UV 254 nm, permite visualizar 4 nuevas bandas ( $\operatorname{Rf} 0,69$ a 0,94).

Con Luz UV 366 se observan tres bandas que no se apreciaban al visible, de Rf 0,17 (café); 0,82 (Azulado) y 0,95 (azul intensa).

Esta última con el reactivo de productos naturales (RPN) fluoresce con un tono cremaazulado y mostró capacidad de evitar la oxidación del $\beta$-caroteno cuando se utilizó éste como revelador, comportamiento típico de los aglucones de cumarinas cuya presencia ha sido citada para algunas especies de Viola.

Al revelar con anisaldehído sulfúrico la banda que presentó fluorescencia con RPN (Rf $0,94)$ adquiere una tonalidad café, y aparecen dos bandas violáceas: una a Rf 0,88 y otra a $\operatorname{Rf} 0,75$ que es una de las que no fue detectada al visible

\section{Extracto diclorometánico}

Para el extracto diclorometánico se obtuvo una mejor resolución con el sistema cromatográfico II. (ver fig 5.12 y tabla 5.3).

En estas condiciones a la luz visible se detectaron un mayor número de bandas que en el extracto hexánico: 13 bandas en total, siendo las principales: una de color verde oscuro muy intensa en el punto de siembra y otra de color amarillo- naranja justo bajo el frente del solvente, con un Rf coincidente con la banda de iguales características presentes en el extracto hexánico ( $\mathrm{Rf} 0,98)$.

En la primera mitad de la placa se concentran 8 de las 13 bandas.

Observadas al visible, cuatro bandas de color amarillo destacan en el primer tercio de la placas, dos de ellas con $\mathrm{Rf}$ muy próximos a sus pares de la placa anterior ( $\mathrm{Rf}=0,1$ y $0,13)$, una ubicada bajo estas dos $(R f=0,07)$ y la otra sobre estas tres y mostrando una mayor intensidad 
Observadas con luz UV 366 se muestran como manchas opacas de color oscuro.

El color amarillo al visible que se intensifica con RPN .

Este comportamiento, sumado a las observaciones anteriores y al comportamiento al UV366 hacen pensar que podría tratarse de aglucones tipo flavona.

A $R f=0,19$ aparece otra banda de color café-grisáceo (visible) que al iluminarla con UV366 se vuelve azul-violácea

Revelado con AS o RPN no se observan cambios en la coloración.

Tabla 5.3. Perfil cromatográfico del extracto DCM

\begin{tabular}{|c|c|c|c|c|}
\hline \multicolumn{5}{|c|}{ Rf } \\
\hline Vis & $U^{254}$ & $U V_{366}$ & $R P N+U_{366}$ & AS \\
\hline $\begin{array}{c}0 \\
\text { (verde oscuro) }\end{array}$ & & & & \\
\hline $\begin{array}{c}0,07 \\
\text { (amarillo) }\end{array}$ & & $\begin{array}{c}0,07 \\
\text { (marrón) }\end{array}$ & $\begin{array}{c}0,07 \\
\text { (amarillo) }\end{array}$ & \\
\hline $\begin{array}{c}0,1 \\
\text { (amarillo) }\end{array}$ & & $\begin{array}{c}0,1 \\
\text { (marrón) }\end{array}$ & $\begin{array}{c}0,1 \\
\text { (amarillo) }\end{array}$ & \\
\hline $\begin{array}{c}0,13 \\
\text { (amarillo) }\end{array}$ & & $\begin{array}{c}0,13 \\
\text { (marrón) }\end{array}$ & $\begin{array}{c}0,13 \\
\text { (amarillo) }\end{array}$ & \\
\hline $\begin{array}{c}0,17 \\
\text { (amarillo intenso) }\end{array}$ & & $\begin{array}{c}0,17 \\
\text { (marrón) }\end{array}$ & $\begin{array}{c}0,17 \\
\text { (amarillo intenso) }\end{array}$ & \\
\hline $\begin{array}{c}0,19 \\
\text { (café-grisaceo) }\end{array}$ & & $\begin{array}{c}0,19 \\
\text { (azul violaceo) }\end{array}$ & & \\
\hline $\begin{array}{c}0,98 \\
\text { (naranja) }\end{array}$ & & & & \\
\hline
\end{tabular}

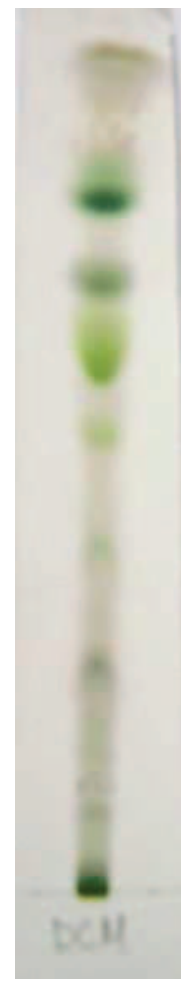

Fig. 5.12. Ext DCM + AS

\section{Extracto Metanólico}

Para el extracto Metanólico la mejor resolución se obtuvo utilizando el sistema cromatográfico III. (ver tabla 5.4) 


\section{5. - Resultados y Discusión}

Tabla 5.4. Perfil cromatográfico del extracto Metanólico

\begin{tabular}{|c|c|c|c|c|}
\hline \multicolumn{5}{|c|}{$R f$} \\
\hline Vis & $U^{254}$ & $U V_{366}$ & RPN + UV 366 & AS \\
\hline $\begin{array}{c}0 \\
\text { (marrón) }\end{array}$ & & & & \\
\hline $\begin{array}{c}0,21 \\
\text { (amarillo) }\end{array}$ & & $\begin{array}{c}0,21 \\
\text { (marrón) }\end{array}$ & $\begin{array}{c}0,21 \\
\text { (amarillo intenso) }\end{array}$ & \\
\hline $\begin{array}{c}0,44 \\
\text { (amarillo) } \\
\end{array}$ & & $\begin{array}{c}0,44 \\
\text { (marrón) }\end{array}$ & $\begin{array}{c}0,44 \\
\text { (amarillo intenso) }\end{array}$ & \\
\hline $\begin{array}{c}0,52 \\
\text { (amarillo) }\end{array}$ & & $\begin{array}{c}0,52 \\
\text { (marrón) }\end{array}$ & $\begin{array}{c}0,52 \\
\text { (amarillo intenso) }\end{array}$ & \\
\hline & 0,62 & & & \\
\hline & 0,75 & $\begin{array}{c}0,75 \\
\text { Fluores. Celeste NH3 }\end{array}$ & & \\
\hline & 0,85 & & & \\
\hline $\begin{array}{c}0,89 \\
\text { (gris verdoso) }\end{array}$ & & & & \\
\hline $\begin{array}{c}0,98 \\
\text { (verde oscuro) }\end{array}$ & & & & \\
\hline
\end{tabular}

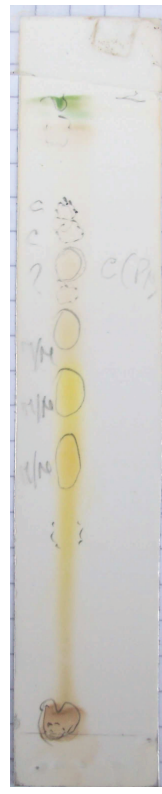

Fig. 5.13. Ext $\mathrm{MeOH}+$ RPN

En estas condiciones al visible se observaron 7 bandas, una en el origen, de color marrón muy intensa y justo bajo el frente del solvente $(\operatorname{Rf} 0,98)$ otra de color verde oscuro muy notoria.

Observada la placa al visible, destacan tres bandas de color amarillo (Rf 0,21 ; $0,44$ y 0,52$)$.

Todas se muestran opacas y oscuras al observar con luz UV366, mientras que con el reactivo de productos naturales se tornan amarillo muy intenso, lo cual nos lleva a pensar en la presencia de flavonas, presentes como heterósidos en el extracto metanólico.

Una banda adicional de tono gris-verdosa está presente en $\mathrm{Rf} 0,89$. (Vis)

Al UV254 aparecen tres nuevas bandas, ausentes en el visible, a $\operatorname{Rf} 0,62 ; 0,75$ y 0,85 aparecen tres nuevas bandas. Destaca entre éstas la segunda banda indicada, que al someter la placa a vapores de $\mathrm{NH}_{3}$ adquiere una fluorescencia celeste.

Aparece también otra banda indetectable anteriormente y que solo es visible con NH3 y fluoresce como una banda crema-celeste que con anisaldehído sulfúrico se colorea de violeta.

Este comportamiento es compatible con el de una saponina. 
Este extracto $\mathrm{MeOH}$ se comparó además con testigos de Rutina, quercetina, pero con éstos no se encontraron coincidencias.

Además analizado el comportamiento cromatográfico y del extracto metanólico en el sistema cromatográfico Tolueno: Acetato de etilo / 8:2 (sistema VI) frente a testigo de ácido salicílico se demostró la ausencia de este metabolito en el extracto.

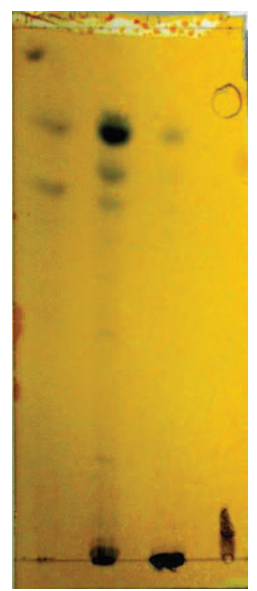

Fig. 5.14

\subsection{4.- Caracterización de ciclótidos por TLC.}

La aplicación del protocolo descripto en materiales y métodos para investigar la presencia de ciclótidos en Viola arguta presentó inicialmente algunas complicaciones, fundamentalmente relacionadas con la dificultad para visualizar las reacciones de los reveladores debido al solapamiento o proximidad con los otros compuestos presentes en el extracto.

Para estas primeras pruebas, la extracción se realizó con el procedimiento descripto en la mayoría de los trabajos sobre ciclótidos publicados en los últimos años. Este protocolo consiste en una extracción inicial con metanol al 60\% seguido de una partición Líquido-Líquido con Diclorometano.

El inconveniente inicial que hemos mencionado se tornaba más severo en las placas sometidas a hidrólisis, en las que aparecía un oscurecimiento generalizado de toda la zona por la que se desplazaban los metabolitos. 


\section{5. - Resultados y Discusión}

Esta situación nos llevó a intentar procedimientos en lo posible simples y rápidos que nos permitieran eliminar la mayor cantidad de las sustancias interferentes.

De esta manera, el aprovechamiento de las particulares características de solubilidad de estos péptidos en relación a las de la mayoría de los componentes del extracto, resultaba ser una primera alternativa a explorar.

Como primer paso se realizaron extracciones preliminares del material vegetal (10g) de forma secuencial con Hexano y Diclorometano, lo que nos permitió contar con extractos Hexánico y Diclorometánico adicionales para otras actividades, al tiempo que retiramos componentes de tipo liposolubles sin extraer los ciclótidos del vegetal.

La insolubilidad de los ciclótidos en estos solventes se encuentra descripta desde los primeros trabajos de Claeson (1998) y obviamente está en concordancia con el natural comportamiento de las sustancias peptídicas en este tipo de solventes.

Como siguiente paso se usó el marco de la extracción con DCM que una vez libre del solvente se extrajo con solución de Metanol al 60\% en la que los ciclótidos si se solubilizan (Burman., et al 2010) y constituye la mezcla que se usa comúnmente como paso inicial de extracción.

Debido a que estas concentraciones de Metanol nos permiten extraer los ciclótidos del material vegetal pero a la vez conserva las características de un solvente general, el extracto presentaba aun una composición muy compleja que se evidenciaba por los perfiles cromatográficos en CCD en donde a un Rf superior a 0,5 predominaban sustancias con características semejantes a flavonas y además en la placa hidrolizada persistía el oscurecimiento en la zona de tránsito de los metabolitos (fig. 5.15). 


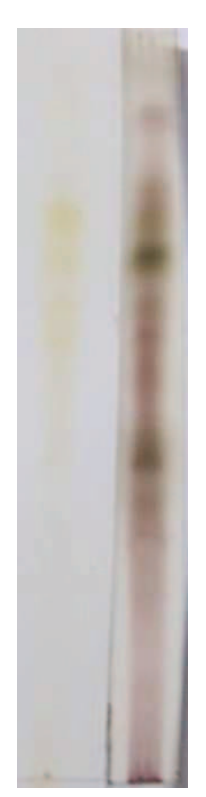

5. - Resultados y Discusión

Fig. 5.15. Comparación de una placa sin Hidrolizar (Izquierda) y con hidrólisis

Un paso mas que se implementó con el propósito de eliminar más sustancias interferentes del extracto, consistió en intentar la precipitación de los péptidos en un medio en el que muchas de las sustancias que los acompañaban siguieran siendo solubles. Es así que optamos por evaporar totalmente el extracto metanólico al $60 \%$ y retomarlo con una mezcla de Metanol con Diclorometano $(10 \mathrm{ml}+1 \mathrm{ml})$.

El objetivo fue disminuir la polaridad del metanol lo suficiente para reducir la posibilidad de que este solvente fuera capaz de solubilizar los ciclótidos pero siguiera conservando su poder de disolver el resto de sustancias acompañantes.

Luego de tres ciclos de centrifugación y lavado con esta mezcla de solventes se obtuvo un precipitado que se redisolvió en Metanol al 60\%

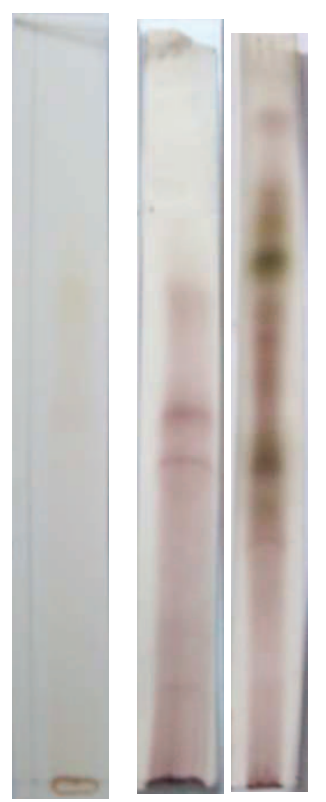


Con la reducción de la cantidad de componentes en el extracto la observación del comportamiento en presencia de los reveladores fue más sencilla (Fig.5.16.).

El extracto metanólico al 60\% se sembró en tres placas de sílica gel (Placas A, B y C) que se desarrollaron simultáneamente en las condiciones del sistema cromatográfico antes indicado.

Concluido el desarrollo se evaporó la fase móvil y se colocó una de las placas (A) suspendida en un tubo de vidrio junto a $1 \mathrm{ml}$ de $\mathrm{HCl}(37 \%)$ y se lo sometió a calentamiento en una estufa a $110^{\circ} \mathrm{C}$ por 2 horas para generar la hidrólisis de los péptidos presentes.

Pasadas las dos horas se sacó la placa del tubo, se eliminó totalmente el $\mathrm{HCl}$ usando aire caliente y se reveló (Fig. 5.17.).

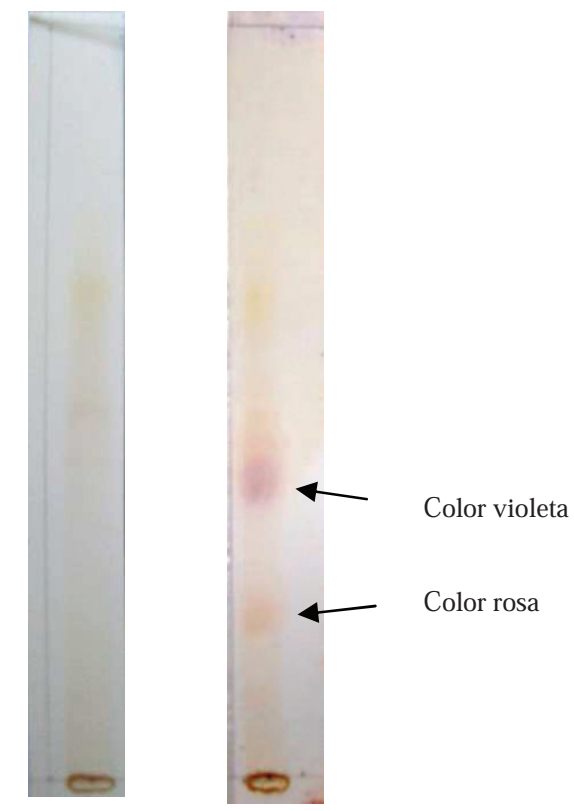

Fig. 5.17. Comparación de la placa sin hidrólisis Antes (izquierda) y después del Revelado con Ninhidrina

La placa C (no hidrolizada) se reveló con el Azul Brillante de Coomassie mientras que la placa A (hidrolizada) y la placa B (no hidrolizada) se revelaron con Ninhidrina al $0,2 \%$ y calentando con un secador de aire durante varios minutos.

Para la detección de ciclótidos en Viola arguta se utilizó el método reportado por XU Yan et al., (2008) que emplea Ninhidrina y Azul Brillante de Coomassie G-250. 


\section{5. - Resultados y Discusión}

Este método, utilizado para investigar ciclótidos en $V$. labridorica, V. tricolor, $V$. hamiltoniana, Momordica charantia y $M$. cochinchinensis, fue definido por los autores como: "un método de buena especificidad y sensitividad químicas para ciclótidos y puede ser empleado eficazmente no sólo para detectar si extractos de plantas contienen ciclótidos sino también para guiar en su separación y purificación".

XU Yan et al., (2008) explican el comportamiento de los reveladores frente a ciclopéptidos, aminoácidos y otros tipos de péptidos y proteínas según la siguiente tabla:

\begin{tabular}{|l|c|c|c|c|c|}
\hline \multicolumn{1}{|c|}{ Reveladores } & $\begin{array}{c}\text { Aminoácid } \\
\text { os }\end{array}$ & Ciclótidos & Ciclopéptidos & $\begin{array}{c}\text { Péptidos } \\
\text { lineales }\end{array}$ & Proteínas \\
\hline $\begin{array}{l}\text { Ninhidrina (No- } \\
\text { Hidrolizado) }\end{array}$ & +++ & - ò + & - & +++ & + \\
\hline Ninhidrina (Hidrolizado) & +++ & +++ & +++ & +++ & +++ \\
\hline $\begin{array}{l}\text { Azul Brillante de } \\
\text { Coomassie }\end{array}$ & - & + & - & - & +++ \\
\hline
\end{tabular}

"- = Negativo

" $+" \quad=$ Positivo

"+++" = Más Positivo

Si al revelar la placa hidrolizada con ninhidrina aparece una coloración púrpura - rojiza o amarilla y en el mismo Rf de la placa no hidrolizada no aparecen estas coloraciones, este resultado indicaría la presencia de ciclopéptidos ya que éstos al no poseer extremos $\mathrm{N}$ terminales no reaccionan con Ninhidrina y sólo la hidrólisis a la que se someten en la placa permite que se revelen con el reactivo.

Adicionalmente este procedimiento desarrollado por los autores permite ir más allá e identificar dentro de la los ciclopéptidos a los ciclótidos ya que sólo estos últimos pueden ser detectados con Azul Brillante de Coomassie G-250 por su mayor peso molecular comparado con el del resto de los ciclopéptidos que son más pequeños e indetectables para este reactivo,

La modificación sugerida en el trabajo de Xu et al (2008) en la preparación de este revelador (Azul Brillante de Coomassie G-250) consiste en el aumento de su concentración y también en agregar una mayor proporción de etanol para una rápida 
volatilización. De esta manera si los ciclopéptidos antes detectados son ciclótidos aparecerá una coloración turquesa sobre el fondo rojo de esta placa.

Realizadas las cromatografías para el extracto $\mathrm{MeOH} 60 \%$ y $\mathrm{MeOH} 60 \%$ semipurificado de $V$. arguta, se obtuvieron los siguientes resultados:

Al revelar las placas B (no hidrolizada) con Ninhidrina podemos observar que aparecen algunas una banda color violeta $(\mathrm{Rf}=0,38)$ de intensidad media y otra de color rosa, las dos sin buena resolución, estas bandas no fueron visibles antes del tratamiento con este revelador (fig. 5.18), de esta manera identificamos sustancias presentes en el extracto que correspondería a aminoácidos o algunas moléculas aminadas que son capaces de reaccionar con la Ninhidrina, por lo que la presencia de ciclótidos se descartó en estas posiciones (Rfs) de la placa.

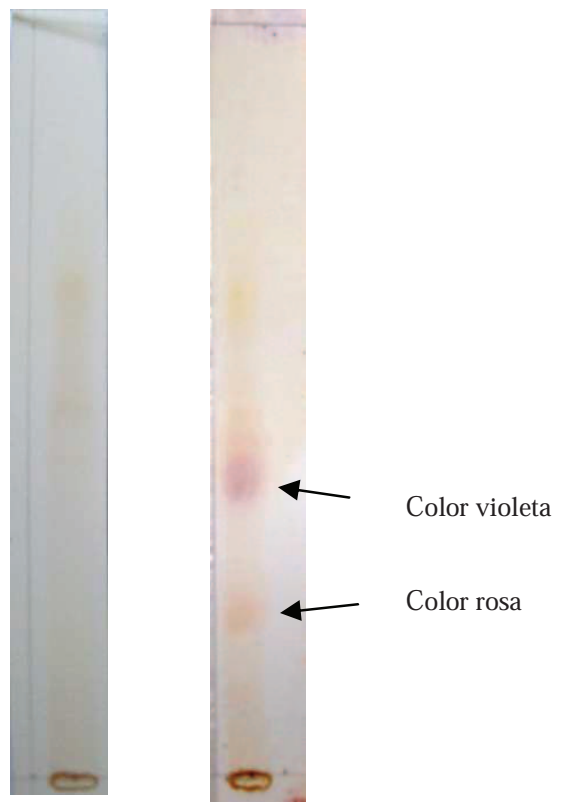

Fig. 5.18. Comparación de la placa sin hidrólisis Antes (izquierda) y después del Revelado con Ninhidrina (der) 
A continuación la placa C (sin Hidrólisis) se reveló con Azul Brillante de Coomassie y se observó la aparición de un color azul que resaltaba en el fondo rosa de la placa y en un $\mathrm{Rf}=0,55$, sin buena resolución y generando una banda amplia (fig. 5.19).

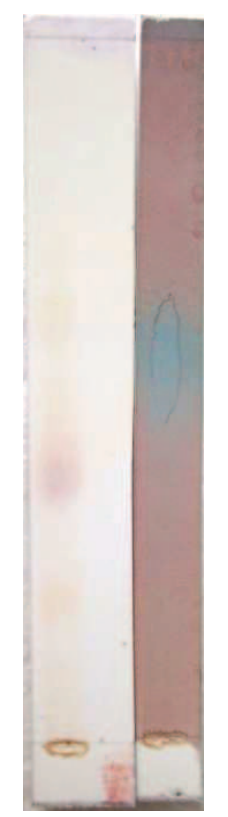

Fig. 5.19. Comparación de las placas reveladas con Ninhidrina (izquierda) y con Azul Brillante de Coomassie.

La aparición de esta banda únicamente en esta zona nos indicó que las sustancias que anteriormente reaccionaron con Ninhidrina necesariamente debían ser aminoácidos o péptidos muy pequeños ya que su escaso tamaño hace que el revelador que ahora empleamos no los alcance a detectar y a la vez nos indicó la presencia en esta amplia zona azul de alguna sustancia o sustancias de tipo peptídico que en cambio no fueron detectados por Ninhidrina, todos estos criterios cumplieron, hasta ese momento, con el comportamiento que debían tener los ciclótidos.

Sin embargo restaba por investigar si esta banda detectada por el Azul Brillante de Coomassie, tras el tratamiento con Ácido Clorhídrico a $110^{\circ} \mathrm{C}$ por 2 Horas al que se sometería la placa podría reaccionar con Ninhidrina, de hacerlo indicaría que su 
estructura original creaba impedimentos para reaccionar con este último revelador. Este fue justamente el resultado que se observó.

Tras la mencionada hidrólisis se obtuvo una placa que una vez revelada con Ninhidrina de la forma que se explica en la sección de Métodos, vuelve a presentar zonas coloreadas donde antes fue positiva la reacción con Ninhidrina pero con una intensidad menor, mientras la banda violeta también se tornó rosa, pero lo más destacado es que aparece una nueva banda, otra vez sin buena resolución, de color rosa al mismo $\mathrm{Rf}$ de la banda revelada con Azul Brillante de Commassie lo que finalmente, al haber observado la concordancia de nuestros resultados con aquellos que los autores indican en su Protocolo, nos indicaría que esta especie de Violeta posee ciclótidos en su composición.

Como se manifestó anteriormente, si bien la existencia de estas moléculas está ampliamente documentada en la familia Violaceae, ésta es la primera vez que se describe su presencia en Viola arguta.

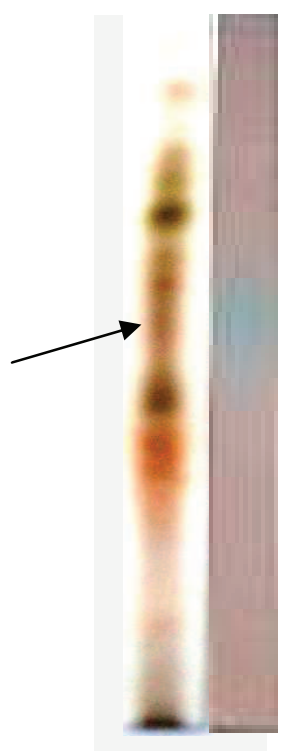

Comparación de la placa hidrolizada y revelada con ninhidrina

(izq.) con la placa sin hidrolizar revelada con azul brillante 


\subsection{5.- Detección de ácidos por CCD}

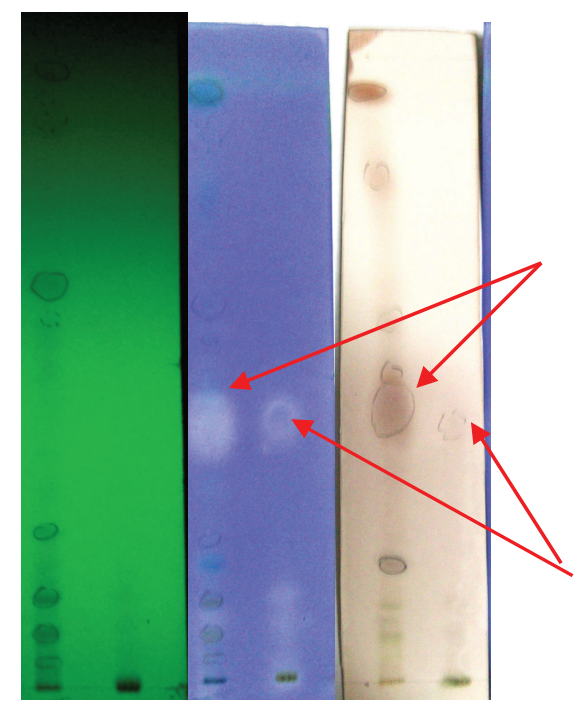

CCD del extracto hexanico y hexanico purificado con distintos reveladores UV254 (izq.); azul bromofenol (centro); Anisaldehido sulfurico (der.)

El extracto purificado obtenido partir del extracto hexanico, se cromatografio con el solvente Eter etílico/éter de petróleo/ acido fórmico 70:30:1

Al observar la placa al UV254 se ven 8 manchas en la calle correspondiente al extracto hexanico y no se aprecia ninguna en el extracto purificado.

Al revelar con azul de bromofenol, aparece, tanto en el extracto hexanico como en el extracto purificado, una mancha amarillenta a $\operatorname{Rf} 0,46$ que toma coloracion rosada si la placa se revela con Anisaldehido sulfurico.

Este comportamiento sugiere que se ha aislado a partir del extracto hexanico una sustancia de naturaleza acida, que podria ser de naturaleza terpenica. Según Wagner y Bladt (1996), las saponinas, a excepción de la glicirricina y el acidoglicirretico presentes en el regaliz, no son detectables por exposición a la luz UV254 o UV366 requiriendo un tratamiento químico.

Dadas las reacciones orientativas previamente realizadas y el comportamiento que observamos al revelar las CCD, podríamos inferir que la sustancia aislada a partir del extracto hexanico seria el aglucon de una saponina. 


\section{3.- Actividades}

\subsection{1.- Actividad antioxidante por métodos espectrofotométricos}

\subsubsection{1.- Actividad frente al radical 2,2-difenil-1-picrilhidrazilo (DPPH)}

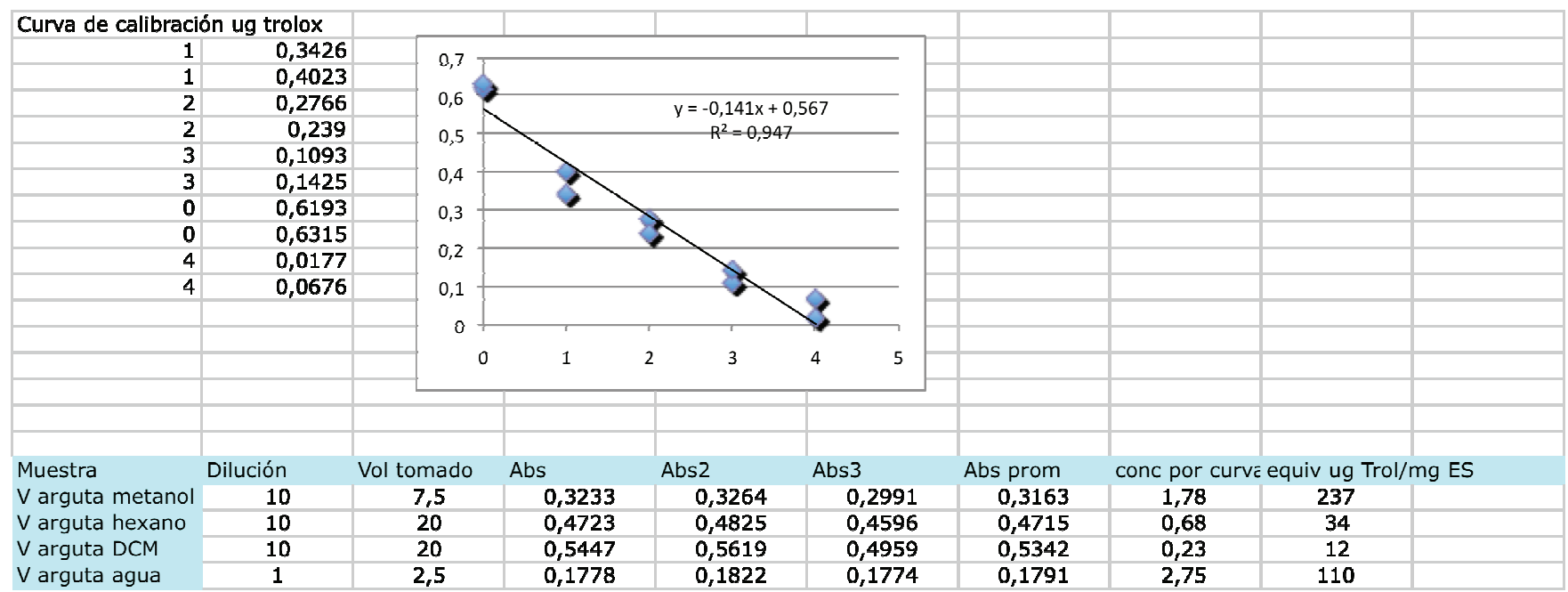

5.3.1.2.- Actividad frente al radical $2,2^{\prime}$-azino-bis(3-etilbenztiazolin-6-sulfonato de amonio) (ABTS)

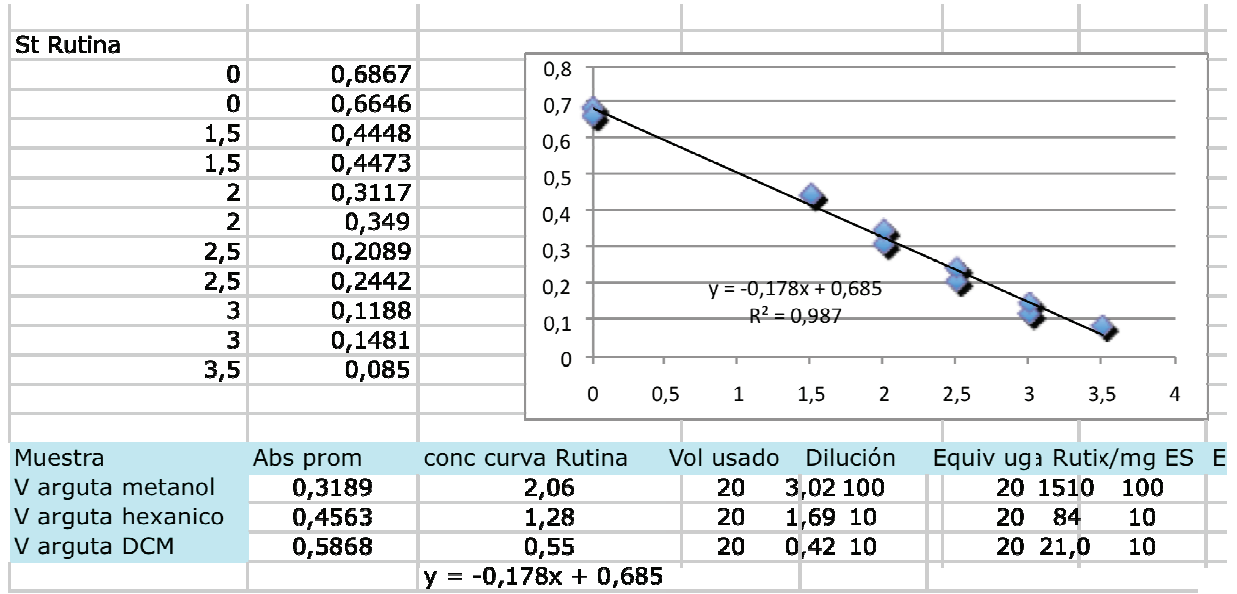




\subsubsection{3.- Evaluación de la capacidad reductora por el método FRAP}

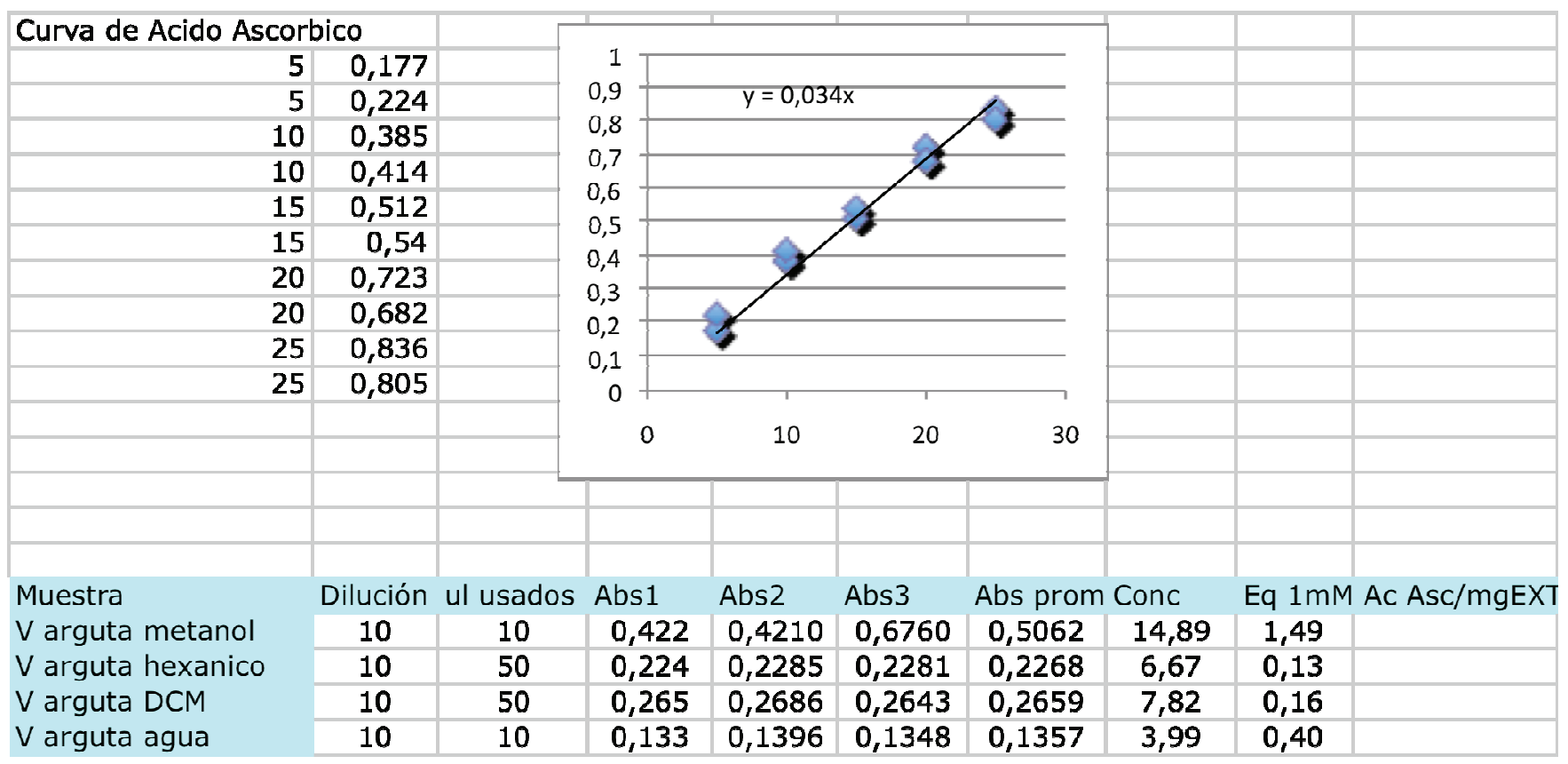

\subsubsection{4.- Determinación del contenido de fenoles totales}

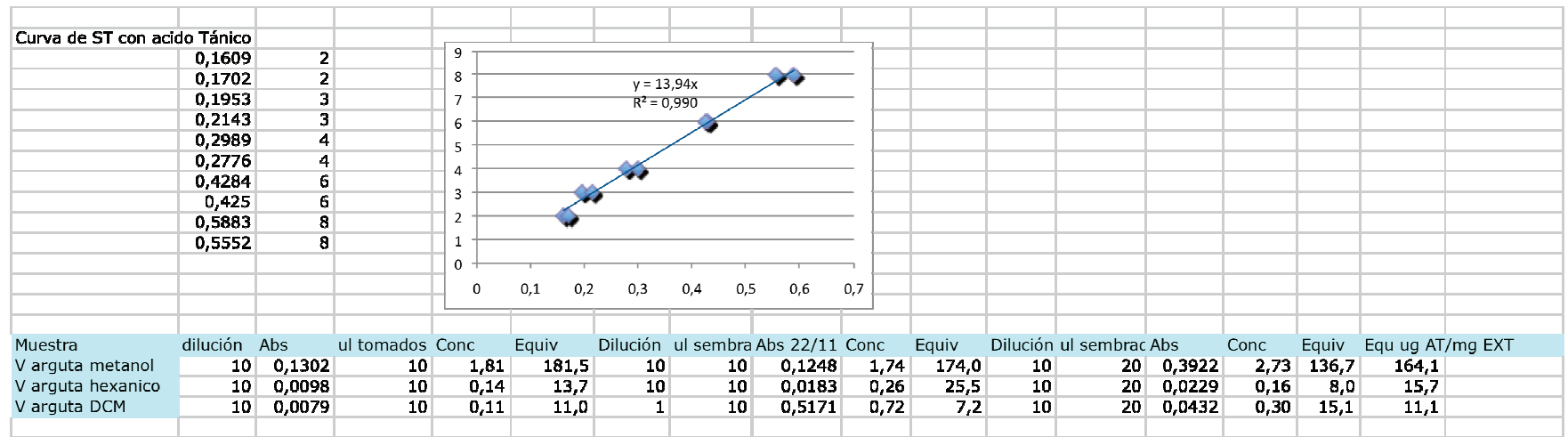




\section{5. - Resultados y Discusión}

\subsubsection{5.- Determinación del contenido de flavonoides totales}

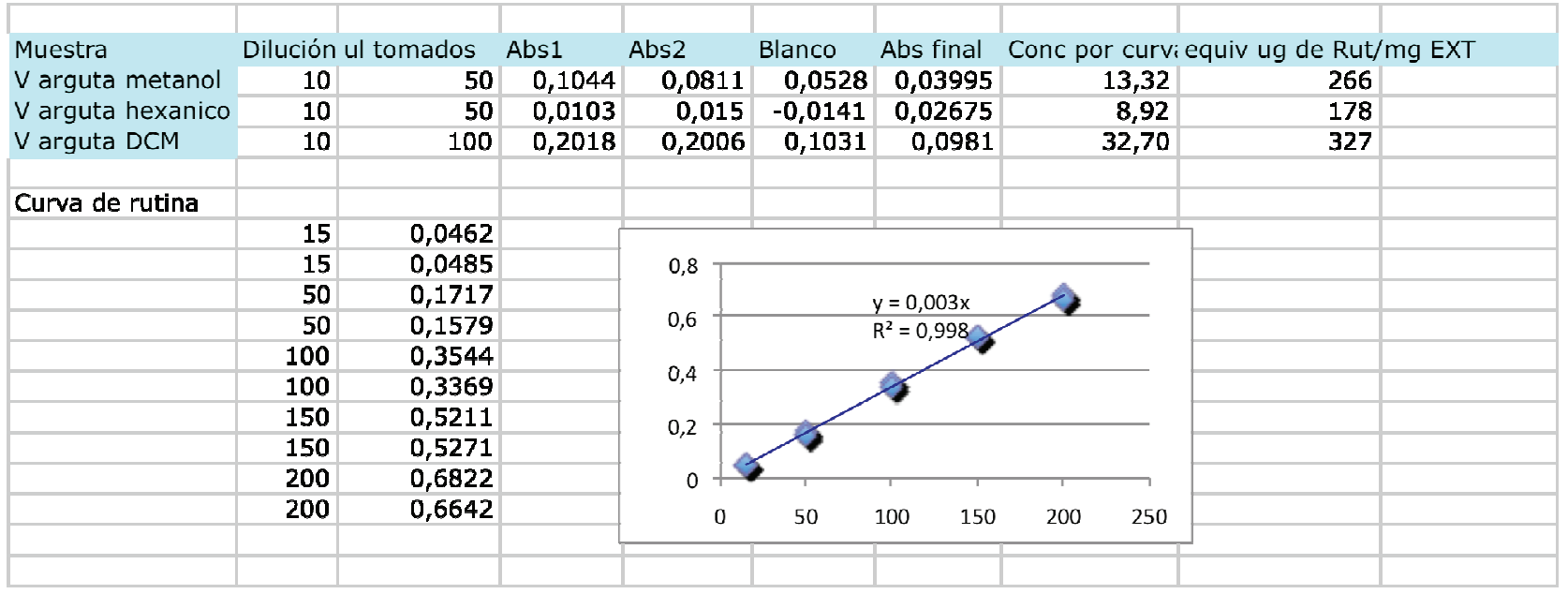

Existe consenso respecto a la necesidad de utilizar más de un método cuando se evalúa la capacidad antioxidante de extractos vegetales, ya que los compuestos antioxidantes pueden actuar por diversos mecanismos según el sistema de reacción utilizado. Los métodos empleados miden la capacidad reductora de los extractos al actuar sobre diversos radicales preformados, lo cual permite la evaluación en un amplio rango del perfil metabólico de la planta ensayada. (Fernández Pachón et al., 2006; Aubad López, 2007; Rojano et al., 2008; Gan et al., 2010).

En general, podemos decir que la actividad antioxidante de una planta es el resultado del balance existente entre los compuestos de alta y baja polaridad existentes (Kuskoski et al., 2004; Repo de Carrasco y Encina Zelada, 2008).

De la observación de los gráficos y tablas, se desprende que las TEAC ( $\mu$ g trolox / mg extracto seco) calculadas por el método DPPH para $V$. arguta, resultaron mayores para el extracto mas polar $(\mathrm{MeOH})$.

Asimismo la concentración de fenoles totales, resultó ser muy superior para el extracto metanólico, lo cual sugiere que uno de los responsables de la actividad 


\section{5. - Resultados y Discusión}

antioxidante de $V$. arguta serian los compuestos polifenolicos presentes en los extractos mas polares.

La capacidad antioxidante calculada por el método ABTS ( $\mu$ g rutina/mg ES), también resultó mayor para el extracto metanólico, en concordancia con los resultados del método DPPH.

La concentración de sustancias reductoras, calculadas por el método FRAP ( $\mu \mathrm{g}$ acido ascórbico/ mg extracto seco) también resulto ser diez veces mayor para el extracto metanólico.

Por otra parte, el contenido de flavonoides es inversamente proporcional a la actividad antioxidante calculada por cualquiera de los métodos anteriormente citados. O sea, los extractos más polares son los que contienen la menor concentración de flavonoides totales expresados como rutina. O dicho de otro modo, los flavonoides se encuentran preferentemente como aglucones (solubles en hexano y diclorometano) y no como heterósidos (más solubles en metanol).

Sin embargo, es bien conocido que los flavonoides poseen actividad antioxidante demostrada. Una posible explicación para estas observaciones aparentemente contradictorias, podría ser que los flavonoides no fueran los únicos compuestos con actividad antioxidante presentes en los extractos metanólico y acuoso de $V$. arguta, compartiendo esta actividad con otras clases de metabolitos reductores.

La determinación del contenido de fenoles totales arroja valores de hasta 10 veces superior en el extracto metanólico con respecto a los extractos hexánico y diclorometánico, por lo cual es lógico pensar que las sustancias reductoras que contribuyen a la acción antioxidante en ese extracto, sean compuestos polifenolicos.

Es de destacar también que aunque en pequeñas cantidades, los compuestos fenólicos también están presentes en los extractos menos polares (hexano y diclorometano). 


\section{5. - Resultados y Discusión}

\subsection{2.- Actividad antiinflamatoria: Estudio de la inhibición de la producción de oxido nítrico in vitro}

\section{1) Ensayo de citotoxicidad.}

Este ensayo se realiza con la Linea RAW 264,7 con la finalidad de conocer el efecto de las diferentes concentraciones de los extractos sobre la viabilidad de estas células y así determinar el rango de concentraciones para el ensayo.

Las células fueron cultivadas por 24 horas a $37^{\circ} \mathrm{C}$ en medio DMEM (Dulbecco's modified Eagle's medium) suplementado con $10 \%$ de suero fetal bovino, Penicilina (100 units $/ \mathrm{mL}$ ) y sulfato de Estreptomicina (100 units $/ \mathrm{mL}$ ), en una atmósfera con $5 \%$ de $\mathrm{CO}_{2}$, a continuación se controló la viabilidad celular y se determinó la densidad usando una cámara de Neubauer con Azul de Tripan como colorante con la finalidad de establecer la dilución del cultivo adecuada para obtener 200.000 células /200 $\mu$ / pocillo en dos placas de 96 pocillos .

La dilución que se calculó para las dos placas fue de 7,9ml de suspensión celular en 30,5 ml de medio DMEM con la composición antes indicada.

Se colocaron en cada pocillo de cada placa $200 \mu \mathrm{l}$ de la suspensión celular y se incubaron por 24 Horas en las mismas condiciones anteriores, pasado este tiempo se voltearon las placas para eliminar el medio, se lavaron con el mismo volumen anterior de medio fresco, se eliminó nuevamente este medio y se agregó medio de cultivo compuesto por DMEM con $0,5 \%$ de Suero fetal bovino y de los antibióticos en las concentraciones antes indicadas colocando $195 \mu$ l en 12 pocillos (Blancos) y $175 \mu \mathrm{l}$ en los 84 restantes (fig. 5.20.)

Se añadieron $5 \mu \mathrm{l}$ del cada uno de los extractos disueltos en Dimetilsufóxido (DMSO) que permite solubilizar la mayoría de los metabolitos de tipo liposolubles, mientras que el acuoso se disolvió en agua destilada, obviamente el grupo de 12 pocillos que sirvieron como blanco y de 12 para control en lugar de los extractos se colocaron los solventes, en estas condiciones se regresaron las placas a la incubadora por 1 hora. 

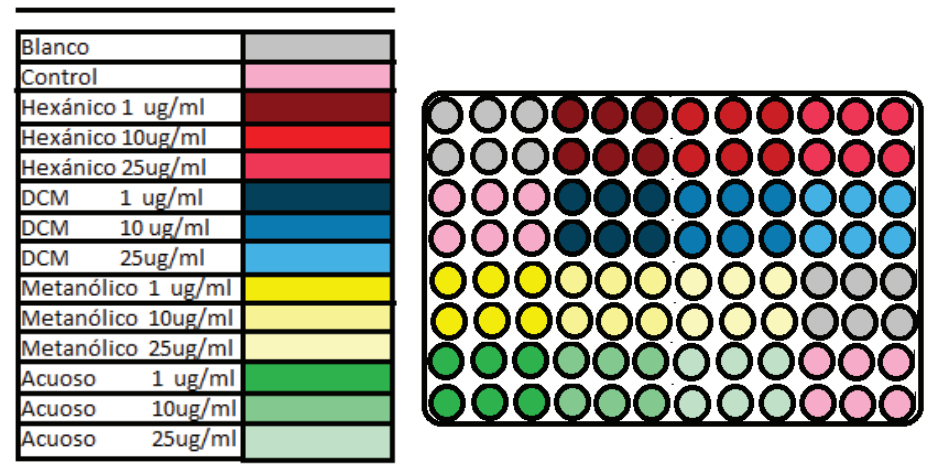

Fig. 5.20. Esquema de la Disposición de los extractos en la placa de 96 pocillos

Se sacaron las placas y se añadió Lipolisacárido para una concentración final en pocillo de $10 \mu \mathrm{l} / \mathrm{ml}$; únicamente en el grupo Blanco de las dos placas no se colocó este tratamiento.

Se incubaron por otras 24 horas en las mismas condiciones anteriores y transcurrido este tiempo se tomaron $100 \mu \mathrm{l}$ del medio de cada placa y se traspasaron a otra placa de 96 pocillos, se añadieron $100 \mu$ del reactivo de Griess (Dilución 1 a 1 de ácido sulfanílico al 1\% en 3M de ácido clorhídrico y N -(1) Naftilendiamina al 0,02\% en agua desionizada) (Griess, et al 1982) se midió la Absorbancia a $540 \mathrm{~nm}$ en un espectrofotómetro lector de placas con este valor se calcula la concentración de nitrito presente en el medio de cultivo en una curva de calibración previamente realizada (fig.5.21.).

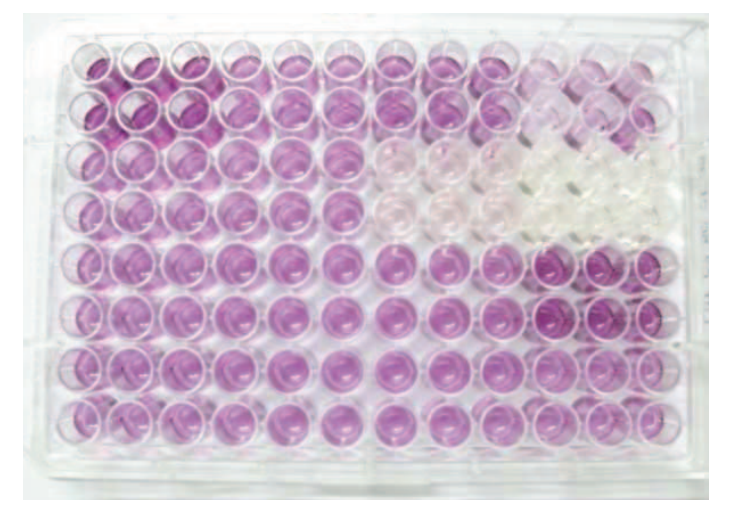

Fig. 5.21. Placa con reactivo MTT para ensayo de citotoxicidad 


\section{5. - Resultados y Discusión}

El ensayo parea determinar citotoxicidad se realizó usando MTT (Bromuro de 3-(4,5dimetiltiazol-2-ilo)-2,5-difeniltetrazol) $(500 \mu \mathrm{g} / \mathrm{ml})$ en las células del ensayo anterior; una vez se extrajeron los $100 \mu \mathrm{l}$ por pocillo se voltean las placas y se elimina el remanente del medio de cultivo, se añaden $200 \mu \mathrm{l} /$ pocillo de medio de cultivo fresco y lo descartamos nuevamente, ahora añadimos $100 \mu \mathrm{l}$ de MTT e incubamos por 30 minutos, se voltean las placas y se lavan con PBS $(100 \mu l)$.

Finalmente se añaden $100 \mu \mathrm{l}$ de Dimetilsulfóxido que permite solubilizar los cristales azules de Formazán generados por las células, se lee la Absorbancia a 570nm en un espectrofotómetro lector de placas.

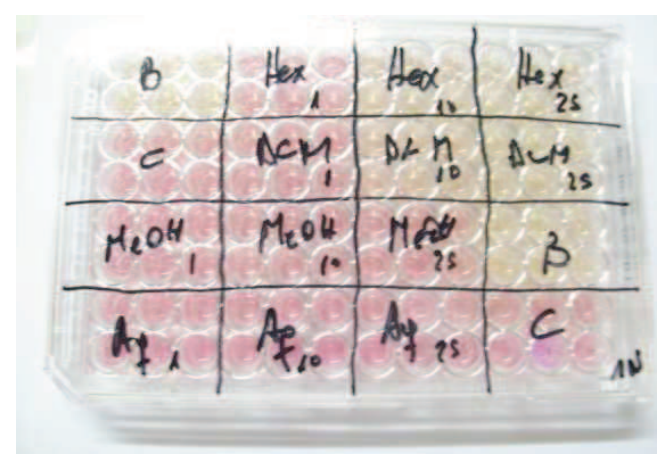

Fig. 5.21. Vista de la Placa para Nitritos con los tratamientos indicados en su tapa

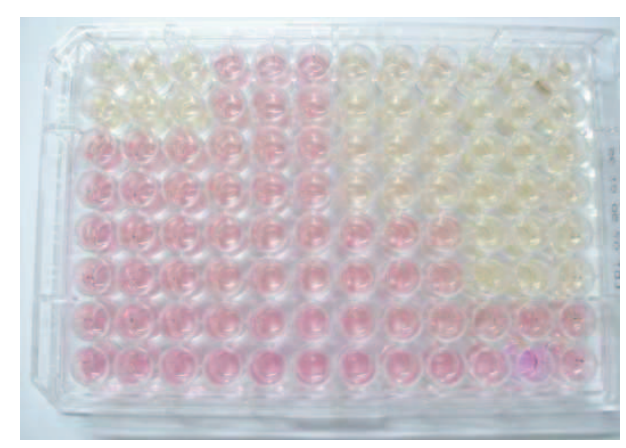

Placa para determinación de nitritos con el Reactivo de Griess

Al comparar los valores del Blanco (sin LPS) y el Control (Con LPS) se evidencia una significativa reducción de la viabilidad celular generada por la presencia de este agente inductor de la producción de Óxido Nítrico (fig. 5.22), por lo que la comparación de la viabilidad de las células sometidas a las diferentes concentraciones de extractos se efectuaron frente al valor de la viabilidad del Control que representa las condiciones de partida del modelo de estudio.

En cuanto al extracto Hexánico, las concentraciones de $1 \mu \mathrm{g} / \mathrm{ml}$ y $10 \mu \mathrm{g} / \mathrm{ml}$ no muestran efectos citotóxicos, sin embargo a la concentración de $25 \mu \mathrm{g} / \mathrm{ml}$ la viabilidad se reduce significativamente $(a<<95 \%$ de viabilidad). 
Con los extractos Diclorometánicos a las concentraciones de 10 y $25 \mu \mathrm{g} / \mathrm{ml}$ se presenta elevada toxicidad siendo la última de éstas la que mayor efecto negativo generó sobre la viabilidad celular entre todos los extractos que se evaluaron $(<23 \%$ de Viabilidad), no así a la concentración de $1 \mu \mathrm{g} / \mathrm{ml}$. que no afectó significativamente la supervivencia de los macrófagos.

Las distintas concentraciones de los extractos Metanólicos y Acuosos no presentaron toxicidad en este modelo, sin embargo hay una aparente tendencia, no significativa, en los extractos acuosos a disminuir la viabilidad del cultivo celular con el incremento de sus concentraciones.

Estos resultados nos permitieron establecer qué concentraciones de los distintos extractos serían consideradas válidos en los ensayos para evaluar la inhibición de la producción de Óxido Nítrico, de esta manera se tomaron en cuenta para esta siguiente prueba los resultados de aquellos extractos con viabilidad superior al 95\%, por consiguiente no se consideraron los valores generados con el extracto hexánico a $25 \mu \mathrm{g} / \mathrm{ml}$ y Diclorometánicos a 10 y $25 \mu \mathrm{g} / \mathrm{ml}$.

Al analizar los resultados del extracto Hexánico en el ensayo de inhibición de la producción de Óxido Nítrico se evidencia actividad a las concentraciones de $1 \mu \mathrm{g} / \mathrm{ml}$ y $10 \mu \mathrm{g} / \mathrm{ml}$ ya que reducen la cantidad de nitrito (producto del oxido nítrico generado) en el medio de cultivo y en el caso de la última concentración llega a disminuirlo en más del $60 \%$, siendo este extracto el único que muestra esta capacidad, los restantes extractos se mostraron inactivos en este modelo de investigación a las concentraciones empleadas (fig. 5.23). 
Fig. 5.23. Efecto de los extractos (frente al control considerado como 100\%) sobre la producción de nitritos

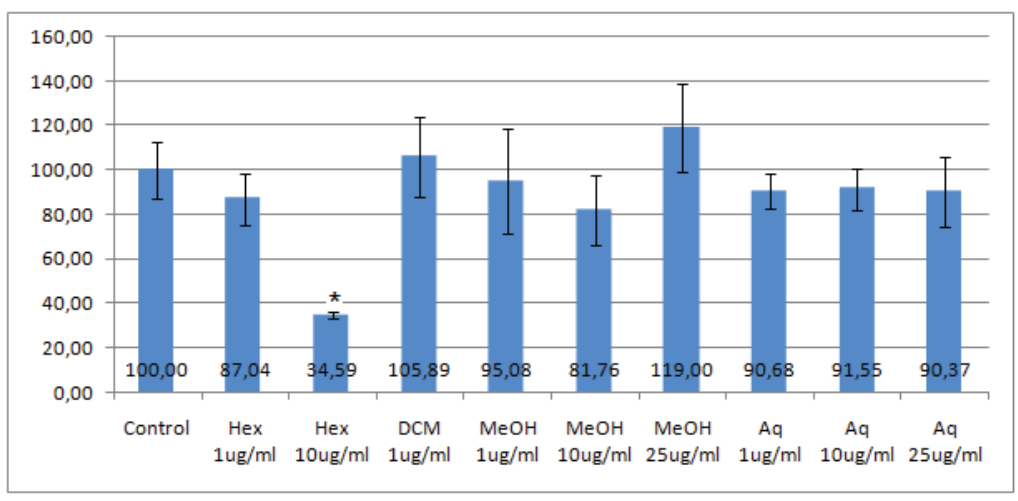

Las barras indican la media de las concentraciones (IC 95\%), se evidencia que solo el Hexánico a $10 \mu \mathrm{g} / \mathrm{ml}$ produce una reducción significativamente diferente $(p<0,05)$

\section{Discusión}

La evaluación de la acción inhibidora sobre la producción de Óxido Nítrico en las células RAW 264,7 de los cuatro extractos (Hexánico, Diclorometánico, Metanólico y Acuoso) a las mismas concentraciones finales $(1,10$ y $25 \mu \mathrm{g} / \mathrm{ml})$ :, indica que el extracto hexánico (a las concentraciones de 1 y $10 \mu \mathrm{g} / \mathrm{ml}$ ) es el único que presenta actividad y que se refleja por la disminución de la cantidad de nitrito en el medio de cultivo y que se deriva del óxido nítrico que se les induce a generar.

Es interesante destacar que a una concentración de $1 \mu \mathrm{g} / \mathrm{ml}$ de extracto hexánico la inhibición en la producción de Oxido Nítrico es menor al 20 \% mientras a la concentración de $10 \mu \mathrm{g} / \mathrm{ml}$ la inhibición supera el 60\% sin que el incremento en 10 veces de la concentración de extracto afecte la viabilidad celular.

Existen antecedentes de un grupo de principios activos conocidos como ácidos anacárdicos presentes en algunas plantas y que también han sido encontrados en Viola websteri cuya extracción del material vegetal la han conseguido usando un solvente apolar como Éter de Petróleo (Lee, 2009); estos ácidos han mostrado capacidad de modular a varios componentes de vías de señalización celular involucradas en procesos inflamatorios inhibiendo mecanismos tanto a nivel epigenético (Ghizzoni ,2010) y de tipo transcripcional al producir una potente inhibición de la activación del factor transcripcional NF-kB (Factor Nuclear kappa B) que controla la transcripción de 


\section{5. - Resultados y Discusión}

varios genes y entre éstos destaca el que codifica para la enzima Oxido Nítrico Sintetasa Inducible (iNOS) (Sung, 2008)

Las citotoxicidades de los extractos Diclorometánicos a las concentraciones de 10 y $25 \mu \mathrm{g} / \mathrm{ml}$, puede prestarse para algunas interpretaciones, ya que si bien se puede observar en los resultados una disminución en la producción de óxido nítrico, en primera instancia podría relacionarse este efecto con la disminución de la viabilidad celular a estas concentraciones, sin embargo, no es menos cierto que aun no se podría descartar que dentro de una composición tan compleja como la de un extracto vegetal puedan coexistir metabolitos que generen esta toxicidad junto a metabolitos bioactivos y que no sean detectados bajo estas condiciones experimentales por afectar a las células pero quizás si puedan ponerse de manifiesto aislándolos a través de procesos de fraccionamiento y purificación, además, la ausencia de toxicidad del extracto a la concentración de $1 \mu \mathrm{g} / \mathrm{ml}$ deja abierta aun la posibilidad de evaluar el extracto a concentraciones un poco superiores aunque en un margen muy estrecho teniendo en cuenta la toxicidad que ya se manifiesta a $10 \mu \mathrm{g} / \mathrm{ml}$.

El caso del extracto metanólico es diferente al anterior, ya que si bien existe una ausencia de efecto inhibidor en la generación de ON, a estas mismas concentraciones tampoco se detectan efectos tóxicos en las células y la posibilidad de utilizar concentraciones superiores a $25 \mu \mathrm{g} / \mathrm{ml}$ es un camino válido en la búsqueda de sustancias con esta actividad biológica.

Para los extractos acuosos es la situación es similar, un primer paso consistiría en determinar el rango de concentraciones mayores a $25 \mu \mathrm{g} / \mathrm{ml}$ que sin afectar la viabilidad celular permita evaluar su actividad en este modelo de investigación, ya que si nos remitimos simplemente a las concentraciones empleadas en este estudio, la ausencia de respuesta inhibitoria por esta vía de señalización celular vinculada con la inflamación nos indica que este no sería el mecanismo por el que puede actuar la infusión de la planta que como hemos anotado anteriormente es la forma en que se la usa en medicina tradicional, teniendo siempre en cuenta varios aspectos:

1) La síntesis de óxido Nítrico es sólo uno de los mecanismo que se ponen en marcha en el proceso de la inflamación, y la complejidad de esta respuesta biológica se debe a 


\section{5. - Resultados y Discusión}

la gran cantidad de actores y que incluyen a Prostaglandinas, Leucotrienos, Histamina, Serotonina, Proteasas, Especies reactivas de Oxígeno (además del ON), infiltración celular, etc. por lo que, para generar una evaluación más cercana del verdadero potencial de una sustancia por métodos in vitro se deberían analizar su actividad frente a varios de estos agentes participantes en la inflamación, así que la evaluación que se ha realizado en este estudio representa solo una parte de esta primera etapa.

2) Los procesos farmacocinéticos a los que se enfrentan los principios activos en el organismo, ausentes en las evaluaciones in vitro, desempeñan papeles fundamentales ya que en muchos casos las reacciones metabólicas que se ejecutan son las que transforman a sustancias inactivas in vitro en moléculas con acción farmacológica in vivo.

Un aspecto que no se podría descartar hasta identificar a la sustancia (o sustancias) en el extracto hexánico responsables de la acción biológica investigada es que ésta se encuentre presente también en la infusión de la planta, obviamente el hecho de que su extracción se haya realizado con un solvente como hexano nos habla de su lipofilicidad, sin embargo, el tratamiento térmico en la infusión de muchas plantas ha mostrado que es capaz de solubilizar sustancias con baja polaridad aunque es claro que estarán en bajas proporciones. 


\section{6.- Conclusiones}


Con los nombres vulgares de "violeta del campo" o "violeta roja" es conocida una especie perteneciente al género Viola, cuyas partes aéreas son utilizadas popularmente en Ecuador para tratar el "dolor de huesos" y otras patologías relacionadas con los procesos inflamatorios.

Se describieron los principales elementos de diagnóstico de las hojas de $V$. arguta, así como los valores de los índices de estoma y de empalizada. Si bien estos últimos no permiten por si solos establecer la identidad de esta especie, son útiles para complementar los datos morfológicos

Microscópicamente, las hojas de $V$. arguta pueden ser identificadas por sus índices de estoma y empalizada y mediante la combinación de distintos caracteres, tales como:

- Hojas hipostomática

- Estomas transicionales entre rubiáceos y crucíferos

- Epidermis adaxial y abaxial con células mucilaginíferas, abundantes en los dientes

- Epidermis abaxial con pelos unicelulares o uniseriados, acintados con cutícula estriada.

- Abundantes cristales (drusas) formando una capa por debajo del parénquima en empalizada.

Teniendo en cuenta el uso tradicional de $V$. arguta y la posibilidad de que en un futuro integre la formulación de medicamentos fitoterapicos, el análisis de estos elementos de diagnóstico, junto a la determinación de los perfiles cromatográficos y ensayos fitoquímicos constituye la base para un futuro control de calidad.

Desde el punto de vista fitoquímico, todos los extractos de $V$. arguta dan positivas las reacciones preliminares para flavonoides, siendo las flavonas los compuestos que parecen predominar en los extractos DCM y metanólico, lo que sugiere que estos metabolitos se hallan tanto como aglucones como en forma de heterósidos 
En tanto que los ensayos para detectar taninos y saponinas solo son positivos para los extractos mas polares (metanólico y acuoso). Todos estos resultados preliminares son confirmados por las respectivas CCD, que también nos permiten confirmar la ausencia de acido salicílico.

En cuanto a la existencia de otros ácidos orgánicos, dadas las reacciones orientativas previamente realizadas y el comportamiento que observamos al revelar las correspondientes CCD, no se descarta la presencia de aglucones de tipo triterpenico en el extracto hexanico.

Mediante la aplicación de métodos descriptos en la bibliografía, que hemos modificado a fin de optimizar el procedimiento de extracción y purificación, se ha podido confirmar la presencia de ciclótidos en la especie estudiada. Estos ciclopéptidos son descriptos por primera vez en esta Viola arguta.

Los compuestos que reaccionan con anisaldehido sulfúrico, predominan en los extractos hexánico y también aparecen en el metanólico (posible presencia de sustancias de naturaleza terpenica).

Respecto a sus actividades, se comprueba la actividad antioxidante, que es mucho más notable en el extracto más polar (metanólico), y la actividad antiinflamatoria in vitro, siendo el extracto hexánico el único que inhibió la producción de oxido nítrico: ca. $60 \%$ de inhibición, sin mostrar toxicidad para las células.

De acuerdo a estos últimos resultados, podría inferirse que $V$. arguta no tendría las propiedades antiinflamatorias que se le atribuyen tradicionalmente, dado que lo que se utiliza es la infusión (acuosa) y los compuestos antiinflamatorios se hallan en el extracto hexánico. Sin embargo, no debe olvidarse la presencia de saponinas, que podrían actuar en forma sinérgica, facilitando la extracción de esos compuestos con solventes mas polares.

En cuanto al trabajo a seguir incluiría poner a punto el paso de extracción que se introdujo ya que si bien nos ayudó a resolver el problema de interferencias antes indicado y sabemos que un proceso de extracción Líquido- Líquido más exhaustivo en relación al realizamos en este trabajo podría llevarnos a mejores resultados, así 
también cabría la posibilidad de que sustituir la centrifugación por otro método como el filtrado y lavado del precipitado faciliten la tarea, también está pendiente definir la composición ideal de la mezcla de solventes que usamos para la precipitación, calcular rendimientos parciales para el proceso y que tan eficiente es en la extracción, además, un paso que se podría agregar es la extracción líquido-líquido: butanol-agua (Broussalisa, et al. 2001) así a través de la suma de estos sencillos procesos se podría llegar a una eliminación eficiente de muchos productos previo a su purificación definitiva

De todo lo expuesto, podemos concluir que $V$. arguta es una especie promisoria desde el punto de vista de un posible uso medicinal, debiéndose encarar la realización de estudios más exhaustivos a fin de:

- Identificar los compuestos presentes en los distintos extractos.

- Purificar, aislar e identificar los ciclótidos presentes.

- Confirmar la actividad antiinflamatoria de V. arguta 
7. - Resumen

\section{7.- Resumen}




\title{
Viola arguta (Violaceae) una especie de la medicina tradicional ecuatoriana
}

\section{Elementos de diagnóstico, ensayos fitoquímicos y actividades biológicas}

\begin{abstract}
Tesis de Maestría para optar al grado de Magíster en Plantas Medicinales, UNLP
\end{abstract}

\author{
Bioquímico \\ Juan Marcelo Carpio Arevalo
}

Directora de Tesis

Dra. María Adelaida Rosella

Lugar de trabajo:

Cátedras de Farmacobotánica y Farmacognosia,

Departamento de Ciencias Biológicas, Facultad de Ciencias Exactas, UNLP 


\section{Introducción}

Ecuador se reconoce desde la Constitución del año 1998 como un país pluricultural y multiétnico y que además está ubicado en uno de los sitios de mayor megabiodiversidad del Planeta.

Dentro de esa biodiversidad, Viola arguta es una planta endémica del país, que crece en la zona cordillerana, a altitudes de 1500 a 3500 msm, en las Provincias de Zamora-Chinchipe, Azuay, Bolívar, Cañar, Carchi, Chimborazo, Cotopaxi, Imbabura, Loja, Morona-Santiago, Pichincha, Zamora-Chinchipe y Loja.

Conocida como violeta del campo o violeta roja, es utilizada tradicionalmente para el tratamiento de diversas afecciones, entre ellas algunas relacionadas con la capacidad antiinflamatoria que se le atribuye.

Hasta donde sabemos, no existen hasta el momento datos botánicos que permitan su reconocimiento, ni información sobre su composición química y actividades biológicas que justifiquen su empleo en terapéutica.

A fin de proveer elementos de diagnostico que contribuyan a su identificación, y eventual control de calidad, así como contribuir a su estudio fitoquímico se encara el análisis micrográfico de esta especie, así como se efectúan los ensayos fitoquímicos preliminares, detección de metabolitos secundarios característicos del genero Viola y la determinación de la acción antioxidante y actividad antiinflamatoria

\section{Resultados obtenidos}

\section{Elementos de diagnostico y determinación de valores numéricos en hojas de V. arguta}

Botánicamente, las hojas de $V$. arguta, pueden ser identificadas por la combinación de diversos caracteres, siendo los principales:

Hojas hipostomática, estomas transicionales entre rubiáceos y crucíferos, epidermis adaxial y abaxial con células mucilaginíferas, abundantes en los dientes, epidermis abaxial con pelos unicelulares o uniseriados, acintados con cutícula estriada, Abundantes cristales (drusas) formando una capa por debajo del parénquima en empalizada.

Los valores numéricos se muestran en la siguiente tabla

Tabla Magnitudes cuantitativas

\begin{tabular}{|l|c|c|c|}
\hline & Rango & Promedio & Moda \\
\hline Índice estomático & $15,15-21,42$ & 17,31 & 15,30 \\
\hline Índice empalizada & $5,00-14,50$ & 9,65 & 9,00 \\
\hline
\end{tabular}

\section{Ensayos fitoquímicos}

Respecto a los ensayos fitoquímicos preliminares, las reacciones efectuadas permiten establecer la presencia de los siguientes grupos fitoquímicos: taninos y saponinas en los extractos metanólico y acuoso; mucílagos, en el extracto acuoso, confirmado mediante la reacción histoquímica con azul de metileno; flavonoides en todos los extractos (hexánico, diclorometánico, metanólico y acuoso).

Tabla resumen de las reacciones químicas orientativa efectuadas en extractos de V.arguta

\begin{tabular}{|c|c|c|c|c|c|c|}
\hline Principio activo & Hexánico & DCM & Metanólico & Acuoso & $\begin{array}{c}\text { Extracto especifico } \\
\text { MeOH } 60 \%\end{array}$ & $\begin{array}{c}\text { Reacción } \\
\text { histoquímica en } \\
\text { hoja }\end{array}$ \\
\hline Alcaloides & $\mathrm{N} / \mathrm{R}$ & $N / R$ & $N / R$ & $N / R$ & Negativo & $N / R$ \\
\hline Antraquinonas & $\mathrm{N} / \mathrm{R}$ & $\mathrm{N} / \mathrm{R}$ & $N / R$ & $N / R$ & Negativo & $\mathrm{N} / \mathrm{R}$ \\
\hline Saponinas & $\mathrm{N} / \mathrm{R}$ & $N / R$ & Positivo & Positivo & $\mathrm{N} / \mathrm{R}$ & $\mathrm{N} / \mathrm{R}$ \\
\hline Taninos & $\mathrm{N} / \mathrm{R}$ & $\mathrm{N} / \mathrm{R}$ & Positivo & Positivo & $\mathrm{N} / \mathrm{R}$ & $\mathrm{N} / \mathrm{R}$ \\
\hline Mucílagos /gomas & $\mathrm{N} / \mathrm{R}$ & $N / R$ & $N / R$ & Positivo & $\mathrm{N} / \mathrm{R}$ & Positiva \\
\hline Flavonoides & Positivo & Positivo & Positivo & Positivo & $\mathrm{N} / \mathrm{R}$ & $\mathrm{N} / \mathrm{R}$ \\
\hline
\end{tabular}

La cromatografía en capa delgada realizadas permite establecer una serie de perfiles cromatográficos típicos para cada extracto y que son concordantes con los resultados obtenidos mediante las reacciones preliminares para los distintos extractos.

Las características de color y fluorescencia y Rf de las bandas, indicaría la presencia de aglucones de cumarinas en el extracto hexánico; aglucones tipo flavona en el extracto diclorometánico; heterósidos de flavonas y cumarinas en el extracto metanólico y la ausencia en este ultimo extracto de acido salicílico.

La CCD contra testigo en el sistema VII (Acetato de etilo/ acido acético/ acido formico/ agua 100:11:11:26) y el análisis por HPLC permiten confirmar, entre los heterósidos flavonoides, la presencia de vitexina en el extracto metanólico. 
Tabla Perfil cromatográfico del extracto hexánico

\begin{tabular}{|c|c|c|c|c|}
\hline \multicolumn{5}{|c|}{$\mathrm{Rf}$} \\
\hline Vis & $\mathrm{UV}_{254}$ & $U^{366}$ & RPN + UV 366 & AS \\
\hline \multicolumn{5}{|c|}{0 (amarillo claro) } \\
\hline \multicolumn{5}{|l|}{0,1 (amarillo) } \\
\hline \multicolumn{5}{|l|}{0,13 (amarillo) } \\
\hline & & 0,17 (café) & & \\
\hline \multicolumn{5}{|c|}{0,38 (verde amarillenta) } \\
\hline \multicolumn{5}{|l|}{0,5 (verdosa) } \\
\hline \multicolumn{5}{|l|}{0,52 (grisácea) } \\
\hline \multicolumn{5}{|l|}{ 0,66 (grisácea) } \\
\hline & 0,69 & & & \\
\hline & 0,75 & & & 0,75 (violácea) \\
\hline & 0,82 & $\begin{array}{l}0,82 \\
\text { (azulado) }\end{array}$ & & \\
\hline & & & & $\begin{array}{l}0,88 \\
\text { (violácea) }\end{array}$ \\
\hline & 0,94 & $\begin{array}{l}0,94 \\
\text { (azul) }\end{array}$ & $\begin{array}{l}0,94 \\
\text { (crema-azulado) }\end{array}$ & $\begin{array}{l}0,94 \\
\text { (café) }\end{array}$ \\
\hline 0,98 (naranja) & & & & \\
\hline
\end{tabular}

Tabla Perfil cromatográfico del extracto DCM

\begin{tabular}{|c|c|c|c|}
\hline \multicolumn{3}{|c|}{$\mathbf{R f}$} \\
\hline Vis & $\mathbf{U V}_{\mathbf{2 5 4}}$ & $\mathbf{U V}_{\mathbf{3 6 6}}$ & $\mathbf{R P N}+\mathbf{U V}_{\mathbf{3 6 6}}$ \\
\hline 0 & & & \\
\hline $\begin{array}{c}\text { (verde oscuro) } \\
0,07 \\
\text { (amarillo) }\end{array}$ & & $\begin{array}{c}0,07 \\
\text { (marrón) }\end{array}$ & $\begin{array}{c}0,07 \\
\text { (amarillo) }\end{array}$ \\
\hline 0,1 & 0,1 & 0,1 \\
$\begin{array}{c}\text { (amarillo) } \\
0,13\end{array}$ & $\begin{array}{c}0,13 \\
\text { (marrón) }\end{array}$ & $\begin{array}{c}0,13 \\
\text { (amarillo) }\end{array}$ \\
\hline $\begin{array}{c}\text { (amarillo) } \\
0,17 \\
\text { (amarillo intenso) }\end{array}$ & & $\begin{array}{c}0,17 \\
\text { (marrón) }\end{array}$ & $\begin{array}{c}0,17 \\
\text { (amarillo intenso) }\end{array}$ \\
\hline $\begin{array}{c}0,19 \\
\text { (café-grisaceo) }\end{array}$ & & $\begin{array}{c}0,19 \\
\text { (azul violaceo) }\end{array}$ & \\
\hline $\begin{array}{c}0,98 \\
\text { (naranja) }\end{array}$ & & & \\
\hline
\end{tabular}

Tabla Perfil cromatográfico del extracto Metanólico

\begin{tabular}{|c|c|c|c|}
\hline \multicolumn{4}{|l|}{ Rf } \\
\hline Vis & $U V_{254}$ & $U V_{366}$ & $R P N+U^{366}$ \\
\hline \multicolumn{4}{|l|}{$\begin{array}{c}0 \\
\text { (marrón) }\end{array}$} \\
\hline $\begin{array}{c}0,21 \\
\text { (amarillo) }\end{array}$ & & $\begin{array}{c}0,21 \\
\text { (marrón) }\end{array}$ & $\begin{array}{c}0,21 \\
\text { (amarillo intenso) }\end{array}$ \\
\hline $\begin{array}{c}0,44 \\
\text { (amarillo) }\end{array}$ & & $\begin{array}{l}0,44 \\
\text { (marrón) }\end{array}$ & $\begin{array}{c}0,44 \\
\text { (amarillo intenso) }\end{array}$ \\
\hline \multirow[t]{4}{*}{$\begin{array}{c}0,52 \\
\text { (amarillo) }\end{array}$} & & $\begin{array}{c}0,52 \\
\text { (marrón) }\end{array}$ & $\begin{array}{c}0,52 \\
\text { (amarillo intenso) }\end{array}$ \\
\hline & 0,62 & & \\
\hline & 0,75 & $\begin{array}{c}0,75 \\
\text { Fluores. Celeste NH3 }\end{array}$ & \\
\hline & 0,85 & & \\
\hline \multicolumn{4}{|l|}{$\begin{array}{c}0,89 \\
\text { (gris verdoso) }\end{array}$} \\
\hline $\begin{array}{c}0,98 \\
\text { (verde oscuro) }\end{array}$ & & & \\
\hline
\end{tabular}




\section{Caracterización de ciclótidos}

La extracción y semipurificacion de ciclótidos, se efectuó empleando los métodos de Claeson y Burman, que fueron modificados a fin de optimizar el procedimiento.

Como primer paso se realizaron extracciones preliminares del material vegetal (10g) de forma secuencial con Hexano y Diclorometano,

El marco de la extracción con DCM se extrajo con solución de Metanol al 60\% en la que los ciclótidos se solubilizan (Burman., et al 2010) y constituye la mezcla que se usa comúnmente como paso inicial de extracción.

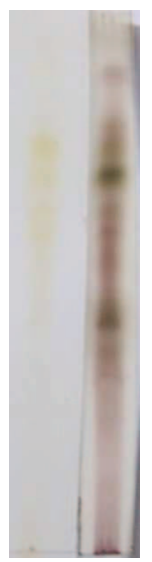

Comparación de una placa sin Hidrolizar (Izquierda) y con hidrólisis

Un paso mas que se implementó con el propósito de eliminar más sustancias interferentes del extracto, consistió en intentar la precipitación de los péptidos en un medio en el que muchas de las sustancias que los acompañaban siguieran siendo solubles. Es así que optamos por evaporar totalmente el extracto metanólico al $60 \%$ y retomarlo con una mezcla de Metanol con Diclorometano $(10 \mathrm{ml}+1 \mathrm{ml})$.

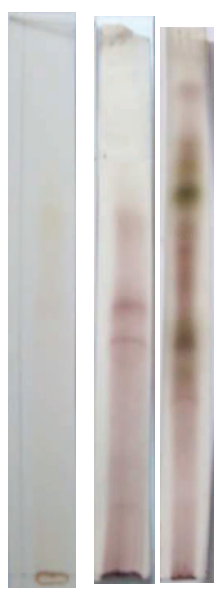

Comparación de una placa sin hidrolizar

(izq.) y una hidrolizada luego del proceso de semipurificación (centro) y la placa hidrolizada sin el procedimiento (der.) 
El objetivo fue disminuir la polaridad del metanol lo suficiente para reducir la posibilidad de que este solvente fuera capaz de solubilizar los ciclótidos pero siguiera conservando su poder de disolver el resto de sustancias acompañantes.

Para la detección de ciclótidos en Viola arguta se utilizó el método reportado por XU Yan et al., (2008) que emplea Ninhidrina y Azul Brillante de Coomassie G-250.

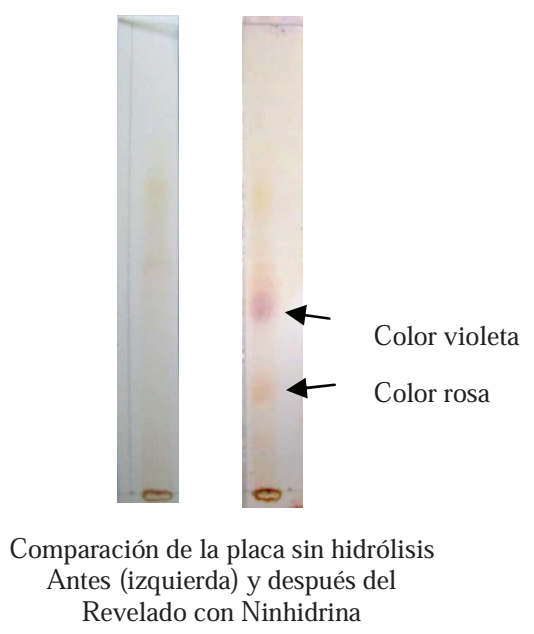

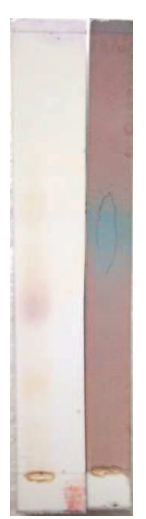

Comparación de las placas reveladas con Ninhidrina (izquierda) y con Azul Brillante de Coomassie.

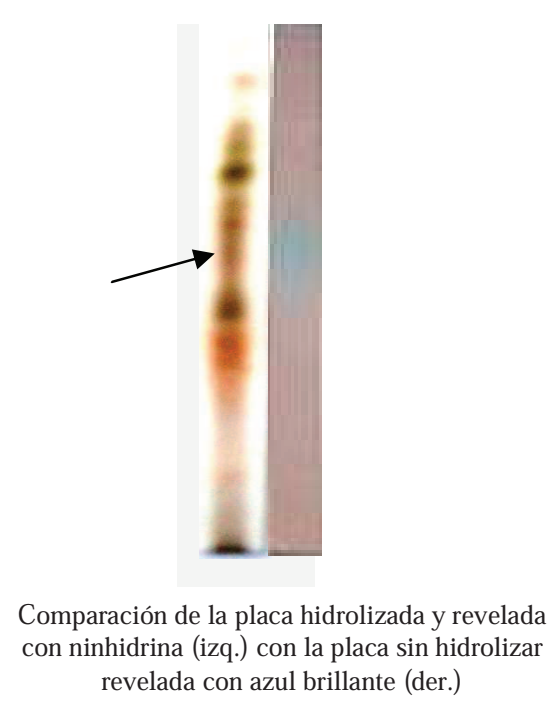

Al haber observado la concordancia de nuestros resultados con aquellos que los autores indican en su Protocolo, nos indicaría que esta especie de Violeta posee ciclótidos en su composición.

\section{Detección de ácidos por CCD}

El extracto purificado obtenido partir del extracto hexanico, se cromatografio con el solvente Eter etílico/éter de petróleo/ acido fórmico 70:30:1

Al observar la placa al UV254 se ven 8 manchas en la calle correspondiente al extracto hexanico y no se aprecia ninguna en el extracto purificado. 
Al revelar con azul de bromofenol, aparece, tanto en el extracto hexanico como en el extracto purificado, una mancha amarillenta a $\mathrm{Rf} 0,46$ que toma coloracion rosada si la placa se revela con Anisaldehido sulfurico.

Este comportamiento sugiere que se ha aislado a partir del extracto hexanico una sustancia de naturaleza acida, que podria ser de naturaleza terpenica. Según Wagner y Bladt (1996), las saponinas, a excepción de la glicirricina y el acidoglicirretico presentes en el regaliz, no son detectables por exposición a la luz UV254 o UV366 requiriendo un tratamiento químico.

Dadas las reacciones orientativas previamente realizadas y el comportamiento que observamos al revelar las CCD, podríamos inferir que la sustancia aislada a partir del extracto hexanico seria el aglucon de una saponina.

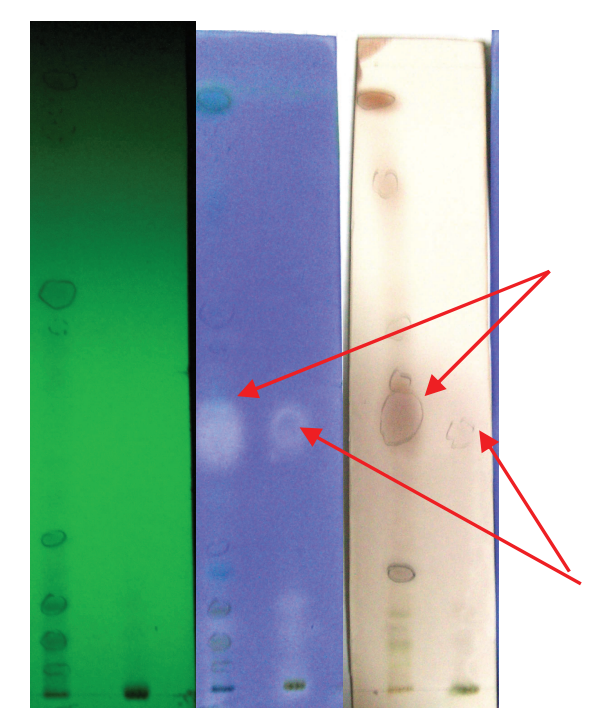

CCD del extracto hexanico y hexanico purificado con distintos reveladores UV254 (izq.); azul bromofenol (centro); Anisaldehido sulfurico (der.)

\section{Actividad antioxidante in vitro}

La actividad antioxidante in vitro fue evaluada por dos métodos espectrofotométricos: DPPH Y ABTS, expresándola como $\mu \mathrm{g}$ trolox/mg extracto seco y $\mu \mathrm{g}$ rutina/mg extracto seco respectivamente.

Se determino además la capacidad reductora (metodo FRAP), expresada como $\mu \mathrm{g}$ acido ascórbico/mg extracto seco; el contenido de fenoles totales, expresados como $\mu \mathrm{g}$ acido tanico/mg extracto seco y el contenido de flavonoides totales, expresados como $\mu \mathrm{g}$ rutina/mg extracto seco.

Los resultados obtenidos se resumen en las siguientes tablas:

\section{Actividad frente al radical 2,2-difenil-1-picrilhidrazilo (DPPH)}

\begin{tabular}{|l|c|c|c|c|c|c|c|c|}
\hline Muestra & Dilución & Vol tomado & Abs & Abs2 & Abs3 & Abs prom & conc por curvé equiv ug Trol/mg ES \\
\hline V arguta metanol & 10 & 7,5 & 0,3233 & 0,3264 & 0,2991 & 0,3163 & 1,78 & 237 \\
\hline V arguta hexano & 10 & 20 & 0,4723 & 0,4825 & 0,4596 & 0,4715 & 0,68 & 34 \\
\hline V arguta DCM & 10 & 20 & 0,5447 & 0,5619 & 0,4959 & 0,5342 & 0,23 & 12 \\
\hline V arguta agua & 1 & 2,5 & 0,1778 & 0,1822 & 0,1774 & 0,1791 & 2,75 & 110 \\
\hline
\end{tabular}


Actividad frente al radical 2,2'-azino-bis(3-etilbenztiazolin-6-sulfonato de amonio) (ABTS )

\begin{tabular}{|l|c|c|c|c|c|}
\hline Muestra & Abs prom & conc curva Rutina & Vol usado & Dilución & Equiv uga Rutix/mg ES \\
V arguta metanol & 0,3189 & 2,06 & 20 & 100 & 1510 \\
\hline V arguta hexanico & 0,4563 & 1,28 & 20 & 10 & 84 \\
\hline V arguta DCM & 0,5868 & 0,55 & 20 & 10 & 21,0 \\
\hline
\end{tabular}

\section{Evaluación de la capacidad reductora por el método FRAP}

\begin{tabular}{|l|c|c|c|c|c|c|c|c|c|}
\hline Muestra & \multicolumn{2}{c}{ Dilución ul usados } & Abs1 & \multicolumn{1}{c}{ Abs2 } & Abs3 & \multicolumn{2}{c}{ Abs prom Conc } & Eq $1 \mathrm{mM} \mathrm{AC} \mathrm{Asc/mgEXT}$ \\
\hline V arguta metanol & 10 & 10 & 0,422 & 0,4210 & 0,6760 & 0,5062 & 14,89 & 1,49 & \\
\hline V arguta hexanico & 10 & 50 & 0,224 & 0,2285 & 0,2281 & 0,2268 & 6,67 & 0,13 & \\
\hline V arguta DCM & 10 & 50 & 0,265 & 0,2686 & 0,2643 & 0,2659 & 7,82 & 0,16 & \\
\hline V arguta agua & 10 & 10 & 0,133 & 0,1396 & 0,1348 & 0,1357 & 3,99 & 0,40 & \\
\hline
\end{tabular}

\section{Determinación del contenido de fenoles totales}

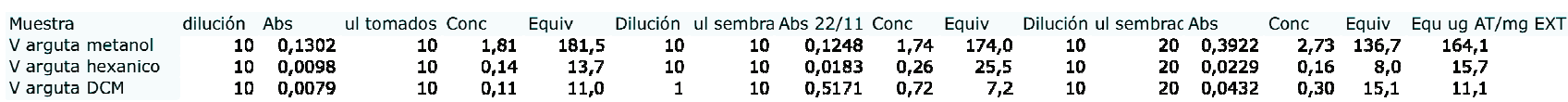

\section{Determinación del contenido de flavonoides totales}

\begin{tabular}{|l|r|r|r|r|r|r|r|r|r|}
\hline Muestra & Dilución ul tomados & Abs1 & Abs2 & \multicolumn{1}{|c|}{ Blanco } & Abs final & \multicolumn{2}{c|}{ Conc por curvi equiv ug de Rut/mg EXT } \\
\hline V arguta metanol & 10 & 50 & 0,1044 & 0,0811 & 0,0528 & 0,03995 & 13,32 & 266 \\
\hline V arguta hexanico & 10 & 50 & 0,0103 & 0,015 & $-0,0141$ & 0,02675 & 8,92 & 178 \\
\hline V arguta DCM & 10 & 100 & 0,2018 & 0,2006 & 0,1031 & 0,0981 & 32,70 & 327 \\
\hline
\end{tabular}

De la observación de las tablas, se desprende que las TEAC ( $\mu$ g trolox / mg extracto seco) calculadas por el método DPPH para $V$. arguta, resultaron mayores para el extracto mas polar (MeOH).

Asimismo la concentración de fenoles totales, resultó ser muy superior para el extracto metanólico, lo cual sugiere que uno de los responsables de la actividad antioxidante de $V$. arguta serian los compuestos polifenólicos presentes en los extractos mas polares.

La capacidad antioxidante calculada por el método ABTS ( $\mu$ g rutina/mg ES), también resultó mayor para el extracto metanólico, en concordancia con los resultados del método DPPH.

La concentración de sustancias reductoras, calculadas por el método FRAP ( $\mu \mathrm{g}$ acido ascórbico/ mg extracto seco) también resulto ser diez veces mayor para el extracto metanólico. 
Por otra parte, el contenido de flavonoides es inversamente proporcional a la actividad antioxidante calculada por cualquiera de los métodos anteriormente citados. O sea, los extractos más polares son los que contienen la menor concentración de flavonoides totales expresados como rutina. O dicho de otro modo, los flavonoides se encuentran preferentemente como aglucones (solubles en hexano y diclorometano) y no como heterósidos (más solubles en metanol).

Las sustancias reductoras que contribuyen a la acción antioxidante en ese extracto, son fundamentalmente compuestos polifenólicos.

Actividad antiinflamatoria:

\section{Estudio de la inhibición de la producción de oxido nítrico in vitro}

Ensayo de citotoxicidad Linea RAW 264,

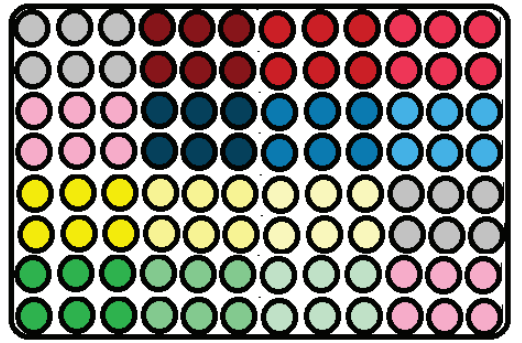

Esquema de la Disposición de los extractos en la placa de 96 pocillos



Placa con reactivo MTT para ensayo de citotoxicidad

MTT: Bromuro de 3-(4,5-dimetiltiazol-2-ilo)-2,5-difeniltetrazol 


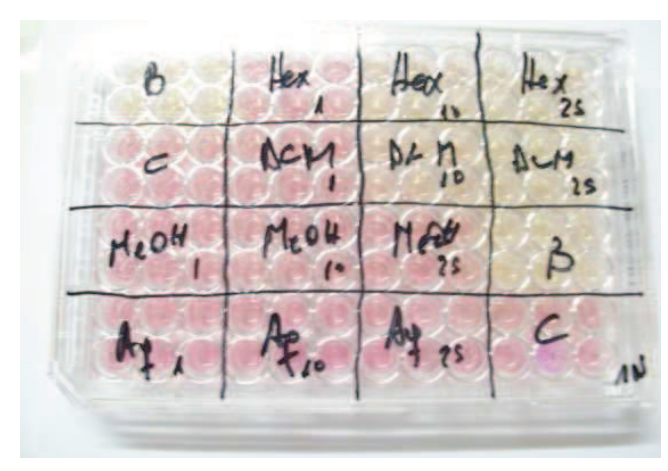

Vista de la Placa para Nitritos con los tratamientos indicados en su tapa

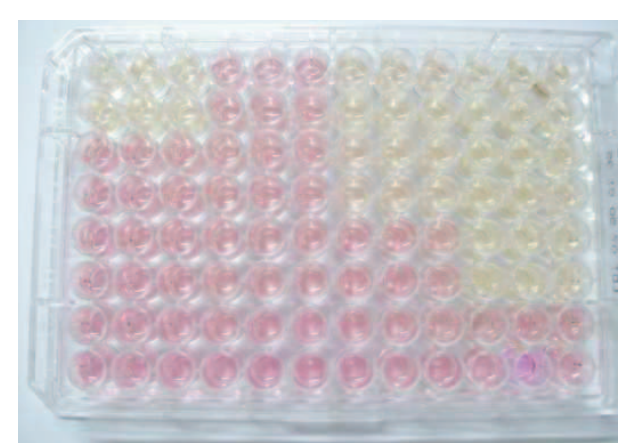

Placa para determinación de nitritos con el Reactivo de Griess

Al comparar los valores del Blanco (sin LPS) y el Control (Con LPS) se evidencia una significativa reducción de la viabilidad celular generada por la presencia de este agente inductor de la producción de Óxido Nítrico, por lo que la comparación de la viabilidad de las células sometidas a las diferentes concentraciones de extractos se efectuaron frente al valor de la viabilidad del Control que representa las condiciones de partida del modelo de estudio.

En cuanto al extracto Hexánico, las concentraciones de $1 \mu \mathrm{g} / \mathrm{ml}$ y $10 \mu \mathrm{g} / \mathrm{ml}$ no muestran efectos citotóxicos, sin embargo a la concentración de $25 \mu \mathrm{g} / \mathrm{ml}$ la viabilidad se reduce significativamente ( $a<<95 \%$ de viabilidad)-

Con los extractos Diclorometánicos a las concentraciones de 10 y $25 \mu \mathrm{g} / \mathrm{ml} \mathrm{se}$ presenta elevada toxicidad siendo la última de éstas la que mayor efecto negativo generó sobre la viabilidad celular entre todos los extractos que se evaluaron $(<23 \%$ de Viabilidad), no así a la concentración de $1 \mu \mathrm{g} / \mathrm{ml}$. que no afectó significativamente la supervivencia de los macrófagos.

Las distintas concentraciones de los extractos Metanólicos y Acuosos no presentaron toxicidad en este modelo, sin embargo hay una aparente tendencia, no significativa, en los extractos acuosos a disminuir la viabilidad del cultivo celular con el incremento de sus concentraciones.

Estos resultados nos permitieron establecer qué concentraciones de los distintos extractos serían consideradas válidos en los ensayos para evaluar la inhibición de la producción de Óxido Nítrico, de esta manera se tomaron en cuenta para esta siguiente prueba los resultados de aquellos extractos con viabilidad superior al $95 \%$, por consiguiente no se consideraron los valores generados con el extracto hexánico a $25 \mu \mathrm{g} / \mathrm{ml}$ y Diclorometánicos a 10 y $25 \mu \mathrm{g} / \mathrm{ml}$. 
Fig. 5.23. Efecto de los extractos (frente al control considerado como 100\%) sobre la producción de nitritos



Las barras indican la media de las concentraciones (IC 95\%), se evidencia que solo el Hexánico a $10 \mu \mathrm{gg} / \mathrm{ml}$ produce una reducción significativamente diferente $(p<0,05)$

Al analizar los resultados del extracto Hexánico en el ensayo de inhibición de la producción de Óxido Nítrico se evidencia actividad a las concentraciones de $1 \mu \mathrm{g} / \mathrm{ml}$ y $10 \mu \mathrm{g} / \mathrm{ml}$ ya que reducen la cantidad de nitrito (producto del oxido nítrico generado) en el medio de cultivo y en el caso de la última concentración llega a disminuirlo en más del $60 \%$, siendo este extracto el único que muestra esta capacidad, los restantes extractos se mostraron inactivos en este modelo de investigación a las concentraciones empleadas.

\section{Conclusiones}

Se describieron los principales elementos de diagnóstico de las hojas de $V$. arguta, así como los valores de los índices de estoma y de empalizada. Si bien estos últimos no permiten por si solos establecer la identidad de esta especie, son útiles para complementar los datos morfológicos

Microscópicamente, las hojas de $V$. arguta pueden ser identificadas por sus índices de estoma y empalizada y mediante la combinación de distintos caracteres, tales como:

- Hojas hipostomática

- Estomas transicionales entre rubiáceos y crucíferos

- Epidermis adaxial y abaxial con células mucilaginíferas, abundantes en los dientes

- Epidermis abaxial con pelos unicelulares o uniseriados, acintados con cutícula estriada. 
- Abundantes cristales (drusas) formando una capa por debajo del parénquima en empalizada.

Teniendo en cuenta el uso tradicional de $V$. arguta y la posibilidad de que en un futuro integre la formulación de medicamentos fitoterapicos, el análisis de estos elementos de diagnóstico, junto a la determinación de los perfiles cromatográficos y ensayos fitoquímicos constituye la base para un futuro control de calidad.

Desde el punto de vista fitoquímico, todos los extractos de $V$. arguta dan positivas las reacciones preliminares para flavonoides, siendo las flavonas los compuestos que parecen predominar en los extractos DCM y metanólico, lo que sugiere que estos metabolitos se hallan tanto como aglucones como en forma de heterósidos

En tanto que los ensayos para detectar taninos y saponinas solo son positivos para los extractos mas polares (metanólico y acuoso). Todos estos resultados preliminares son confirmados por las respectivas CCD, que también nos permiten confirmar la ausencia de acido salicílico.

En cuanto a la existencia de otros ácidos orgánicos, dadas las reacciones orientativas previamente realizadas y el comportamiento que observamos al revelar las correspondientes CCD, no se descarta la presencia de aglucones de tipo triterpenico en el extracto hexanico.

Mediante la aplicación de métodos descriptos en la bibliografía, que hemos modificado a fin de optimizar el procedimiento de extracción y purificación, se ha podido confirmar la presencia de ciclótidos en la especie estudiada. Estos ciclopéptidos son descriptos por primera vez en esta Viola arguta.

Los compuestos que reaccionan con anisaldehido sulfúrico, predominan en los extractos hexánico y también aparecen en el metanólico (posible presencia de sustancias de naturaleza terpenica).

Respecto a sus actividades, se comprueba la actividad antioxidante, que es mucho más notable en el extracto más polar (metanólico), y la actividad antiinflamatoria in vitro, siendo el extracto hexánico el único que inhibió la producción de oxido nítrico: $c a$. $60 \%$ de inhibición, sin mostrar toxicidad para las células.

De acuerdo a estos últimos resultados, podría inferirse que $V$. arguta no tendría las propiedades antiinflamatorias que se le atribuyen tradicionalmente, dado que lo que se utiliza es la infusión (acuosa) y los compuestos antiinflamatorios se hallan en el extracto hexánico. Sin embargo, no debe olvidarse la presencia de saponinas, que podrían actuar en forma sinérgica, facilitando la extracción de esos compuestos con solventes mas polares.

En cuanto al trabajo a seguir incluiría poner a punto el paso de extracción que se introdujo ya que si bien nos ayudó a resolver el problema de interferencias antes indicado y sabemos que un proceso de extracción Líquido- Líquido más exhaustivo en relación al realizamos en este trabajo podría llevarnos a mejores resultados, así también cabría la posibilidad de que sustituir la centrifugación por otro método como el filtrado y lavado del precipitado faciliten la tarea, también está pendiente definir la composición ideal de la mezcla de solventes que usamos para la precipitación, calcular rendimientos parciales para el proceso y que tan eficiente es en la extracción, además, 
un paso que se podría agregar es la extracción líquido-líquido: butanol-agua (Broussalisa, et al. 2001) así a través de la suma de estos sencillos procesos se podría llegar a una eliminación eficiente de muchos productos previo a su purificación definitiva

De todo lo expuesto, podemos concluir que $V$. arguta es una especie promisoria desde el punto de vista de un posible uso medicinal, debiéndose encarar la realización de estudios más exhaustivos a fin de:

- Identificar los compuestos presentes en los distintos extractos.

- Purificar, aislar e identificar los ciclótidos presentes.

- Confirmar la actividad antiinflamatoria de V. arguta 
8. Bibliografia

\section{8.- Bibliografía}




\section{Bibliografia}

AL-QURAN. (2008) Taxonomical and Pharmacological Survey of Therapeutic Plants in Jordan. Journal of Natural Products. 1:10-26

ANTIL, V.; Kumar P, Kannappan N, Diwan A, Saini P, Singh S (2011) Evaluation of the analgesic activity of Viola odorata aerial parts in rats. Journal of Natural Pharmaceuticals 2(1): 24-27

ARANGO MEJÍA, María Cristina (2006) “Plantas medicinales: botánica de interés medico" Ed. María Cristina Arango Mejía, Mexico DC

AUBAD LOPEZ, P.; Rojano, B.A.; Lobo Echeverri, T. (2007) Actividad antioxidante en musgos. Scientia et Técnica Universidad tecnológica de Pereira, Colombia. XIII (033): 23-26

BALLARD, Harvey E. Jr (1994) Flora del bajío y de regiones adyacentes. Fascículo 31 VIOLACEAE. Department of Botany University of Wisconsin-Madison. Madison, Wisconsin, U.S.A.

BARREIRO Olga, Pilar Martın, Roberto Gonzalez-Amaro, Francisco Sanchez-Madrid. (2010) Molecular cues guiding inflammatory responses Cardiovascular Research $86,174-182$

BECK P. L., R. Xavier, J. Wong, I. Ezedi, H. Mashimo, A. Mizoguchi, E. Mizoguchi, A. K. Bhan, D. K. Podolsky. (2004). Paradoxical roles of different nitric oxide synthase isoforms in colonic injury. Am J Physiol Gastrointest Liver Physiol 286: G137G147.

BENZIE, I.F.F.; Strain, J.J. (1996). The ferric reducing ability of plasma (FRAP) as a measure of "antioxidant power": The FRAP assay. Anal. Biochem. 239:70-76.

BOHLIN,Lars; Ulf Goransson; Cecilia Alsmark Christina Weden; Anders Backlund. (2010) Natural products in modern life science. Phytochem Rev 9:279-301

BRAND-WILLIAMS, W.; Cuvelier, ME; Berset, C. (1995) Use of a free radical method to evaluate antioxidant activity. Lebensmittel-Wissenschaft und Technologie 28: $25-30$

BROUSSALISA Adriana M., Ulf Goransson, Jorge D. Coussio, Graciela Ferraro, Virginia Martino, Per Claeson. (2001) First cyclotide from Hybanthus (Violaceae) Phytochemistry 58: 47-51 


\section{Bibliografia}

BURMAN, ROBERT. (2010). Distribution and chemical diversity of cyclotides from Violaceae. Thesis for the degree of Doctor of Philosophy (Faculty of Pharmacy). Upsala Universiteit, Sweden.

BURMAN Robert, Christian W. Gruber, Kristina Rizzardi, Anders Herrmann, David J. Craik, Mahabir P. Gupta, Ulf Göransson. (2010). Cyclotide proteins and precursors from the genus Gloeospermum: Filling a blank spot in the cyclotide map of Violaceae. Phytochemistry 71: 13-20

CAIA Yizhong, Qiong Luob, Mei Sunc, Harold Corke (2004) Antioxidant activity and phenolic compounds of 112 traditional Chinese medicinal plants associated with anticancer. Life Sciences 74 2157-2184

CAMARERO, Julio A. (2011). Legume cyclotides shed light on the genetic origin of knotted circular proteins. PNAS 108 (25): 10025-10026

CATALOGO de plantas vasculares de Ecuador

(2011) http://www.tropicos.org/specimen/252964?projectid=2 $\quad$ (recuperado Diciembre 2011)

CAVIN, A.; Hostettmann, K.; Dyatmyko, W.; Potterat, O. (1998) Antioxidant and Lipophilic Constituents of Tinospora crispa. Planta Med 64: 393-396

CHEN Bin, Colgrave Michelle L, Daly Norelle L., K. Rosengren Johan, Gustafson Kirk R, Craik David J. (2005). Isolation and Characterization of Novel Cyclotides from Viola hederaceae. The Journal of Biological Chemistry, 280(23):22395-405

CHEN, Ing-Chien, Hui-Chi CHANG, Hui-Wen YANG, Gan-Lin CHEN (2004) Evaluation of Total Antioxidant Activity of Several Popular Vegetables and Chinese Herbs: A Fast Approach with ABTS/H2O2/HRP System in Microplates. Journal of Food and Drug Analysis 12(1): 29-33

CHOI Hyon K.; David B. Mount; Anthony M. Reginato. (2005) Pathogenesis of Gout Ann Intern Med.143: 499-516.

CHUNG1 III-Min, Su-Hyun Seo, Eun-Young Kang, Won-Hwan Park, Hyung-In Moon. (2009) Anti-malarial activity of 6-(8'Z-pentadecenyl)-salicylic acid from Viola websteri in mice. Malaria Journal 8:151

CLAESON Per, Ulf Goransson, Senia Johansson, Teus Luijendijk, Lars Bohlin (1998).

Fractionation Protocol for the Isolation of Polypeptides from Plant Biomass. J. 


\section{Bibliografia}

Nat. Prod. 61: 77-81

COLGRAVE Michelle L., Kotze Andrew C., Huang Yen-Hua, O'Grady John, Simonsen Shane M., Craik David J. (2008) Cyclotides: Natural, Circular Plant Peptides that Possess Significant Activity against Gastrointestinal Nematode Parasites of Sheep. Biochemistry 47 (20): 5581-5589

CONTRERAS Janette, Ahmed Y.O. Elnagar, Sarah F. Hamm-Alvarez, Julio A. Camarero (2011) Cellular uptake of cyclotide MCoTI-I follows multiple endocytic pathways. Journal of Controlled Release 155: 134-143

COZZOLINO, Rosanna, Pasquale Palladino, Filomena Rossi, Gaetano Calı, Ettore Benedetti, Paolo Laccetti. (2005) Antineoplastic cyclic astin analogues kill tumour cells via caspase-mediated induction of apoptosis. Carcinogenesis 26(4): .733--739

CRAIK, David J., Joshua S. Mylne, Norelle L. Daly. Cyclotides: macrocyclic peptides with applications in drug design and agriculture. Cell. Mol. Life Sci. 67: 9-16

DALBETH N., D. O. Haskard (2005) Mechanisms of inflammation in gout. Rheumatology 44:1090-1096

DALY, Norelle L., Rosengren K. Johan, Craik David J. (2009) Discovery, structure and biological activities of cyclotides. Advanecd Drug Delievery Reviews 61(11):91830.

De LEÓN EJ, Alcaraz MJ, Dominguez JM, Charris J, Terencio MC. (2003). 1-(2,3,4trimetoxiphenyl)-3-(3(2-chloroquinolinyl))-2-propen-1-one, a chalcone derivate whit analgesic, anti-inflammatory and immunomodulatory properties. Inflamm. Res. 52:246-257.

DELLAI Afef, Igor Maricic, Vipin Kumar, Sergey Arutyunyan, Abderrahman Bouraoui, Adel Nefzi. (2010). Parallel synthesis and anti-inflammatory activity of cyclic peptides cyclosquamosin D and Met-cherimolacyclopeptide B and their analogs. Bioorganic \& Medicinal Chemistry Letters 20: 5653-5657

DIAZ ACOSTA AE, Membrillo Hernandez J (2006) Consecuencias fisiológicas de la oxidación de proteínas por carbonilacion en diversos sistemas biológicos. TIP revista especializada en ciencias químico-biológicas 9(1): 34-44

DIZZEO DE STRITMATTER, C. (1973). Nueva técnica de diafanización. Boletín de la 


\section{Bibliografia}

Sociedad Argentina de Botánica 15:126-129.

DOMINGUEZ, X. A. (1973). Métodos de Investigación Fitoquímica. Ed. Limusa S. A., México, D. F.

EBRAHIMZADEH Mohammad Ali, Nabavi Mohammad Seyed. Nabavi Fazel Seyed, Bahramian Fatemeh, Bekhradnia Ahmad Reza, (2010). Antioxidant and free radical scavenging activity of $H$. officinalis L. var. angustifolius, V. odorata, B. hyrcana and C. speciosum., Pakistan Journal of Pharmaceutical Sciences, 23(1): 29-34

EVANS, William Charles (2009). Trease and Evans' Pharmacognosy, 16th Edition. Ed. Saunders Ltd Elsevier, USA

FARMACOPEA Nacional Argentina VI ed, (1978)

FEGHALI Carol A., Timothy M. Wright. (1997). Cytokines in acute and chronic inflammation. Frontiers in Bioscience 2: 12-26

FERMOR, B; SE Christensen, I Youn, JM Cernanec, CM Davies, JB Weinberg. (2007). Oxygen, nitric oxide and articular cartilage. ECells and Materials 13: $56-65$

GAN Ren-You, Lei Kuang, Xiang-Rong Xu, Yuan Zhang, En-Qin Xia, Feng-Lin Song, HuaBin Li. (2010) Screening of Natural Antioxidants from Traditional Chinese Medicinal Plants Associated with Treatment of Rheumatic Disease. Molecule 15: $5988-5997$

GEORGÉ, S.; Brat, P.; Alter, P.; Amiot, M.J. (2005) Rapid determination of polyphenols and vitamin C in plant-derived products. J. Agric. Food Chem. 53:1370-1373

GHIZZONI Massimo, André Boltjes, Chris de Graaf, Hidde J. Haisma, Frank J. Dekke. (2010). Improved inhibition of the histone acetyltransferase PCAF by an anacardic acid derivative. Bioorganic \& Medicinal Chemistry 18: 5826-5834

GOMES DE MELO, Joabe, Ariane Gaspar Santos, Elba Lúcia Cavalcanti de Amorim, Silene Carneiro do Nascimento, Ulysses Paulino de Albuquerque.(2011). Phytochemical and pharmacological notes of plants indicated to treat tumors in Brazil. Revista Brasileira de Farmacognosia 21(4): 744-753.

GOVERS Roland, Ton J. Rabelink (2001). Cellular regulation of endothelial nitric oxide synthase Am J Physiol Renal Physiol 280:F193-F206,

ANDERS, Herrmann (2007) Structure and Activity of Circular Plant Proteins Cytotoxic 


\section{Bibliografia}

Effects of Viola Cyclotides. Thesis for the degree of Doctor of Philosophy (Faculty of Pharmacy). Upsala Universiteit, Sweden

IWALEWA, E. O.; L. J. McGaw, V. Naidoo, J. N. Eloff. (2007) Inflammation: the foundation of diseases and disorders. African Journal of Biotechnology 6 (25): 2868-2885.

IZCO Jesús, Pulgar Íñigo, Aguirre Zhofre, Santin Fernando, (2007) Estudio florístico de los páramos de pajonal meridionales de Ecuador. Revista peruana de biología, 14(2): 237-246.

JANOVSKÁ D., K, Kubíková, L. Kokoška (2003) Screening for Antimicrobial Activity of Some Medicinal Plants Species of Traditional Chinese Medicine Czech J. Food Sci. 21( 3): 107-110

KHATIBI, A., A.H. Shah, A.M. Ageel, M.S. Ahmad, M.A. AL-Yahya, M. Tariq Saudi (1989). Folk medicine: phytochemical and antimicrobial screening Pakistan J. Pharm. Sci.2(1): 29- 34,

KARIOTI Anastasia, Claudia Furlan, Franco Francesco Vincieri, Anna Rita Bilia. (2011). Analysis of the constituents and quality control of Viola odorata aqueous preparations by HPLC-DAD and HPLC-ESI-MS. Anal Bioanal Chem 399(4):171523.

KORHONEN, Riku, Aleksi Lahti, Hannu Kankaanranta, Eeva Moilanen. (2005). Nitric Oxide Production and Signaling in Inflammation. Current Drug Targets Inflammation \& Allergy 4: 471-479.

KORWAR, Prakash G., Arun Kumar Beknal, Basawaraj S. Patil, M. A. Halkai, Upendra Kulkarni, Hariprasanna R. C., Srinivas R. Soodam. (2010). A study on phytochemical investigation of Drynaria quercifolia Linn. Rhizome. IJPSR 1 (12): 148-158

KUBO Isao, Noriyoshi Masuoka, Tae Joung Ha, Kazuo Tsujimoto (2006). Antioxidant activity of anacardic acids. Food Chemistry 99: 555-562

KUSKOSKI, M.; Asuero, A.G.; García-Parilla, M; Troncoso, A.M.; Fett, R. (2004) Antioxidant Activity of Anthocyanin Pigments. Ciênc. Tecnol. Aliment. 24(4): 691-693

KHATIBI A., A.H. Shah, A.M. Ageel, M.S. Ahmad, M.A. Al-Yahya and M. Tariq (1989). 


\section{Bibliografia}

Saudi folk medicine: phytochemical and antimicrobial screening. Pakistan J. Pharm. Sci. 2(1): 29- 34.

LEE Sung Jae, Won-Hwan Park, Hyung-In Moon (2009) Bioassay-guided isolation of antiplasmodial anacardic acids derivatives from the whole plants of Viola websteri. Hemsl Parasitol Res 104:463-466.

MINGA O. Danilo, Montesinos C. Mónica, (2009), "Puesta en Valor del Qhapaqñan-Red vial Prehispanica Zonas 3 Cañar, 4 Azuay y 5 Loja: Informe de Etnobotánica y cultivos de la Zona 3: Cañar", Ministerio Coordinador del Patrimonio Cultural y Natural, Instituto Nacional de Patrimonio Cultural, Facultad de Ciencias de la Hospitalidad de la Universidad de Cuenca.

http://www.vivetupatrimonio.gob.ec/qn/?p=digitallibrary/digitalcontent\&id=203 Recuperado en Octubre del 2011

MOON Hyung-In, Ji Eun Kim, Joongku Lee, Ok-Pyo Zee, Jin Ho Chung. (2005). Matrix Metalloproteinase-1 Inhibitor from the Aerial Parts of Viola ibukiana Makino Bull. Korean Chem. Soc. 26(3): 451-453.

MOON Hyung-In, Jae-Chul Jung, Joongku Lee (2007) Antiplasmodial activity of triterpenoid isolated from whole plants of Viola genus from South Korea Parasitol. Res. 100: 641-644.

MOSMMAN T. (1983). Rapid colorimetric assay for cellular growth and survival: applications to proliferation and cytotoxicity assays. J. Immunol. Methods. 65: $55-63$.

MUÑOZ JÁUREGUI, A.M.; Ramos-Escudero, F.; Alvarado-Ortiz, C.; Castañeda Castañeda, B. (2007) Evaluación de la capacidad antioxidante y contenido de compuestos fenólicos en recursos vegetales promisorios. Rev Soc Quím Perú., 73(3): 142-149

MURPHY COWAN Marjorie (1999) Plant Products as Antimicrobial Agents Clin. Microbiol. Rev. 12(4): 564-582

NEIRA GONZÁLEZ, Adriana M. (2009) Aislamiento e identificación de los compuestos con actividad antioxidante del extracto clorofórmico de la orquídea comestible Prosthechea michuacana. Tesis de Maestría (Instituto Politécnico Nacional, México) 


\section{Bibliografia}

NICOLAOU K. C., Jason S. Chen, David J. Edmonds, Anthony A. Estrada (2009). Recent Advances in the Chemistry and Biology of Naturally Occurring Antibiotics. Angew Chem Int Ed Engl. 48(4): 660-719

PALADINI, A. (1996). ¿Cómo se Descubre o Inventa un Medicamento? Ciencia Hoy 6 (34) http://www.cienciahoy.org.ar/hoy34/medic01.htm. Recuperado en Noviembre de 2011.

PHAM-HUY, Lien Ai, Hua He, Chuong Pham-Huy. (2008). Free Radicals, Antioxidants in Disease and Health. Int. J. Biomed. Sci. 4 (2): 89-96

POURAHMAD Jalal (2002). Identification of Intracellular Sources Responsible for Endogenous Reactive Oxygen Species Formation. Iranian Journal of Pharmaceutical Research 1: 21-29

PRANTING, Maria, Camilla Loov, Robert Burman, Ulf Goransson, Dan I. Andersson. (2010) The cyclotide cycloviolacin O2 from Viola odorata has potent bactericidal activity against Gram-negative bacteria. J Antimicrob Chemother 65: 1964-1971

QU X W, R A Rozenfeld,W Huang, G B Bulkley, W Hsueh (1999). The role of xanthine oxidase in platelet activating factor induced intestinal injury in the rat. Gut. 44: 203-211.

RE, R.; Pellegrini, N.; Proteggente, A.; Pannala, A.; Yang, M.; Rice-Evans, C. (1999) Antioxidant activity applying an improved ABTS radical cation decolorization assay. Free Rad. Biol. Med. 26: 1231-1237

REUTER, Simone, Subash C. Gupta, Byoungduck Park, Ajay Goel, Bharat B. Aggarwal, (2011) Epigenetic changes induced by curcumin and other natural compounds. Genes Nutr 6: 93-108.

REY R. PLAN, Manuel, Ivana Saska, Arsenia G. Cagauan, David J. Craik. (2008). Backbone Cyclised Peptides from Plants Show Molluscicidal Activity against the Rice Pest Pomacea canaliculata (Golden Apple Snail). J. Agric. Food Chem. 2008, 56, $5237-5241$

RIMKIENË Silvija, Ona Ragapinskienë, Nijolë Savickienë (2003) The cumulation of Wild pansy (Viola tricolor L.) accessions: the possibility of species preservation and 


\section{Bibliografia}

usage in medicine. MEDICINA 39 (4): 411-416.

RIOS, Monserrat, Koziol Michael, Borgtoft Pedersen Henrik, Granda Gabriela, (2007).

Plantas Útiles del Ecuador. Editoriales: Universidad Católica del Ecuador, SAMAI, Abya-Yala/UPS Publicaciones, CODEMPE, UICN Conservación Internacional, Quito,

RODRIGO-GARCÍA, J.; Álvarez-Parrilla, J.; de la Rosa, L.A.; Mercado Mercado, G.; Herrera Duene, B. (2006). Valoración de la capacidad antioxidante y actividad polifenol oxidasa en duraznos de diferentes áreas de producción. I Simpósio Ibero-Americano de Vegetais Frescos Cortados, San Pedro, SP Brazil,

ROJANO Benjamin A., Carlos A. Gaviria, Maritza A. Gil., Jairo A. Saez, Guillermo Schinella, Horacio Tournier. (2008). Actividad antioxidante del isoespintanol en diferentes medios antioxidant activity of the isoespintanol in different media. Vitae 15 (1): 173-181.

SALISBURY, E. (1927). On the causes and ecological significance of stomatal frequency with special reference to the woodland flora. Philosophical Transcription Royal Society of London Ser B 216: 1-65.

SAMRA Bibi, Ghulam Dastagir, Farrukh Hussain, Parveen Sanaullah. (2006). Elemental composition of Viola odorata Linn. Pak. J. Pl. Sci., 12 (2): 141-143.

SARVAJEET Singh Gill, Narendra Tuteja (2010) Reactive oxygen species and antioxidant machinery in abiotic stress tolerance in crop plants. Plant Physiology and Biochemistry 48: 909-930

SASKA Ivana, Amanda D. Gillon, Noriyuki Hatsugai, Ralf G. Dietzgen, Ikuko HaraNishimura. (2007) An Asparaginyl Endopeptidase Mediates in Vivo Protein Backbone Cyclization. The journal of biological chemistry 282 (40): 2972129728.

SEYDEL, Peter, Heike Dornenburg. (2006). Establishment of in vitro plants, cell and tissue cultures from Oldenlandia affinis for the production of cyclic peptides. Plant Cell, Tissue and Organ Culture. 85: 247-255

STEFANOWICZ Piotr (2001) Detection and sequencing of new cyclic peptides from linseed by electrospray ionization mass spectrometry. Acta bioquimica polonica 48 (4): 1125-1129. 


\section{Bibliografia}

SUKSAMRARN Sunit, Narisara Suwannapoch, Natthachai Aunchai, Mayuso Kuno,

Piniti Ratananukul, Rachada Haritakun, Chawewan Jansakul, Somsak Ruchirawat (2005). Ziziphine N, O, P and Q, new antiplasmodial cyclopeptide alkaloids from Ziziphus oenoplia var. brunoniana. Tetrahedron 61: 1175-1180

RIMKIENË Silvija, Ona Ragapinskienë, Nijolë Savickienë (2003). The cumulation of Wild pansy (Viola tricolor L.) accessions: the possibility of species preservation and usage in medicine. MEDICINA 39(4): 411-416.

TAN Ning-Hua, Jun Zhou (2006) Plant Cyclopeptides. Chem. Rev. 106: 840-895

TANGA, Jun, Conan K. Wang, Xulin Pana, He Yana, Guangzhi Zeng, Wenyan Xua, Wenjun Hea, Norelle L. Daly, David J. Craik, Ninghua Tana. (2010) Isolation and characterization of cytotoxic cyclotides from Viola tricolor. Peptides 31: 14341440

TENE, Vicente; Malagon, Omar; Vita Finzi, Paola; Vidari, Giovanni; Armijos Chabaco Tomás. (2007). An ethnobotanical survey of medicinal plants used in Loja and Zamora-Chinchipe, Ecuador. Journal of Ethnopharmacology 111(1): 63-81.

TOBEY Robert A., David J. Orlicky, Larry L. Deaven (1978). Effects of Bouvardin (NSC 259968), a Cyclic Hexapeptide from Bouvardia ternifolia, on the Progression Capacity of Cultured Chinese Hamster Cells. Cancer. Res. 38:4415-4421.

TOIU, ANCA, Edward Muntean, Ilioara Oniga. (2009). Pharmacognostic research on Viola declinata Waldst. Et Kit. (Violaceae). MIRCEA TĂMAŞ FARMACIA 57(2): $218-222$

TRABI, Manuela, David J. Craik. (2004). Tissue-Specific Expression of Head-to-Tail Cyclized Miniproteins in Violaceae and Structure Determination of the Root Cyclotide Viola hederacea root cyclotide. The Plant Cell. 16: 2204-2216

VANE, John, Regina Botting. (1987). Inflammation and the mechanism of action of anti-inflammatory drugs. FASEBJ. 1: 89-96.

VUKICS Viktoria, Agnes Kery, Guenther K. Bonn, Andras Guttman (2008). Major flavonoid components of heartsease (Viola tricolor L.) and their antioxidant activities. Anal Bioanal Chem 390:1917-1925

WALKER Gaby, Josef Pfeilschifter, Dieter Kunz. Mechanisms of Suppression of Inducible Nitric-oxide Synthase (iNOS). Expression in Interferon (IFN)-g- 


\section{Bibliografia}

stimulated RAW 264.7 Cells by Dexamethasone. The journal of biological chemistry

WAGNER, H.; S. Bladt (1996). Plant Drug Analysis. $2^{\text {nd }}$ Edition. Ed. Springer-Verlag. Berlin Heidelberg New York

WITKOWSKA-BANASZCZAK E, Bylka W, Matławska I, Goślińska O, Muszyński Z (2005) "Antimicrobial activity of Viola tricolor herb" . Fitoterapia. 76(5):458-61

XIE Chen, Nigel C. Veitch, Peter J. Houghton, Monique S. J. Simmonds. (2003) Flavone C-Glycosides from Viola yedoensis MAKINO. Chem. Pharm. Bull. 51(10) 12041207

XU WenYan, Tang Jun, JI ChangJiu, He WenJun, Tan NingHua. (2008) Application of a TLC chemical method to detection of cyclotides in plants. Chinese Science Bulletin 53(11): 1671-1674.

YANG, Eun-Jin, Sang-Suk Kim, Tae-Heon Oh, Jong Seok Baik, Nam Ho Lee, Chang-Gu Hyun. (2009). Essential Oil of Citrus Fruit Waste Attenuates LPS-induced Nitric Oxide Production and Inhibits the Growth of Skin Pathogens. Int. J. Agric. Biol. 11( 6): 791-794

YUAN Gaofeng, Mark L Wahlqvist, Guoqing He, Min Yang MD, Duo Li, (2006) Natural products and anti-inflammatory activity. Asia Pac J Clin Nutr. 15 (2): 143-152.

ZORNING H., G. Weiss. (1925). Beiträge zur Anatomie des Laubblattes offizineller und pharmäzeutisch gebräuchlicher Compositen-Drogen. Archiv für Pharmakologie Berlin 263: 451-470 